UNIVERSIDADE DE SÃO PAULO

INSTITUTO DE QUÍMICA

\title{
SÍNTESE, CARACTERIZAÇÃO E ESTUDO DE PROPRIEDADES CATALÍTICAS DE HIDRÓXIDOS MISTOS LAMELARES CONTENDO $\mathrm{Cu}(\mathrm{II}) / \mathrm{Mg}$ (II)/AI(III)
}

\author{
VICTOR SOLYMOSSY
}

Dissertação apresentada como requisito à obtenção do grau de Mestre em Química, Área de concentração: Química Inorgânica.

Orientadora: Prof. ${ }^{a}$ Dr. ${ }^{\text {a }}$ Vera R. Leopoldo Constantino

SÃO PAULO 
Dedico este trabalho à memória de Zoltán e Marlene Solymossy, aos meus pais e à Ana Paula Fiuza. 


\section{Agradecimentos}

Primeiramente aos meus pais, por todo o apoio e dedicação fornecidos desde o início desta longa e ainda inacabada jornada.

À Ana Paula Fiuza, por todo o carinho e compreensão dedicada ao seu namorado caprichoso e de gênio difícil.

Aos amigos André Luiz de Araújo e Fábio Rogério de Moraes por terem me acompanhado e apoiado desde o início dos meus estudos e também pela incondicional amizade.

À Professora Vera, pela orientação e ímpar contribuição ao desenvolvimento deste trabalho.

Ao Professor Dr. Carlos José Leopoldo Constantino, não apenas pela disponibilização do equipamento para registro dos espectros Raman, mas também pela atenção e hospitalidade.

À Professora Dr. a Ana Maria da Costa Ferreira, pelo registro e auxílio na interpretação dos dados de EPR.

Aos colegas de laboratório César A. S. Barbosa e Marcos A. Bizeto, pelos conselhos.

Ao CNPq pela bolsa concedida.

À FAPESP pelo auxílio financeiro para aquisição de equipamentos e reagentes.

E por último, porém não menos importante, a todos aqueles que, direta ou indiretamente, contribuíram para a realização e divulgação deste trabalho. 
"Devemos jamais cessar a exploração; e o final de todo explorar será chegar onde começamos e conhecer o lugar pela primeira vez." Thomas Stearns Eliot $(1888-1965)$ 


\section{Sumário}

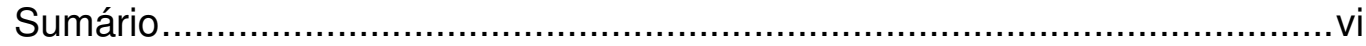

Resumo

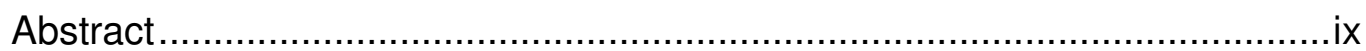

Abreviações Utilizadas ........................................................................

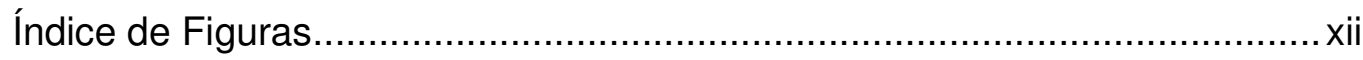

Índice de Tabelas ............................................................................

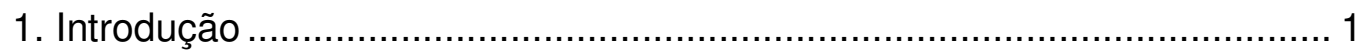

1.1. Hidróxidos Mistos Lamelares ...................................................... 2

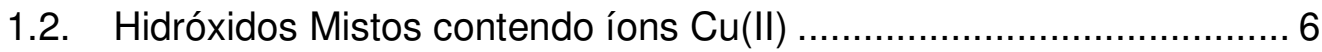

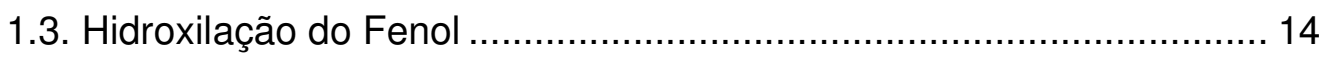

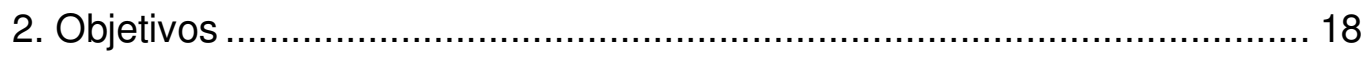

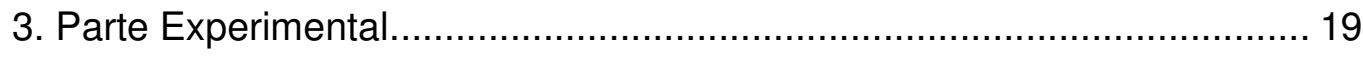

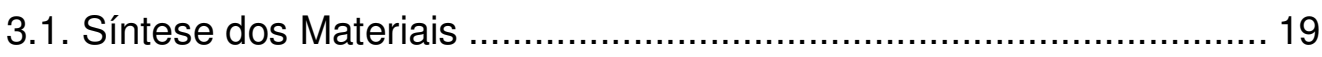

3.2. Testes Catalíticos de Hidroxilação de Fenol ..................................... 22

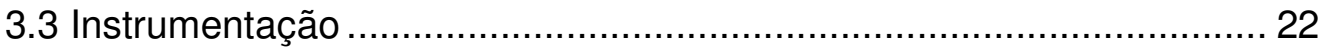

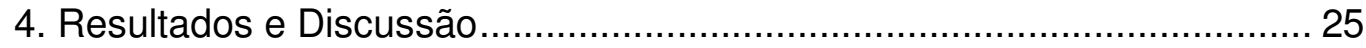

4.1. Síntese e Caracterização dos Materiais ………………………........ 25

4.2. Testes Catalíticos de Hidroxilação de Fenol ...................................... 76

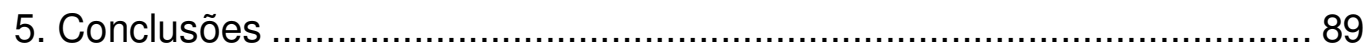

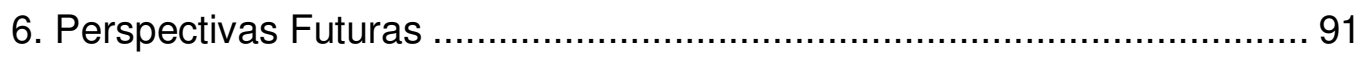

7. Referências Bibliográficas .................................................................. 92

Anexo A - Método para Deconvolução de Curvas ........................................A1

Anexo B - Espectros de Espalhamento Raman ......................................... B1

Anexo C - Imagens das amostras HT-Cux sob aquecimento......................... 1

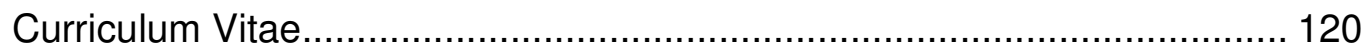




\section{Resumo}

O presente trabalho trata da preparação e da caracterização textural e espectroscópica de hidróxidos mistos lamelares de composição $\left[\mathrm{Mg}_{3-\mathrm{x}} \mathrm{Cu}_{x} \mathrm{Al}(\mathrm{OH})_{8}\right]\left(\mathrm{CO}_{3}\right)_{0,5} \cdot \mathrm{yH}_{2} \mathrm{O}(\mathrm{x}=0,3 ; 0,6 ; 0,9 ; 1,2 ; 1,5 ; 1,8 ; 2,1 ; 2,4 ; 2,7 \mathrm{e}$ $3,0)$, bem como do estudo da reatividade desses materiais na hidroxilação do fenol, utilizando peróxido de hidrogênio como oxidante. Os sólidos foram preparados através do método da co-precipitação e caracterizados por difratometria de raios $\mathrm{X}$, análises elementares (C, $\mathrm{H}, \mathrm{N}$ e metais) e termogravimétricas, medidas de área superficial e, também, pelas seguintes técnicas espectroscópicas: vibracional no infravermelho e espalhamento Raman, eletrônica de absorção no visível-infravermelho próximo e ressonância paramagnética eletrônica.

Observou-se que quanto maior o conteúdo de cobre(II) nas amostras, maior é a tendência à formação de CuO. Materiais de coloração azul contendo apenas uma fase cristalina foram obtidos por co-precipitação no intervalo de pH 8-10 e efetuando as etapas de envelhecimento e secagem na temperatura ambiente. Quanto maior a quantidade de íons $\mathrm{Cu}^{2+}$ no hidróxido misto lamelar, menor a cristalinidade e a estabilidade térmica do material. Os espectros de EPR são anisotrópicos (parâmetros $g_{/ /}$e $g_{\perp}$ bem definidos), indicando que os íons cobre(II) se encontram em sítio com simetria axial. À medida que a quantidade de $\mathrm{Cu}^{2+}$ nas amostras aumenta, ocorre uma diminuição no sinal do metal de transição, que pode ser interpretada como decorrência de um acoplamento antiferromagnético entre os íons cobre. Dados de espectroscopia vibracional sugerem que nos hidróxidos mistos há dois tipos de íons carbonato. Além disso, foi observado o fenômeno de abaixamento de simetria dos ânions 
$\mathrm{CO}_{3}{ }^{2-}$ ao longo do processo de aquecimento, originando, conforme a temperatura e a composição, materiais de coloração variada. $\mathrm{O}$ abaixamento de simetria pode estar sendo ocasionado pela coordenação (ou enxertia) dos íons carbonato aos centros metálicos das lamelas. Os sólidos verdes obtidos por aquecimento possuem, além de bandas no espectro eletrônico atribuídas às transições do tipo d-d (700-800 nm), absorção na região abaixo de 400 nm, que pode ser atribuída à transferência de carga $\mathrm{O}^{2-} \rightarrow \mathrm{Cu}^{2+}$. Apesar dos difratogramas de raios $\mathrm{X}$ apresentarem picos de baixas intensidades referentes às fases espinélio, a coloração ocre observada pode ser devida à presença da fase $\mathrm{CuAl}_{2} \mathrm{O}_{4}$ (sólido marrom). Nas amostras cinzas e pretas, os difratogramas de raios $\mathrm{X}$ mostram picos intensos atribuídos ao $\mathrm{CuO}$.

Os testes de reatividade dos hidróxidos mistos sintetizados na hidroxilação do fenol pelo peróxido de hidrogênio em meio aquoso envolveram a variação de parâmetros reacionais como temperatura, tempo, concentração de substrato e influência de luz, mantendo-se constante a relação molar fenol/ $/ \mathrm{Cu}^{2+}$. O substrato orgânico foi oxidado a catecol, hidroquinona e p-benzoquinona. As substâncias no meio reacional foram quantificadas pela deconvolução do espectro eletrônico da mistura na região do ultravioleta. Como esperado, o material sintetizado sem íons cobre(II) não apresenta atividade catalítica para o sistema reacional estudado. 


\section{Abstract}

In this work it was investigated the preparation and spectroscopic characterization of layered hydroxides of composition $\left[\mathrm{Mg}_{3-x} \mathrm{Cu}_{x} \mathrm{Al}(\mathrm{OH})_{8}\right]\left(\mathrm{CO}_{3}\right)_{0.5 .} \mathrm{yH} \mathrm{H}_{2} \mathrm{O}(\mathrm{x}=0.3 ; 0.6 ; 0.9 ; 1.2 ; 1.5 ; 1.8 ; 2.1 ; 2.4 ; 2.7$ and 3.0), as well the reactivity of these materials towards phenol hydroxylation, using hydrogen peroxide as oxidizing agent. The solids had been prepared through the co-precipitation method and characterized by $\mathrm{X}$ ray diffractometry, elemental analysis ( $\mathrm{C}, \mathrm{H}, \mathrm{N}$ and metals), thermogravimetric analysis, surface area measurements, and also by the following spectroscopic techniques: infrared vibrational absortion (FTIR), Raman scattering, vis-NIR electronic absorption and electron paramagnetic resonance (EPR).

It was observed that the increase of copper(II) content in the samples favours the $\mathrm{CuO}$ formation. Materials of blue coloration containing only one crystalline phase were obtained by the co-precipitation method in the $\mathrm{pH}$ range $10-8$, and were submitted to aging and drying processes at room temperature. As the amount of $\mathrm{Cu}^{2+}$ ions increases in the layered hydroxide material, it was observed a decrease in crystallinity and thermal stability. EPR spectra are anisotropic (parameters $g_{/ /}$and $g \perp$ well defined), indicating that copper(II) ions are in sites with axial symmetry. As the amount of $\mathrm{Cu}^{2+}$ in the samples increases, EPR signal decreases, what can be interpreted as result of an antiferromagnetic coupling between copper ions. FTIR data suggests that the layered hydroxides gave two types of cabornate ions. Moreover, the symmetry lowering phenomena of $\mathrm{CO}_{3}{ }^{2-}$ anions during the heating process was observed, originating, according to the temperature and sample composition, materials of varied coloration. This lowering of symmetry can be due to coordination (or 
grafting) of carbonate ions to the metal ions in the layers. Vis-NIR electronic spectra of green solids obtained by heating show absorption in the region below $400 \mathrm{~nm}$, besides bands attributed to $d$ - $d$ transitions (700-800 $\mathrm{nm})$, that can be attributed to $\mathrm{O}^{2-} \rightarrow \mathrm{Cu}^{2+}$ charge transfer transition. Despite the $X$ ray diffraction peaks of low intensities attributed to spinel phases, the ochre coloration observed can be due to the presence of $\mathrm{CuAl}_{2} \mathrm{O}_{4}$ (brown solid). For gray and black samples, $\mathrm{X}$ ray diffractograms shows intense peaks attributed to CuO. Reactivity tests about phenol hydroxylation involved the variation of experimental parameters as temperature, time, substrate concentration and influence of light, keeping constant the phenol/ $\mathrm{Cu}^{2+}$ molar ratio. The organic substrate was oxidized to cathecol, hydroquinone and p-benzoquinone and these products were quantified by deconvolution of the electronic spectra. As expected, the material synthesized without copper(II) ions does not show catalytic activity for the studied reaction. 


\section{Abreviações Utilizadas}

HDL - Hidróxido Duplo Lamelar

DRX - Difratograma de raios $X$ (método do Pó)

FTIR - Espectro Vibracional no Infravermelho

EPR - Ressonância Paramagnética Eletrônica

TA - Temperatura Ambiente

TGA - Análise Termogravimétrica

DTG -Derivada da curva Termogravimétrica

$\mathrm{HQ}$ - hidroquinona ou 1,4-dihidroxibenzeno ou quinol

CT - catecol ou 1,2-dihidroxibenzeno ou pirocatecol

$\mathrm{BQ}$ - $p$-benzoquinona ou 1,4-diona-2,5-ciclohexadieno

$\mathrm{HT}-\mathrm{Cux}-\left[\mathrm{Mg}_{\mathrm{x}-3} \mathrm{Cu}_{\mathrm{x}} \mathrm{Al}(\mathrm{OH})_{8}\right]\left(\mathrm{CO}_{3}\right)_{0,5} \cdot \mathrm{yH}_{2} \mathrm{O}$

$\mathrm{HT}$ - Hidrotalcita $-\left[\mathrm{Mg}_{3} \mathrm{Al}(\mathrm{OH})_{8}\right]\left(\mathrm{CO}_{3}\right)_{0,5} \cdot 2 \mathrm{H}_{2} \mathrm{O}$ 


\section{Índice de Figuras}

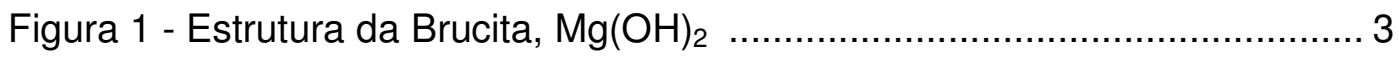

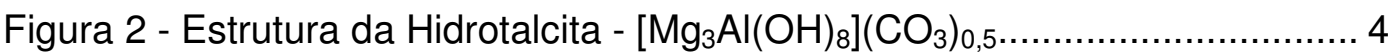

Figura 3 - Relação entre raios iônicos e estrutura de $\mathrm{HDL}$, com $\mathrm{M}^{2+} / \mathrm{M}^{3+}=2 \ldots .5$

Figura 4 - Efeito da distorção tetragonal prevista por Jahn-Teller para íon $\mathrm{Cu}^{2+}$

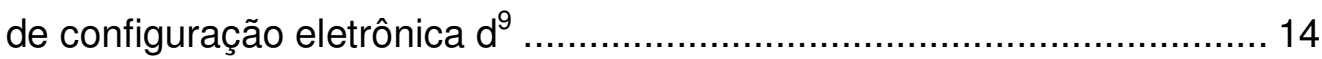

Figura 5 - DRX das amostras HT e HT-Cu0,3 ……................................. 25

Figura 6 - DRX da amostra HT-Cu0,6 obtida por secagem em estufa a $80^{\circ} \mathrm{C}$ e em dessecador sob vácuo .............................................................. 26

Figura 7 - DRX da amostra HT-Cu0,9 preparada com tratamento térmico a 50,

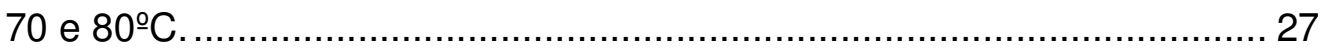

Figura 8 - Esquema das estruturas dos compostos (a) $\mathrm{Cu}(\mathrm{OH})_{2}$ e (B) $\mathrm{CuO} \ldots . .30$

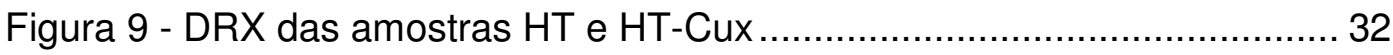

Figura 10 - Curvas TGA (-) e DTG (-) para as amostras HT e HT-Cu x .......... 37

Figura 11 - Temperatura do pico DTG de cada evento térmico para as amostras HT e HT-Cux. 38

Figura 12 - Diagrama de Equilíbrio Ácido Carbônico - Bicarbonato - Carbonato 41

Figura 13 - Modos normais de vibração do íon carbonato. (R) : modo ativo no Raman; (IV): modo ativo no infravermelho. As regiões espectrais indicadas se referem à calcita e à aragonita $(\mathrm{CaCO} 3)^{[81]}$. 42

Figura 14 - Espectros FTIR das amostras HT e HT-Cux .............................. 44

Figura 15 - Espectro de espalhamento Raman para as amostras HT-Cux e HT 45

Figura 16 - Espectros EPR para as amostras HT-Cux e CuO na temperatura de $\mathrm{N}_{2}$ líquido. 47

Figura 17 - Histograma de intensidade do sinal EPR para as amostras HT-Cux

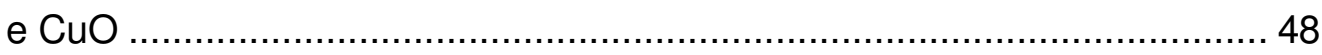

Figura 18 - Estrutura de espinélio normal $\mathrm{M}^{\prime \prime} \mathrm{M}^{\prime \prime \prime}{ }_{2} \mathrm{O}_{4}\left(\right.$ ou $\left.\mathrm{AB}_{2} \mathrm{O}_{4}\right) \ldots \ldots \ldots \ldots \ldots \ldots . . . . . . . . .50$ 
Figura 19 - DRX das amostras calcinadas em forno a $900^{\circ} \mathrm{C}$ por 1 hora: $\bullet \mathrm{MgO}$; - $\mathrm{MgAl}_{2} \mathrm{O}_{4}$ e/ou $\mathrm{CuAl}_{2} \mathrm{O}_{4} ; \nabla \mathrm{CuO}$

Figura 20 - Espectros FTIR das amostras HT-Cux, calcinadas em forno a $900^{\circ} \mathrm{C}$ por $1 \mathrm{~h}$ (calcinação ex-situ) 53

Figura 21 - Espectros de Espalhamento Raman das amostras HT-Cu x, calcinadas em forno a $900^{\circ} \mathrm{C}$ por $1 \mathrm{~h}$ (calcinação ex-situ) 54

Figura 22 - Espectros FTIR da amostra HT calcinada em diferentes temperaturas. 56

Figura 23 - Espectros FTIR da amostra HT-Cu0,6 calcinada em diferentes temperaturas. 57

Figura 24 - Espectros FTIR da amostra HT-Cu1,2 calcinada em diferentes temperaturas 58

Figura 25 - Espectros FTIR da amostra HT-Cu1,8 calcinada em diferentes temperaturas 59

Figura 26 - Espectros FTIR da amostra HT-Cu2,4 calcinada em diferentes temperaturas 60

Figura 27 - Espectros FTIR da amostra HT-Cu3,0 calcinada em diferentes temperaturas. 61

Figura 28 - (A) Modos de coordenação do íon carbonato aos centros metálicos; (B) Modos de coordenação (ou enxertia) dos íons carbonato aos centros metálicos das lamelas de hidróxidos mistos.

62

Figura 29 - Espectros de Espalhamento Raman da amostra HT calcinada em diferentes temperaturas. 63

Figura 30 - Espectros de Espalhamento Raman da amostra HT-Cu0,6 calcinada em diferentes temperaturas 64

Figura 31 - Espectros de Espalhamento Raman da amostra HT-Cu1,2 calcinada em diferentes temperaturas. 65

Figura 32 - Espectros de Espalhamento Raman da amostra HT-Cu1,8 calcinada em diferentes temperaturas 66

Figura 33 - Espectros de Espalhamento Raman da amostra HT-Cu2,4 calcinada em diferentes temperaturas.

Figura 34 - Espectros de Espalhamento Raman da amostra HT-Cu3,0 calcinada em diferentes temperaturas. 68 
Figura 35 - Imagens em microscópio óptico, com lente de 50x, da amostra HTCu1,2 em diferentes temperaturas 72

Figura 36 - Espectro eletrônico da amostra HT-Cu1,2 sem tratamento térmico (azul) e aquecida a $300^{\circ} \mathrm{C}$ (verde) 76

Figura 37 - Estruturas do fenol e dos compostos formados na reação . 77

Figura 38 - Curva cinética de consumo de $\mathrm{H}_{2} \mathrm{O}_{2}$ para hidroxilação de fenol com HT-Cu1,5 como catalisador, em diferentes temperaturas. 79

Figura 39 - Espectros eletrônicos de absorção normalizados das prováveis espécies existentes após a reação de hidroxilação do fenol 82

Figura 40 - Espectro eletrônico do filtrado obtido após separação do catalisador com filtro Millipore 83

Figura 41 - Concentração dos componentes da mistura reacional em função do tempo, para reação com HT-Cu3,0 como catalisador 84

Figura 42 - Porcentagem de conversão de fenol por quantidade de íons $\mathrm{Cu}^{2+}$ presentes no catalisador 86

Figura 43 - Proporção dos produtos obtidos em solução na reação de hidroxilação de fenol em função da quantidade de íons $\mathrm{Cu}^{2+}$ no catalisador

Figura 44 - Gráfico resultante do método de ranking A4

Figura 45 - Espectro eletrônico experimental e simulado para uma mistura conhecida

Figura 46 - Espectro de Espalhamento Raman da amostra HT calcinada em diferentes temperaturas.

Figura 47 - Espectro de Espalhamento Raman da amostra HT-Cu0,3 calcinada em diferentes temperaturas. B2

Figura 48 - Espectro de Espalhamento Raman da amostra HT-Cu0,6 calcinada em diferentes temperaturas. B3

Figura 49 - Espectro de Espalhamento Raman da amostra HT-Cu0,9 calcinada em diferentes temperaturas . B4

Figura 50 - Espectro de Espalhamento Raman da amostra HT-Cu1,2 calcinada em diferentes temperaturas. B5

Figura 51 - Espectro de Espalhamento Raman da amostra HT-Cu1,5 calcinada em diferentes temperaturas. B6 
Figura 52 - Espectro de Espalhamento Raman da amostra HT-Cu1,8 calcinada em diferentes temperaturas.

Figura 53 - Espectro de Espalhamento Raman da amostra HT-Cu2,1 calcinada em diferentes temperaturas . B8

Figura 54 - Espectro de Espalhamento Raman da amostra HT-Cu2,4 calcinada em diferentes temperaturas. B9

Figura 55 - Espectro de Espalhamento Raman da amostra HT-Cu2,7 calcinada em diferentes temperaturas.

Figura 56 - Espectro de Espalhamento Raman da amostra HT-Cu3,0 calcinada em diferentes temperaturas. B11

Figura 57 - Imagens em microscópio óptico, com lente de 50x, da amostra HTCu0,3 em diferentes temperaturas

Figura 58 - Imagens em microscópio óptico, com lente de 50x, da amostra HTCu0,6 em diferentes temperaturas

Figura 59 - Imagens em microscópio óptico, com lente de 50x, da amostra HTCu0,9 em diferentes temperaturas

Figura 60 - Imagens em microscópio óptico, com lente de 50x, da amostra HTCu1,2 em diferentes temperaturas . 4

Figura 61 - Imagens em microscópio óptico, com lente de 50x, da amostra HTCu1,5 em diferentes temperaturas . 55

Figura 62 - Imagens em microscópio óptico, com lente de 50x, da amostra HTCu1,8 em diferentes temperaturas . 6

Figura 63 - Imagens em microscópio óptico, com lente de 50x, da amostra HTCu2,1 em diferentes temperaturas

Figura 64 - Imagens em microscópio óptico, com lente de 50x, da amostra HTCu2,4 em diferentes temperaturas C8

Figura 65 - Imagens em microscópio óptico, com lente de 50x, da amostra HTCu2,7 em diferentes temperaturas C9

Figura 66 - Imagens em microscópio óptico, com lente de 50x, da amostra HTCu3,0 em diferentes temperaturas C10 


\section{Índice de Tabelas}

Tabela 1 - Artigos sobre hidróxidos mistos lamelares contendo íons $\mathrm{Cu}^{2+}$ publicados no período de janeiro de 1992 a julho de 2005. 10

Tabela 2 - Condições industriais utilizadas para hidroxilação de fenol ${ }^{[53,54]} \ldots 16$ Tabela 3 - Artigos sobre compostos sólidos utilizados para hidroxilação de fenol com peróxido de hidrogênio publicados de janeiro de 2004 a julho de

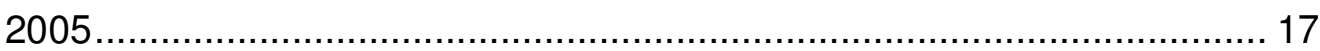

Tabela 4 - Listagem dos reagentes utilizados ............................................ 19

Tabela 5 - Composição das soluções e pH de síntese dos materiais ............... 21

Tabela 6 - Condições experimentais das sínteses dos hidróxidos ternários de $\mathrm{Cu}^{2+} / \mathrm{Mg}^{2+} / \mathrm{Al}^{3+}$ empregadas neste trabalho ........................................... 30

Tabela 7 - Condições experimentais empregadas na síntese por coprecipitação dos hidróxidos ternários que resultaram apenas em fase do tipo HT

Tabela 8 - Alguns valores cristalográficos para as amostras HT e HT-Cux, obtidos a partir dos DRXs da Figura 9 33

Tabela 9 - Dados de medidas de área superficial para as amostras HT e HTCux 34

Tabela 10 - Temperaturas e porcentagens de perda de massa, conforme TGA 38

Tabela 11 - Resultado de Análise de Metais por ICP e de CHN ..................... 40 Tabela 12 - Principais bandas observadas nos espectros FTIR das amostras HT-Cux 45

Tabela 13 - Parâmetros de EPR para as amostras HT-Cu0,3; 0,6; 0,9; 1,2 e 1,5 48

Tabela 14 - Principais bandas observadas nos espectros de espalhamento Raman para as amostras HT e HT-Cux em diferentes temperaturas ........ 69

Tabela 15 - Massa de cada catalisador utilizada para realização dos testes catalíticos. 81

Tabela 16 - Concentrações finais obtidas para cada componente 85

Tabela 17 - Constantes $A_{i}^{\prime}(\lambda)$ e $\varepsilon_{l}$ utilizadas para cálculo de concentração .....A6 



\section{Introdução}

Materiais lamelares são todos aqueles em cuja estrutura é possível observar uma organização dos átomos de forma tal que esses formem camadas que se sobrepõem em uma determinada orientação e de maneira regular ao longo de um determinado eixo cristalográfico. O que mantém coesa a estrutura desses materiais são interações eletrostáticas ou do tipo ligações de hidrogênio ou van der Waals ${ }^{[1]}$.

Os materiais lamelares são conhecidos e estudados já há muito tempo, sendo talvez a grafite o exemplo mais difundido desse tipo de material: um sólido lamelar formado por átomos de carbono ligados entre si formando hexágonos que compartilham as arestas entre si, formando camadas que se sobrepõem de maneira regular e organizada.

Os hidróxidos mistos lamelares, por sua vez, fazem parte de uma classe de materiais lamelares denominada de argilas aniônicas. As argilas aniônicas, bem como as catiônicas, são materiais que apresentam sua estrutura organizada em camadas carregadas eletricamente, que se repetem de maneira regular e cujo espaço interlamelar é preenchido por íons de carga oposta à das lamelas, de forma a atingir a neutralidade ${ }^{[1],[2]}$.

Uma característica que se observa em alguns materiais lamelares, tanto nos compostos de camadas neutras, como a grafite, como nos carregados eletricamente como os hidróxidos mistos lamelares, é a capacidade de inserir ou trocar espécies interlamelares, chamadas também de espécies convidadas. Por esse motivo, tais materiais são conhecidos também como compostos de intercalação e o estudo desses é chamado de química de intercalação ${ }^{[2]}$. Parte do interesse nos compostos de intercalação se deve ao fato de que algumas 
das propriedades, tanto das espécies imobilizados quanto dos hospedeiros, podem ser alteradas. Com isso, é possível planejar a obtenção de materiais que apresentarão características mistas entre as da matriz lamelar pura e as da espécie convidada. Por isso, os compostos de intercalação encontram diversas aplicações científicas e tecnológicas, desde catalisadores até trocadores iônicos ${ }^{[4]}$. Esses compostos podem ser utilizados em processos de remediação ambiental, como seqüestradores de espécies poluentes; como eletrodos de baterias (que envolvem eletrointercalação de íons lítio); como transportadores de fármacos ou substâncias de interesse; bem como suportes para catalisadores em reações heterogêneas, entre diversas outras aplicações.

\subsection{Hidróxidos Mistos Lamelares}

Os hidróxidos duplos lamelares (HDLs), também conhecidos como argilas aniônicas, têm como principal característica o fato das lamelas hidroxiladas serem formadas por cátions de dois metais. Sua estrutura é semelhante à estrutura da brucita (hidróxido de magnésio), um sólido lamelar, no qual os íons metálicos estão coordenados octaédricamente às hidroxilas e cada octaedro formado está conectado a outro por meio de uma das arestas, conforme observado na Figura $1^{[1]}$. Observa-se que cada íon $\mathrm{OH}^{-}$está coordenado a três íons metálicos. 


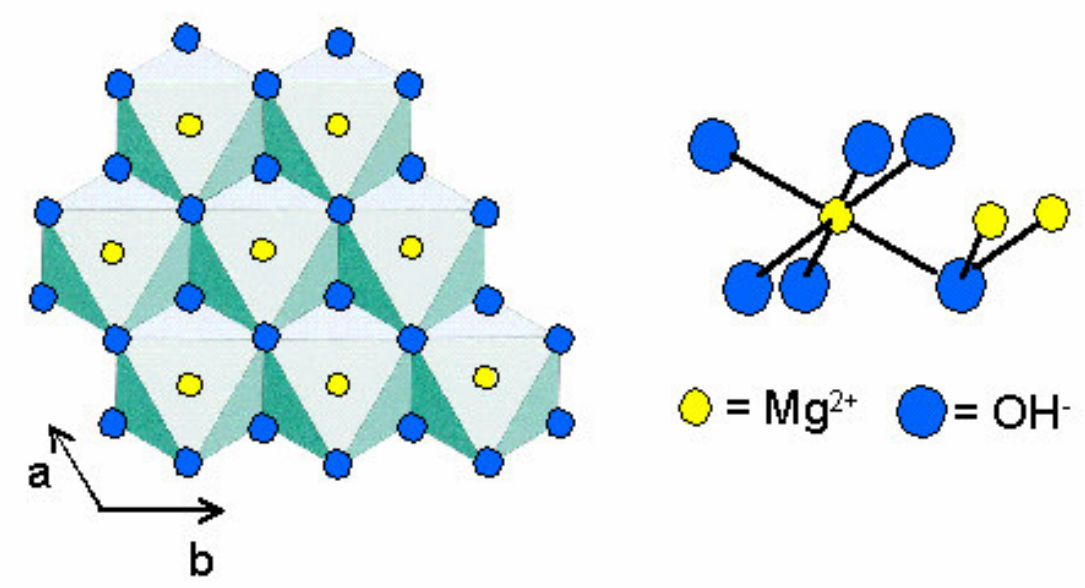

Figura 1 - Estrutura da Brucita, $\mathrm{Mg}(\mathrm{OH})_{2}\left[{ }^{3}\right]$

O exemplo mais conhecido de HDL é a hidrotalcita, sendo um dos casos de $\mathrm{HDL}$ de ocorrência natural, e de composição $\left[\mathrm{Mg}_{3} \mathrm{Al}(\mathrm{OH})_{8}\right]\left(\mathrm{CO}_{3}\right)_{0,5} \cdot 2 \mathrm{H}_{2} \mathrm{O}$. A hidrotalcita se forma quando, parte dos íons magnésio da brucita são substituídos por íons alumínio, na presença de íons carbonato. Conforme pode ser observado na Figura 2, na hidrotalcita os íons alumínio também se encontram coordenados octaédricamente de maneira similar aos íons magnésio, e os íons carbonato, bem como as moléculas de água, se encontram na região interlamelar ${ }^{[1]}$. 


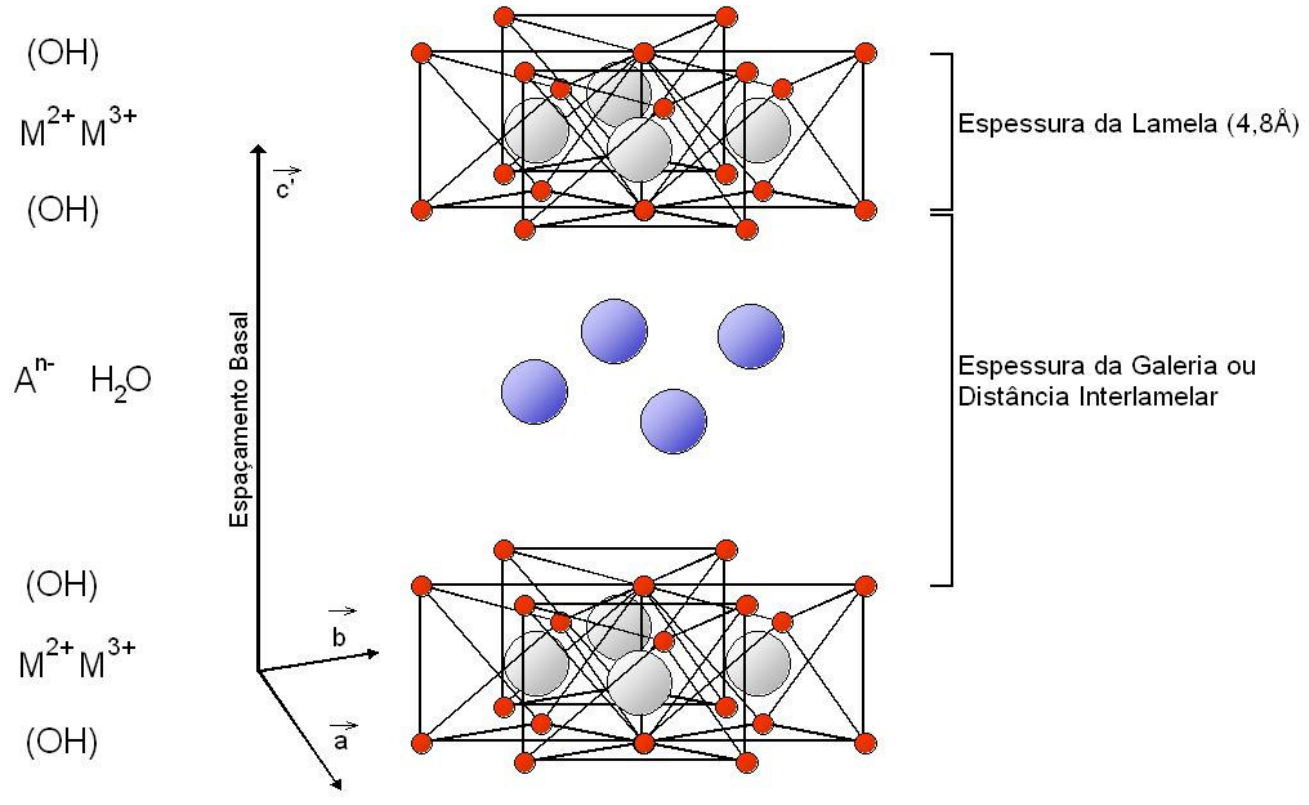

Figura 2 - Estrutura da Hidrotalcita - $\left[\mathrm{Mg}_{3} \mathrm{Al}(\mathrm{OH})_{8}\right]\left(\mathrm{CO}_{3}\right)_{0,5}$

Uma característica dos HDLs é justamente a ampla gama de composições que se é possível alcançar. De fórmula geral $\left[\mathrm{M}^{2+}{ }_{1-\mathrm{x}} \mathrm{M}^{3+}{ }_{\mathrm{x}}(\mathrm{OH})_{2}\right]^{\mathrm{x}+}\left(\mathrm{A}^{\mathrm{n}-}\right)_{\mathrm{x} / \mathrm{n}} \cdot \mathrm{yH}_{2} \mathrm{O}$, os HDLs apresentam não apenas poucas limitações quanto ao ânion $A^{n-}$ que será utilizado como contra-íon, mas também se podem combinar diversos metais $\mathrm{M}^{2+}$ e $\mathrm{M}^{3+}$ nas lamelas (geralmente $\mathrm{M}^{2+}=$ $\left.\mathrm{Zn}^{2+}, \mathrm{Mg}^{2+}, \mathrm{Cu}^{2+}, \mathrm{Ni}^{2+} \mathrm{e}^{3+}=\mathrm{Al}^{3+}, \mathrm{Cr}^{3+}, \mathrm{Fe}^{3+}\right)$ em composições que podem ser binárias, ternárias ou até mesmo quaternárias. $A$ composição $\mathrm{M}^{2+} / \mathrm{M}^{3+}$ pode ser variada em um intervalo que depende dos metais utilizados. Essa grande flexibilidade quanto à composição dos HDLs torna quase infinita a lista de possíveis materiais $^{[1,4,5,6,7]}$.

Porém, apesar de se poder utilizar uma grande variedade de metais, nem todos os elementos da tabela periódica são apropriados para a formulação de HDLs. Apesar de existirem casos de materiais cujas lamelas são formadas com íons $\mathrm{Li}^{+}{ }^{[8]}{\mathrm{e} \mathrm{Ti}^{4+}{ }^{[9]} \text {, sendo esse último ainda controverso }}^{[10,11]}$, um primeiro fator limitante na composição de HDLs é a carga dos metais a serem utilizados. 
Outra limitação, que apesar de ser de fácil dedução deve ser ressaltada, é a necessidade do íon metálico a ser utilizado ser estável quanto ao seu número de oxidação nas condições de síntese. Conseqüentemente, tal condição descarta a possibilidade de síntese de materiais contendo, por exemplo, íons $\mathrm{Ti}^{3+}$ na lamela, pelo menos em meio aquoso.

Outro fator que deve ser levado em consideração é o tamanho dos íons a serem utilizados: eles devem possuir tamanhos compatíveis, uma vez que formarão octaedros que terão arestas compartilhadas. Apesar da estrutura dos HDLs ser baseada na estrutura da brucita, não existe a obrigatoriedade nem de que exista $\mathrm{Mg}^{2+}$ na composição do material nem de que os íons a serem utilizados tenham tamanho próximos a ele. Rousselot et al. ${ }^{[12]}$ equacionou uma relação entre raios iônicos dos metais, na forma de subtração entre os raios iônicos, para HDLs com relação $\mathrm{M}^{2+} / \mathrm{M}^{3+}$ igual a 2, determinando como sendo adequadas para a formação de HDLs combinações onde a diferença entre os raios varia de $0,02 \AA$ até $0,18 \AA ̊$, conforme ilustrado na Figura 3 .

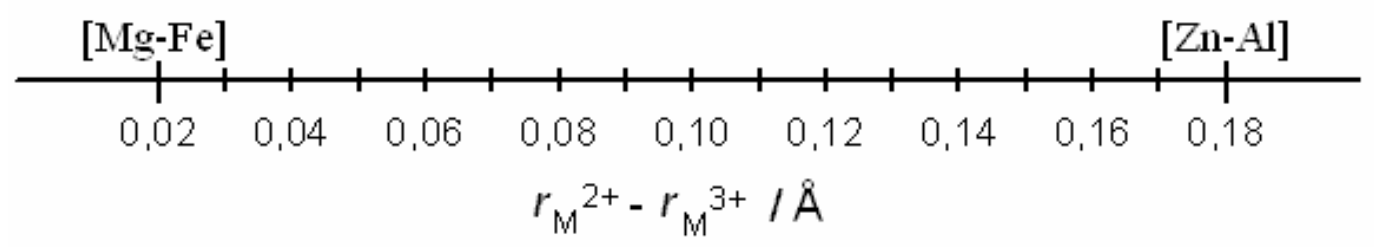

Figura 3 - Relação entre raios iônicos e estrutura de $\mathrm{HDL}$, com $\mathrm{M}^{2+} / \mathrm{M}^{3+}=2^{[12]}$

Os HDLs podem ser sintetizados de diversas maneiras diferentes, empregando desde metodologias que utilizam altas temperaturas e pressões, em um processo denominado hidrotérmico, até metodologias brandas, ou soft chemistry, como o método da co-precipitação ${ }^{[1],[6],[13],[14]}$. A possibilidade de se sintetizar materiais versáteis, de maneira simples, em condições brandas e de baixo custo, aumenta o interesse no estudo dos HDLs. 
A grande variedade de composições possíveis, bem como a diversidade de metodologias de preparo de HDLs, resulta não apenas numa quase multiplicidade ímpar de materiais, mas também numa infinidade de aplicações possíveis. Algumas das diversas aplicações possíveis para os HDLs podem ser: como catalisador ou suporte para catalisador ${ }^{[15],}[16]$, como peneira molecular, como trocador iônico, em processos de remoção de poluentes de efluentes $^{[17]}$, como imobilizador e/ou carregador de fármacos ${ }^{[18]}$ e como carregador de hormônios vegetais de crescimento[ ${ }^{[19]}$.

A empresa Bayer comercializa hidrotalcita sob o nome Talcid®, um antiácido produzido na Alemanha e que, desde 2004, passou a ser fabricado também na China ${ }^{[20]}$. A principal aplicação comercial da hidrotalcita é como aditivo para plásticos (PVC e poliolefinas), área em que é conhecida com os nomes Sorbacid® e Hycite $\AA_{713^{[21]}}$. Nos polímeros, o aditivo inorgânico atua como retardante de chama e, no caso particular do PVC, também como agente neutralizante do ácido gerado na queima ou degradação do material orgânico.

\subsection{Hidróxidos Mistos contendo íons $\mathrm{Cu}(\mathrm{II})$}

Como mencionado anteriormente, os hidróxidos mistos lamelares são materiais de interesse na área da catálise. As investigações nessa área consideram principalmente três tipos de materiais ${ }^{[4,6,15,16,22]}$ :

1. os hidróxidos lamelares originais, que possuem as hidroxilas como centros de atividade básica e os cátions de metais de transição nas lamelas como sítios de atividade redox; 
2. os hidróxidos lamelares originais contendo ânions intercalados que possuem atividade catalítica como, por exemplo, os polioxometalatos $\left(\mathrm{PW}_{12} \mathrm{O}_{40}{ }^{3-}, \mathrm{GeW}_{11} \mathrm{CuO}_{39}{ }^{6-}\right)$;

3. os hidróxidos lamelares calcinados a $400-500^{\circ} \mathrm{C}$, que geram uma mistura de óxidos metálicos (solução sólida) de alta área superficial. Esses catalisadores multimetálicos apresentam sítios $\mathrm{O}^{2-}$ fortemente básicos e, dependendo do cátion, atividade redox. No caso de hidróxidos mistos contendo metal que é facilmente reduzido, a exposição ao hidrogênio gasoso, por exemplo, pode gerar um sólido contendo partículas metálicas dispersas.

A atividade catalítica dos hidróxidos mistos (originais ou calcinados) pode ser explorada através da variação de diferentes parâmetros (natureza dos cátions, razão $\mathrm{M}^{\prime \prime} / \mathrm{M}^{\prime \prime \prime}$, espécie intercalada, temperatura de calcinação etc.). No caso particular dos materiais não calcinados contendo metais de transição, são gerados catalisadores bifuncionais que promovem, por exemplo, reações de hidroxilação, oxidação de grupo alquil ou álcool a carbonil, cetona a éster e epoxidação ${ }^{[6,22]}$. Quando decompostos termicamente, podem ativar reações de condensação aldólica, acilação, epoxidação, hidrogenação, redução de grupo nitro e oxidação de tióis, entre outras ${ }^{[4,22]}$.

Existem três maneiras principais para a obtenção de HDLs contendo íons $\mathrm{Cu}^{2+}$ que são:

1. complexos aniônicos de $\mathrm{Cu}(\mathrm{II})$ inseridos na região interlamelar ${ }^{[23]}$;

2. complexos neutros ou aniônicos de $\mathrm{Cu}(\mathrm{II})$ adsorvidos na superfície ${ }^{[23],[24]}$;

3. lamelas que contenham $\mathrm{Cu}(\mathrm{II})$ em sua composição ${ }^{[4,6]}$. 
Apesar de não serem menos importantes, as duas primeiras possibilidades não foram exploradas no presente trabalho.

A principal motivação para a síntese de hidróxidos lamelares contendo íons $\mathrm{Cu}^{2+}$ se deve ao fato dos compostos de cobre apresentarem propriedades redox que permitem a catálise de uma grande variedade de processos oxidativos. Na indústria química, tem-se como exemplo a oxidação de alcenos a aldeídos no processo Wacker ${ }^{[25]}$. Vários trabalhos têm se voltado para o uso de catalisadores a base de cobre para a redução seletiva de óxidos de nitrogênio dos gases de exaustão de automóveis ${ }^{[26]}$, assim como para a oxidação completa de $\mathrm{CO}$, hidrocarbonetos e álcoois ${ }^{[27]}$. Atualmente, os catalisadores contendo óxido de cobre suportado são considerados candidatos em potencial para substituírem os catalisadores de metais nobres empregados em processos de controle de emissão de gases. Outras áreas de interesse incluem a produção de $\mathrm{H}_{2}$ a partir da reforma a vapor do metanol (ou da oxidação desse álcool com oxigênio molecular) para uso em células a combustível ${ }^{[28]}$. Nos processos biológicos, os íons de cobre são os centros ativos de enzimas como a galactose oxidase, lacase, tirosinase e a superóxido dismutase ${ }^{[29]}$.

Tal capacidade dos íons $\mathrm{Cu}^{2+}$ de iniciar reações oxidativas utilizando agente oxidante "limpo" do ponto de vista ambiental, como o peróxido de hidrogênio, somada ao fato dos HDLs serem insolúveis em meio aquoso, torna os hidróxidos mistos contendo íons $\mathrm{Cu}^{2+}$ uma opção interessante de catalisador heterogêneo para processos oxidativos de baixo custo, empregando condições reacionais relativamente brandas e com minimização de resíduos. 
A síntese de HDLs contendo íons $\mathrm{Cu}^{2+}$ em suas lamelas é possível pois em seu estado de oxidação 2+, ele não somente é estável em meio aquoso mas também apresenta raio similar ao do íon $\mathrm{Mg}^{2+}$. Portanto, é possível preparar materiais baseados na hidrotalcita nos quais uma parte dos íons magnésio são substituídos por íons cobre(II). Apesar de não serem muito numerosos, diversos estudos, sumarizados na Tabela 1, já foram publicados acerca de materiais contendo íons $\mathrm{Cu}^{2+}$ em suas lamelas. 
Tabela 1 - Artigos sobre hidróxidos mistos lamelares contendo íons $\mathrm{Cu}^{2+}$ publicados no período de janeiro de 1992 a julho de 2005.

\begin{tabular}{|c|c|c|}
\hline Composição & Fases Obtidas & Ref. \\
\hline $\begin{array}{l}\mathrm{Cu}_{1,7} \mathrm{Zn}_{2,1} \mathrm{Al}-\mathrm{CO}_{3} \\
\mathrm{Cu}_{2,4} \mathrm{Zn}_{3,2} \mathrm{Al}-\mathrm{CO}_{3} \\
\mathrm{Cu}_{3,3} \mathrm{Zn}_{4,1} \mathrm{Al}-\mathrm{CO}_{3} \\
\mathrm{Cu}_{3,2} \mathrm{Zn}_{4,3} \mathrm{Al}-\mathrm{CO}_{3} \\
\mathrm{Cu}_{2,6} \mathrm{Zn}_{3,4} \mathrm{Al}-\mathrm{CO}_{3} \\
\end{array}$ & $\begin{array}{l}\mathrm{HDL} \\
\mathrm{HDL}+\mathrm{BA}^{\mathrm{a}}+\mathrm{AU}^{\mathrm{b}} \\
\mathrm{HDL}+\mathrm{BA}^{\mathrm{a}}+\mathrm{AU}^{\mathrm{b}} \\
\mathrm{HDL}+\mathrm{BA}^{\mathrm{a}}+\mathrm{AU}^{\mathrm{b}} \\
\mathrm{HDL}+\mathrm{HCZC}^{\mathrm{c}}+\mathrm{MQ}^{\mathrm{d}}\end{array}$ & 30 \\
\hline $\begin{array}{l}\mathrm{Cu}_{3} \mathrm{Cr}-\mathrm{Cl} \\
\mathrm{Cu}_{3} \mathrm{Cr}-\mathrm{NO}_{3} \\
\mathrm{Cu}_{9} \mathrm{Cr}-\mathrm{Cl} \\
\mathrm{Cu}_{9} \mathrm{Cr}-\mathrm{NO}_{3} \\
\end{array}$ & $\begin{array}{l}\mathrm{HDL} \\
\mathrm{HDL}+\mathrm{CuO}+\mathrm{Cr}_{2} \mathrm{O}_{3}+\mathrm{Cr}(\mathrm{OH})_{3} \\
\mathrm{CuO} \\
\mathrm{HDL}+\mathrm{CuO}+\mathrm{Cr}_{2} \mathrm{O}_{3}+\mathrm{Cu}(\mathrm{OH})_{2}+\mathrm{Cr}(\mathrm{OH})_{3}\end{array}$ & 31 \\
\hline $\mathrm{Cu}_{2} \mathrm{Cr}-\mathrm{Cl}$ & $\mathrm{HDL}$ & 32 \\
\hline $\mathrm{CuAl}{ }_{4}-\mathrm{CO}_{3}$ & $\mathrm{HDL}+\mathrm{GE}^{\mathrm{e}}$ & 33 \\
\hline $\begin{array}{l}\mathrm{CuZnFe}{ }_{0,3} \mathrm{Al}_{0,7}-\mathrm{CO}_{3} \\
\mathrm{CuZn}_{0,7} \mathrm{Mn}_{0,3} \mathrm{Fe}_{0,3} \mathrm{Al}_{0,7}-\mathrm{CO}_{3} \\
\mathrm{CuZn}_{0,5} \mathrm{Mn}_{0,5} \mathrm{Fe}_{0,3} \mathrm{Al}_{0,7}-\mathrm{CO}_{3} \\
\mathrm{CuZn}_{0,3} \mathrm{Mn}_{0,7} \mathrm{Fe}_{0,3} \mathrm{Al}_{0,7}-\mathrm{CO}_{3} \\
\text { CuMnFe }_{0,3} \mathrm{Al}_{0,7}-\mathrm{CO}_{3}\end{array}$ & $\begin{array}{l}\mathrm{HDL} \\
\mathrm{HDL}+\mathrm{Mn}_{2} \mathrm{O}_{3} \\
\mathrm{HDL}+\mathrm{Mn}_{2} \mathrm{O}_{3} \\
\mathrm{HDL}+\mathrm{Mn}_{2} \mathrm{O}_{3} \\
\mathrm{HDL}+\mathrm{Mn}_{2} \mathrm{O}_{3}+\mathrm{Mn}_{3} \mathrm{O}_{4}\end{array}$ & 34 \\
\hline $\begin{array}{l}\mathrm{Cu}_{0,33} \mathrm{Mg}_{1,67} \mathrm{Al}-\mathrm{CO}_{3} \\
\mathrm{CuMgAl}-\mathrm{CO}_{3} \\
\mathrm{Cu}_{1,67} \mathrm{Mg}_{0,33} \mathrm{Al}-\mathrm{CO}_{3} \\
\mathrm{Cu}_{2} \mathrm{Al}-\mathrm{CO}_{3}\end{array}$ & $\begin{array}{l}\mathrm{HDL} \\
\mathrm{HDL} \\
\mathrm{HDL} \\
\mathrm{HDL}+\mathrm{CuO}+\mathrm{MQ}\end{array}$ & 35 \\
\hline $\mathrm{Cu}_{3} \mathrm{Cr}-\mathrm{CO}_{3}$ & $\mathrm{HDL}+\mathrm{Cu}(\mathrm{OH})_{2}+\mathrm{CuCO}_{3}$ & 36 \\
\hline $\begin{array}{l}\mathrm{Cu}_{3} \mathrm{Al}-\mathrm{CO}_{3} \\
\mathrm{Cu}_{2} \mathrm{Al}-\mathrm{CO}_{3} \\
\mathrm{CuAl}_{2}-\mathrm{CO}_{3} \\
\mathrm{Cu}_{0,25} \mathrm{Ni}_{0,75} \mathrm{Al}_{2}-\mathrm{CO}_{3} \\
\mathrm{Cu}_{0,5} \mathrm{Ni}_{0,5} \mathrm{Al}_{2}-\mathrm{CO}_{3} \\
\mathrm{Cu}_{0,75} \mathrm{Ni}_{0,25} \mathrm{Al}_{2}-\mathrm{CO}_{3}\end{array}$ & $\begin{array}{l}\mathrm{HDL}+\mathrm{MQ}^{\mathrm{d}} \\
\mathrm{HDL}+\mathrm{MQ}^{\mathrm{d}}+\mathrm{GE}^{\mathrm{e}} \\
\mathrm{HDL}+\mathrm{GI}^{\mathrm{f}} \\
\text { Produtos amorfos } \\
\text { Produtos amorfos } \\
\text { Produtos amorfos }\end{array}$ & 37,38 \\
\hline $\begin{array}{l}\mathrm{Cu}_{0,8} \mathrm{Zn}_{1,2} \mathrm{Al}-\mathrm{NO}_{3} \\
\mathrm{Cu}_{0,6} \mathrm{Zn}_{1,4} \mathrm{Al}-\mathrm{NO}_{3} \\
\mathrm{Cu}_{0,4} \mathrm{Zn}_{1,6} \mathrm{Al}-\mathrm{NO}_{3} \\
\mathrm{Cu}_{0,2} \mathrm{Zn} \mathrm{n}_{1,8} \mathrm{Al}-\mathrm{NO}_{3} \\
\mathrm{Cu}_{0,1} \mathrm{Zn}_{1,9} \mathrm{Al}-\mathrm{NO}_{3} \\
\mathrm{Cu}_{0,03} \mathrm{Zn_{1,97 }} \mathrm{Al}-\mathrm{NO}_{3}\end{array}$ & $\begin{array}{l}\text { HDL } \\
\text { HDL } \\
\text { HDL } \\
\text { HDL } \\
\text { HDL } \\
\text { HDL }\end{array}$ & 39 \\
\hline $\begin{array}{l}\mathrm{Cu}_{2,83} \mathrm{Zn}_{0,95} \mathrm{Al}-\mathrm{CO}_{3} \\
\mathrm{Cu}_{1,92} \mathrm{Zn} \mathrm{n}_{0,96} \mathrm{Al}-\mathrm{CO}_{3} \\
\mathrm{CuZnAl}-\mathrm{CO}_{3}\end{array}$ & $\begin{array}{l}\mathrm{HDL}+\mathrm{HCZC}^{\mathrm{c}}+\mathrm{MQ}^{\mathrm{d}} \\
\mathrm{HDL} \\
\mathrm{HDL}\end{array}$ & 40 \\
\hline $\begin{array}{l}\mathrm{Cu}_{0,50} \mathrm{Ni}_{0,50} \mathrm{Al}-\mathrm{CO}_{3} \\
\mathrm{Cu}_{1,19} \mathrm{Ni}_{0,94} \mathrm{Al}-\mathrm{CO}_{3} \\
\mathrm{Cu}_{1,44} \mathrm{Ni}_{1,56} \mathrm{Al}-\mathrm{CO}_{3} \\
\mathrm{Cu}_{2,32} \mathrm{Ni}_{1,95} \mathrm{Al}-\mathrm{CO}_{3} \\
\mathrm{Cu}_{2,44} \mathrm{Ni}_{0,56} \mathrm{Al}-\mathrm{CO}_{3} \\
\mathrm{Cu}_{0,50} \mathrm{Ni}_{2,67} \mathrm{Al}-\mathrm{CO}_{3}\end{array}$ & $\begin{array}{l}\mathrm{HDL}+\mathrm{Gl}^{\dagger} \\
\mathrm{HDL} \\
\mathrm{HDL} \\
\mathrm{HDL} \\
\mathrm{HDL} \\
\mathrm{HDL}\end{array}$ & 41 \\
\hline $\begin{array}{l}\mathrm{Cu}_{0,52} \mathrm{Co}_{3,04} \mathrm{Al}-\mathrm{CO}_{3} \\
\mathrm{Cu}_{0,68} \mathrm{Co}_{2,32} \mathrm{Al}-\mathrm{CO}_{3} \\
\mathrm{Cu}_{0,92} \mathrm{Co}_{2,12} \mathrm{Al}-\mathrm{CO}_{3} \\
\mathrm{Cu}_{1,4} \mathrm{Co}_{1,56} \mathrm{Al}-\mathrm{CO}_{3} \\
\mathrm{Cu}_{2,2} \mathrm{Co}_{0,8} \mathrm{Al}-\mathrm{CO}_{3} \\
\mathrm{Cu}_{2,44} \mathrm{Co}_{0,52} \mathrm{Al}-\mathrm{CO}_{3}\end{array}$ & $\begin{array}{l}\text { HDL } \\
\text { HDL } \\
\text { HDL } \\
\text { HDL } \\
\text { HDL } \\
\text { HDL }\end{array}$ & 42 \\
\hline
\end{tabular}




\begin{tabular}{|c|c|c|}
\hline $\begin{array}{l}\mathrm{Ni}_{0,94} \mathrm{Cu}_{1,1} \mathrm{Al}-\mathrm{CO}_{3} \\
\mathrm{Ni}_{1,56} \mathrm{Cu}_{1,44} \mathrm{Al}-\mathrm{CO}_{3} \\
\mathrm{Ni}_{1,95} \mathrm{Cu}_{2,31} \mathrm{Al}-\mathrm{CO}_{3} \\
\mathrm{Ni}_{2,56} \mathrm{Cu}_{0,48} \mathrm{Al}-\mathrm{CO}_{3} \\
\mathrm{Ni}_{0,56} \mathrm{Cu}_{2,44} \mathrm{Al}-\mathrm{CO}_{3} \\
\end{array}$ & $\begin{array}{l}\mathrm{HDL} \\
\mathrm{HDL} \\
\mathrm{HDL} \\
\mathrm{HDL} \\
\mathrm{HDL}\end{array}$ & 43 \\
\hline $\mathrm{Co}_{2,04} \mathrm{Al}$ & $\mathrm{HDL}$ & \\
\hline $\mathrm{Cu}_{0,18} \mathrm{Co}_{1,86} \mathrm{Al}$ & $\mathrm{HDL}+$ Paratacamita $^{\mathrm{g}}$ & \\
\hline $\mathrm{Cu}_{0,51} \mathrm{Co}_{1,47} \mathrm{Al}$ & $\mathrm{HDL}+$ Paratacamita $^{\mathrm{g}}$ & \\
\hline CuCoAl & $\mathrm{HDL}+$ Paratacamita $^{9}+\mathrm{CuO}$ & 44 \\
\hline $\mathrm{Cu}_{1,5} \mathrm{Co}_{0,48} \mathrm{Al}$ & HDL & \\
\hline $\mathrm{Cu}_{1,8} \mathrm{Co}_{0,24} \mathrm{Al}$ & $\mathrm{HDL}$ & \\
\hline $\mathrm{Cu}_{2,3} \mathrm{Al}$ & $\mathrm{HDL}$ & \\
\hline $\mathrm{Cu}_{1,5} \mathrm{Mg}_{1,5} \mathrm{Al}-\mathrm{CO}_{3}$ & $\mathrm{HDL}$ & 45 \\
\hline $\mathrm{Cu}_{3,00} \mathrm{Al}$ & $\mathrm{HDL}+\mathrm{GE}^{\mathrm{e}}$ & \\
\hline $\mathrm{Cu}_{2,52} \mathrm{Mg}_{0,48} \mathrm{Al}-\mathrm{CO}_{3}$ & HDL & \\
\hline $\mathrm{Cu}_{2,44} \mathrm{Ni}_{0,56} \mathrm{Al}-\mathrm{CO}_{3}$ & $\mathrm{HDL}$ & 46 \\
\hline $\mathrm{Cu}_{2,48} \mathrm{Co}_{0,52} \mathrm{Al}-\mathrm{CO}_{3}$ & $\mathrm{HDL}$ & \\
\hline $\mathrm{Cu}_{2,52} \mathrm{Mg}_{0,48} \mathrm{Al}-\mathrm{CO}_{3}$ & HDL & \\
\hline $\mathrm{Cu}_{2,24} \mathrm{Mg}_{0,76} \mathrm{Al}-\mathrm{CO}_{3}$ & $\mathrm{HDL}$ & \\
\hline $\mathrm{Cu}_{1,48} \mathrm{Mg}_{1,52} \mathrm{Al}-\mathrm{CO}_{3}$ & $\mathrm{HDL}$ & 47 \\
\hline $\mathrm{Cu}_{0,72} \mathrm{Mg}_{2,28} \mathrm{Al}-\mathrm{CO}_{3}$ & HDL & \\
\hline $\mathrm{Cu}_{0,48} \mathrm{Mg}_{2,52} \mathrm{Al}-\mathrm{CO}_{3}$ & $\mathrm{HDL}$ & \\
\hline $\mathrm{Cu}_{1,15} \mathrm{Mg}_{1,85} \mathrm{Al}-\mathrm{CO}_{3}$ & HDL & \\
\hline $\mathrm{Cu}_{1,72} \mathrm{Mg}_{1,28} \mathrm{Al}-\mathrm{CO}_{3}$ & HDL & \\
\hline $\mathrm{Cu}_{1,92} \mathrm{Mg}_{1,08} \mathrm{Al}-\mathrm{CO}_{3}$ & HDL & \\
\hline $\mathrm{Cu}_{2,02} \mathrm{Mg}_{0,98} \mathrm{Al}-\mathrm{CO}_{3}$ & $\mathrm{HDL}$ & 48 \\
\hline $\mathrm{Cu}_{2,12} \mathrm{Mg}_{0,88} \mathrm{Al}-\mathrm{CO}_{3}$ & $\mathrm{HDL}$ & \\
\hline $\mathrm{Cu}_{2,22} \mathrm{Mg}_{0,78} \mathrm{Al}-\mathrm{CO}_{3}$ & $\mathrm{HDL}+\mathrm{Cu}(\mathrm{OH})_{2}$ & \\
\hline $\mathrm{Co}_{1,98} \mathrm{Fe}-\mathrm{CO}_{3}$ & $\mathrm{HDL}$ & \\
\hline $\mathrm{Co}_{1,74} \mathrm{Cu}_{0,24} \mathrm{Fe}-\mathrm{CO}_{3}$ & $\mathrm{HDL}$ & 49 \\
\hline $\mathrm{Co}_{1,35} \mathrm{Cu}_{0,63} \mathrm{Fe}-\mathrm{CO}_{3}$ & $\mathrm{HDL}+\mathrm{CuO}$ & \\
\hline $\begin{array}{l}\text { a - Baierita, } \mathrm{Al}(\mathrm{OH})_{3} \\
\text { b - Auricalcita, }(\mathrm{Zn}, \mathrm{Cu})_{5} \\
\text { c - Hidróxido } \mathrm{Carbonato} \\
\text { d - Malaquita, } \mathrm{Cu}_{2}(\mathrm{OH})_{2} \\
\text { e - Gerhardtita, } \mathrm{Cu}_{2}(\mathrm{OH} \\
\mathrm{f} \text { - Gibsita, } \mathrm{Al}(\mathrm{OH})_{3} \\
\text { g - Paratacamita, } \mathrm{Cu}_{2}(\mathrm{C}\end{array}$ & obre, $\left(\mathrm{Cu}_{0,2} \mathrm{Zn}_{0,8}\right)_{5}\left(\mathrm{CO}_{3}\right)_{2}(\mathrm{OH})_{6}$ & \\
\hline
\end{tabular}

Em todos os trabalhos já publicados acerca de preparação de HDLs contendo íons $\mathrm{Cu}^{2+}$, não se observam tentativas de variar as condições reacionais para a obtenção de fases cristalinas puras. Logo, o que se observa em todos esses trabalhos é a repetição de métodos de síntese: na maioria, a co-precipitação de solução de nitratos dos metais em baixa super-saturação, seguida de envelhecimento sob aquecimento e secagem do material em estufa. 
O estudo realizado por Alejandre et al ${ }^{[37]}$ tentando sintetizar materiais compostos apenas de $\mathrm{Cu}^{2+}$ e $\mathrm{Al}^{3+}$ com diversas proporções $\mathrm{Cu}^{2+} / \mathrm{Al}^{3+}$ apresentou um resultado bastante interessante, porém não inédito na literatura: em todas as sínteses existe a formação de uma fase lamelar e outros contaminantes cristalinos. A partir de tal observação, pode-se acreditar que é possível ocorrer a formação de fases lamelares puras compostas apenas de $\mathrm{Cu}^{2+}$ e $\mathrm{Al}^{3+}$, bastando apenas determinar quais são a composição e as condições ideais para a obtenção de tal material. Infelizmente, a composição proposta no artigo baseia-se na composição da mistura reacional; os autores não realizam nem propõem nenhum experimento para a determinação da proporção $\mathrm{Cu}^{2+} / \mathrm{Al}^{3+}$ apenas da fase lamelar.

Uma leitura mais atenta do trabalho de Li et al. ${ }^{[34]}$ revela uma proposta bastante interessante para HDLs contendo íons cobre(II): a síntese de um hidróxido misto contendo quatro cátions metálicos diferentes na lamela. Infelizmente, as condições experimentais adotadas não foram eficientes para a obtenção de uma única fase cristalina; os autores observam nos difratogramas de raios $\mathrm{X}$ a presença de diversas fases contaminando o material, como hidroxicarbonatos, hidróxidos e até mesmo óxidos. Apesar de poderem ser observadas as reflexões típicas da estrutura dos HDLs, o que indica que houve a formação do material lamelar, novamente os autores não realizam nem propõem nenhum experimento com 0 intuito de definir a real composição apenas do material lamelar.

Provavelmente o principal motivo para tais resultados seja justamente 0 escopo da maioria dos estudos realizados: a obtenção de materiais contendo íons $\mathrm{Cu}^{2+}$ que possuam atividade catalítica. Alguns estudos, inclusive, propõem 
a utilização de HDLs contendo cobre(II) apenas como precursores que, após calcinação, originarão a mistura de óxidos que será efetivamente utilizada como catalisador ${ }^{[50], ~[51]}$.

No trabalho de Kannan et al. ${ }^{[47]}$ observa-se a proposta de síntese de uma série de $\mathrm{HDLs}$ de composição $\mathrm{Mg}^{2+} / \mathrm{Cu}^{2+} / \mathrm{Al}^{3+}$. É conveniente ressaltar que as condições de síntese utilizadas pelos autores diferem em alguns pontos das condições utilizadas no presente trabalho: o pH de síntese foi mantido sempre em 10 , o envelhecimento das amostras foi feito a $65^{\circ} \mathrm{C}$ por $24 \mathrm{~h}$ e a secagem foi realizada a $80^{\circ} \mathrm{C}$ por $12 \mathrm{~h}$. Apesar dos autores não terem observado nenhuma outra fase cristalina em seus difratogramas de raios $X$, além da fase HDL, eles observaram mudança de coloração dos materiais preparados, conforme reportado ${ }^{47}$ : "Eles [os materiais] exibiram coloração de azul acinzentado à azul claro.".

Os íons $\mathrm{Cu}^{2+}$ apresentam algumas características que tornam a síntese de HDLs relativamente difícil. A primeira dificuldade experimental imposta por esses íons é o fato de, em meio alcalino, apresentarem a tendência de formarem $\mathrm{CuO}^{[52]}$. Tal característica limita não só o valor máximo de $\mathrm{pH}$ de síntese, mas também as composições lamelares possíveis.

Outro problema encontrado na síntese de HDLs contendo íons $\mathrm{Cu}^{2+}$ é o fato dos íons apresentarem um fenômeno denominado Efeito Jahn-Teller. Um complexo octaédrico $d^{\beta}$ possui seus orbitais degenerados porque os orbitais $e_{g}\left(d x^{2}-y^{2}\right)$ e $e_{g}\left(d z^{2}\right)$ possuem a mesma energia e, portanto, o elétron desemparelhado pode ocupar qualquer um deles, conforme ilustrado na Figura $4^{[25]}$. Uma distorção tetragonal resulta em uma quebra dessa degenerescência, sendo a energia do complexo resultante mais baixa que a do complexo não 
distorcido. Esse fenômeno, predito por H. A. Jahn e Edward Teller em 1937, consiste, portanto, basicamente na distorção estrutural que ocorre quando um íon que deveria ter orbitais degenerados apresenta orbitais não degenerados, servindo apenas para identificar geometrias instáveis e não para prever as geometrias preferenciais. Tal efeito é bastante observado, por exemplo, em compostos hexacoordenados de cobre(II), pois esse íon, devido à maior estabilidade de sua configuração em geometria tetragonal, tende a formar um octaedro distorcido. ${ }^{[25]}$ Devido à distorção que ocorre, acreditava-se que não seria possível a síntese não apenas de materiais contendo grandes quantidades de íons $\mathrm{Cu}^{2+}$, mas também de materiais contendo apenas esse como espécie bivalente. Porém alguns estudos propõem que é possível a formação de HDLs relativamente cristalinos contendo grandes quantidades de íons cobre(II).

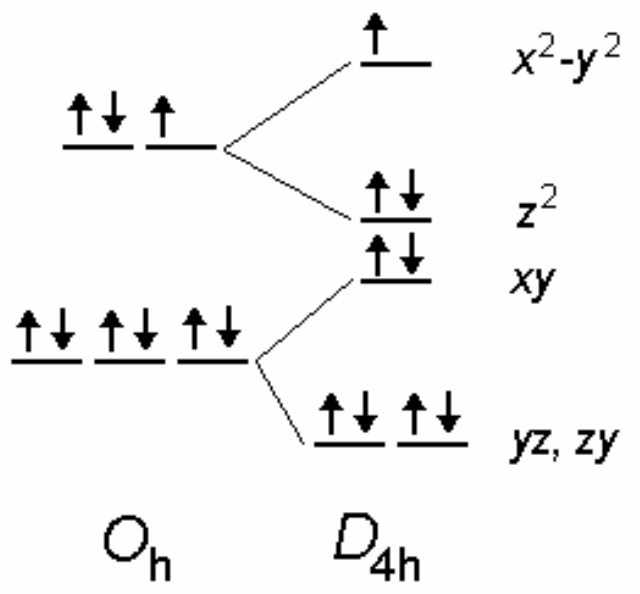
Figura 4 - Efeito da distorção tetragonal prevista por Jahn-Teller para íon $\mathrm{Cu}^{2+}$ de
configuração eletrônica $\mathrm{d}^{9[25]}$

\subsection{Hidroxilação do Fenol}

A reação de hidroxilação do fenol com peróxidos pode gerar dois produtos de interesse comercial: a hidroquinona e o catecol. A hidroquinona é 
um agente redutor que encontra aplicação na área de fotografia, indústria de borracha, estabilizador ou inibidor da polimerização de certas substâncias que polimerizam na presença de radicais livres, e também como intermediário para a produção de antioxidantes de uso alimentar, corantes para a indústria têxtil, substâncias de uso agrícola (herbicidas, por exemplo), e polímeros ${ }^{[53]}$. A hidroquinona e vários derivados são usados em formulações tópicas como agentes de descoloração da pele e despigmentação. O catecol é empregado principalmente como reagente para produção de inibidores de polimerização, perfumes, drogas, pesticidas e corantes; também tem uso na área de fotografia e como reagente analítico ${ }^{[54]}$.

Os processos industriais atualmente utilizados para a produção de hidroquinona e catecol, além de não serem realizados em condições brandas, podem gerar vários resíduos oriundos da posterior oxidação dos produtos formados e pelo manuseio dos catalisadores utilizados. Uma alternativa para o uso de agentes oxidantes ecologicamente agressivos é o peróxido de hidrogênio, cujo único produto de redução é água.

Atualmente, existem três plantas industriais, cada qual adotando um processo específico para a hidroxilação de fenol, localizadas na França, Itália e Japão ${ }^{[3,54]}$. Os três processos utilizam peróxido de hidrogênio como agente oxidante. A única exceção é o processo japonês, no qual o $\mathrm{H}_{2} \mathrm{O}_{2}$ não participa do processo de oxidação do fenol, mas da formação in situ de peróxido cetônico que, por sua vez, é o agente de hidroxilação do fenol. Em todos os processos, o procedimento de separação dos produtos finais é o mesmo: a mistura reacional é separada por destilação, a água é então removida e as frações de baixo ponto de ebulição, bem como fenol que não tenha reagido, 
são reciclados. A demanda pela hidroquinona é maior que pelo catecol. $\mathrm{Na}$ Tabela 2 seguem listadas as condições reacionais e a razão catecol / hidroquinona obtidas em cada um dos processos. Ressalta-se que as soluções aquosas do oxidante possuem concentração entre $60-70 \%$ de $\mathrm{H}_{2} \mathrm{O}_{2}$ e que o fenol se encontra sempre em grande excesso para evitar a oxidação dos produtos da hidroxilação.

Tabela 2 - Condições industriais utilizadas para hidroxilação de fenol ${ }^{[53,54]}$

\begin{tabular}{|c|c|c|c|}
\hline & $\begin{array}{c}\text { França } \\
\text { (Rhône-Poulenc) }\end{array}$ & $\begin{array}{c}\text { Itália } \\
\text { (Enichem) }\end{array}$ & $\begin{array}{c}\text { Japão } \\
\text { (Ube Industries) }\end{array}$ \\
\hline$\left[\mathrm{H}_{2} \mathrm{O}_{2}\right]:[\mathrm{fenol}]$ & $20: 1$ & - & --- \\
\hline temperatura / ${ }^{\circ} \mathrm{C}$ & 90 & 40 & 70 \\
\hline Catalisador & $\mathrm{HClO}_{4}\left(\mathrm{em} \mathrm{H} \mathrm{PO}_{4}\right)$ & ferroceno e/ou & catalisador ácido \\
\hline $\begin{array}{l}\text { Rendimento / \% } \\
\text { catecol/hidroquinona }\end{array}$ & $\overline{3 / 2}$ & $3 / 2-41 / 10$ & $\begin{array}{c}90^{(a)} \\
1 / 1^{\left({ }^{b}\right)}-3 / 2\end{array}$ \\
\hline
\end{tabular}

Os três processos citados são exemplos de catálise homogênea, mas a planta italiana está empregando atualmente um catalisador heterogêneo, a titanosilicalita TS-1 (uma zeólita análoga ao ZMS-5), que produz uma mistura 1:1 de catecol e hidroquinona ${ }^{[55]}$. Esse catalisador atua em condições brandas de síntese (solução aquosa $30 \%$ de $\mathrm{H}_{2} \mathrm{O}_{2}$ ) e substitui catalisadores corrosivos como sais de cobalto em meio ácido. Os resultados positivos obtidos pela introdução da TS-1 em outros processos oxidativos (oxidação de alcanos e epoxidação de olefinas entre outros), têm motivado a investigação de outros catalisadores heterogêneos em reações de oxidação. Na Tabela 3 estão indicados alguns trabalhos envolvendo particularmente a hidroxilação de fenol, utilizando-se peróxido de hidrogênio. 
Tabela 3 - Artigos sobre compostos sólidos utilizados para hidroxilação de fenol com peróxido de hidrogênio publicados de janeiro de 2004 a julho de 2005

\begin{tabular}{lc}
\hline \multicolumn{1}{c}{ Material } & Referência \\
\hline Cu-ZSM-5 & 56 \\
Resina contendo Fe(III) & 57 \\
Zeólitas NaY, $\mathrm{HY}, \mathrm{USHY}, \mathrm{H} \beta$ e HZSM-5 & 58,59 \\
Montmorilonitas pilarizadas & 60,61 \\
$\mathrm{Titanosilicatos}_{\mathrm{TiO}_{2}}$ & 62 \\
$\mathrm{Zeólitas} \beta$ contendo íons alcalino terrosos & 63 \\
$\mathrm{Ru}-(\mathrm{Cr}, \mathrm{Ni}$ ou Cu e La-(Co ou Mn) MCM-41 & 64 \\
Óxidos de Cu²+ obtidos por calcinação de HDL & 65 \\
$\mathrm{~K}_{7} \mathrm{NiV}_{13} \mathrm{O}_{38} 16 \mathrm{H}_{2} \mathrm{O}$ & 40 \\
Complexos de Dioxovanádio(V) encapsulados em Zeólita-Y & 66 \\
Perovskita de $\mathrm{LaTi}_{1-\mathrm{x}} \mathrm{Cu}_{\mathrm{x}} \mathrm{O}_{3}$ & 67 \\
\hline
\end{tabular}

Uma dificuldade encontrada no estudo de hidroxilação de fenol é justamente o acompanhamento da reação. O método atualmente mais utilizado para quantificação dos produtos formados é a cromatografia gasosa ${ }^{[41],[69],[70,}$ ${ }^{[71]}$. O uso de tal técnica, porém, mostra-se controversa. Ma et al. ${ }^{[72]}$ publicaram um estudo interessante comparando a cromatografia gasosa e a cromatografia líquida de alta eficiência na quantificação dos produtos da hidroxilação de fenol com peróxido de hidrogênio. Segundo os autores, a presença do agente oxidante durante a análise por cromatografia gasosa, envolvendo aquecimento, promove a degradação do fenol e de seus produtos, e a possível polimerização de quinonas, induzida pela temperatura, que podem ser formadas na reação. Mesmo sem a presença de peróxido de hidrogênio, a hidroquinona é transformada em benzoquinona durante a análise por cromatografia gasosa. Esses fatores citados são possíveis fontes de erro no experimento, geradas pelo uso de uma técnica que parece não ser a ideal para o estudo desse processo. Por exemplo, a quantidade de fenol convertido em produtos é superestimada. 


\section{Objetivos}

O presente trabalho teve como objetivo geral a síntese e caracterização de uma série de materiais de fórmula $\left[\mathrm{Mg}_{\mathrm{x}-3} \mathrm{Cu}_{\mathrm{x}} \mathrm{Al}(\mathrm{OH})_{8}\right]\left(\mathrm{CO}_{3}\right)_{0,5}$, com $\mathrm{x}$ variando entre 0 e 3 e, também, o estudo da reatividade de tais materiais na reação de hidroxilação de fenol em meio aquoso, utilizando-se peróxido de hidrogênio como agente oxidante.

Os objetivos específicos do presente trabalho são:

1. Investigar a influência de parâmetros de síntese $(\mathrm{pH}$ e temperatura de envelhecimento) na preparação dos hidróxidos mistos lamelares por coprecipitação;

2. Realizar a caracterização estrutural dos sólidos através de medidas de difração de raios $X$ para determinação da cristalinidade e da identificação da(s) fase(s) obtida(s);

3. Determinar a natureza das espécies interlamelares e suas respectivas simetrias, bem como dos produtos de decomposição térmica, utilizando os espectros vibracionais no infravermelho e Raman;

4. Determinar a simetria ao redor do íon cobre(II) através dos espectros de EPR;

5. Avaliar a estabilidade térmica dos hidróxidos mistos lamelares através de medidas termogravimétricas;

6. Investigar a reatividade dos hidróxidos mistos lamelares na oxidação de fenol em meio líquido empregando peróxido de hidrogênio como agente oxidante;

7. Utilizar a espectroscopia eletrônica de absorção na região do UV para determinação das curvas cinéticas das reações catalíticas efetuadas. 


\section{Parte Experimental}

Segue na Tabela 4, a listagem dos reagentes utilizados para a realização do presente trabalho.

Tabela 4 - Listagem dos reagentes utilizados

\begin{tabular}{lcc}
\hline \multicolumn{1}{c}{ Nome } & Fórmula & Procedência \\
\hline Hidróxido de sódio & $\mathrm{NaOH}$ & Merck \\
Nitrato de magnésio & $\mathrm{Mg}\left(\mathrm{NO}_{3}\right)_{2} \cdot 6 \mathrm{H}_{2} \mathrm{O}$ & Merck \\
Nitrato de alumínio & $\mathrm{Al}\left(\mathrm{NO}_{3}\right)_{3} \cdot 9 \mathrm{H}_{2} \mathrm{O}$ & Merck \\
Nitrato de cobre & $\mathrm{Cu}\left(\mathrm{NO}_{3}\right)_{2} \cdot 4 \mathrm{H}_{2} \mathrm{O}$ & Merck \\
Carbonato de sódio & $\mathrm{Na}_{2} \mathrm{CO}_{3}$ & Merck \\
Peróxido de hidrogênio & $\mathrm{H}_{2} \mathrm{O}_{2}$ & Merck \\
Fenol & $\mathrm{C}_{6} \mathrm{H}_{6} \mathrm{O}$ & $\mathrm{CRQ}$ \\
Catecol & $\mathrm{C}_{6} \mathrm{H}_{6} \mathrm{O}_{2}$ & Merck \\
Hidroquinona & $\mathrm{C}_{6} \mathrm{H}_{6} \mathrm{O}_{2}$ & Merck \\
p-Benzoquinona & $\mathrm{C}_{6} \mathrm{H}_{4} \mathrm{O}_{2}$ & Merck \\
\hline
\end{tabular}

\subsection{Síntese dos Materiais}

O material de composição $\left[\mathrm{Mg}_{3} \mathrm{Al}(\mathrm{OH})_{8}\right]\left(\mathrm{CO}_{3}\right)_{0.5}$, a seguir denominado HT, foi sintetizado segundo o método da co-precipitação ${ }^{[73]}$ descrito a seguir.

Prepararam-se soluções $1,0 \mathrm{~mol} / \mathrm{L}$ dos nitratos de magnésio e alumínio na proporção 3:1 respectivamente (16 mL), 2,0 mol/L de hidróxido de sódio (50 $\mathrm{mL}$ ) e $0,2 \mathrm{~mol} / \mathrm{L}$ de carbonato de sódio (10 mL). Em um balão de fundo redondo de 3 bocas foram adicionados $100 \mathrm{~mL}$ de água deionizada e ajustou-se o pH a 10,0, adicionando-se solução de $\mathrm{Na}_{2} \mathrm{CO}_{3}$. Iniciou-se a adição da solução de nitratos metálicos a uma velocidade de aproximadamente $0,5 \mathrm{~mL} / \mathrm{min}$, sob constante e vigorosa agitação magnética e à temperatura ambiente, mantendose o pH constante pela adição de toda a solução de carbonato seguida de solução de hidróxido de sódio.

Após o término da adição, ao balão de 3 bocas foi conectado um condensador de bolas e a suspensão obtida foi mantida a $85^{\circ} \mathrm{C}$ por $12 \mathrm{~h}$. Ao 
término desse período, o sólido obtido foi separado e lavado com água desionizada por centrifugação a 8000 RPM, com raio de centrifugação de $10,3 \mathrm{~cm}$, por $5 \mathrm{~min}$. O sólido obtido foi deixado secar em estufa a $80^{\circ} \mathrm{C}$ por $48 \mathrm{~h}$ e armazenado em dessecador contendo sílica gel como agente secante.

Os materiais de composição $\left[\mathrm{Mg}_{3-x} \mathrm{Cu} \times \mathrm{Al}(\mathrm{OH})_{8}\right]\left(\mathrm{CO}_{3}\right)_{0,5}$, referidos a seguir como HT-Cux, foram sintetizados de maneira semelhante ao HT, diferindo apenas na composição da solução de nitratos utilizada e no pH de síntese, conforme sumarizado na Tabela 5. O envelhecimento do hidróxido misto foi feito por $24 \mathrm{~h}$ à temperatura ambiente e a secagem foi conduzida em dessecador a vácuo, utilizando sílica gel como agente secante. Os sólidos obtidos foram também armazenados em dessecador contendo sílica gel. 
Tabela 5 - Composição das soluções e pH de síntese dos materiais

\begin{tabular}{lccccc}
\hline \multirow{2}{*}{ Amostra } & \multicolumn{3}{c}{ Proporção molar } & $\begin{array}{c}\mathrm{pH} \text { de } \\
\text { Síntese }\end{array}$ & Temperatura \\
\cline { 2 - 5 } & $\mathrm{Mg}$ & $\mathrm{Cu}$ & $\mathrm{Al}$ & \\
\hline HT & 3,0 & 0,0 & 1,0 & 10,0 & $85^{\circ} \mathrm{C}$ \\
HT-Cu0,3 & 2,7 & 0,3 & 1,0 & 10,0 & $85^{\circ} \mathrm{C}$ \\
HT-Cu0,6 & 2,4 & 0,6 & 1,0 & 10,0 & TA \\
HT-Cu0,9 & 2,1 & 0,9 & 1,0 & 9,00 & TA \\
HT-Cu1,2 & 1,8 & 1,2 & 1,0 & 9,00 & TA \\
HT-Cu1,5 & 1,5 & 1,5 & 1,0 & 9,00 & TA \\
HT-Cu1,8 & 1,2 & 1,8 & 1,0 & 9,00 & TA \\
HT-Cu2,1 & 0,9 & 2,1 & 1,0 & 9,00 & TA \\
HT-Cu2,4 & 0,6 & 2,4 & 1,0 & 8,00 & TA \\
HT-Cu2,7 & 0,3 & 2,7 & 1,0 & 8,00 & TA \\
HT-Cu3,0 & 0,0 & 3,0 & 1,0 & 8,00 & TA \\
\hline
\end{tabular}

a) Temperatura de envelhecimento

Após a trituração do material seco, todas as amostras sintetizadas foram peneiradas e tiveram sua fração entre 100 e 200 mesh armazenada em separado. Essas frações foram utilizadas para caracterização por difração de raios $\mathrm{X}$ e determinação de área superficial, bem como para a realização dos testes catalíticos.

Para o preparo das amostras que foram calcinadas foi utilizado forno programado com rampa de aquecimento de $20^{\circ} \mathrm{C} / \mathrm{min}$ e contagem de tempo de calcinação a partir do início do patamar de temperatura.

Todos os materiais sintetizados, bem como os produtos de calcinação, foram caracterizados por difração de raios $X$ (método do pó), espectroscopia vibracional na região do infravermelho, espectroscopia de espalhamento Raman e espectroscopia de ressonância paramagnética eletrônica. Os hidróxidos mistos foram ainda caracterizados por análise termogravimétrica, análise elementar (CHN e metais) e medidas de área superficial. 


\subsection{Testes Catalíticos de Hidroxilação de Fenol}

Os testes catalíticos de hidroxilação de fenol foram realizados conforme descrição a seguir. Adicionou-se em um béquer uma massa determinada de HT-Cux, $14,0 \mathrm{~mL}$ de água desionizada e $600 \mu \mathrm{L}$ de uma solução $8,75.10^{-3} \mathrm{~mol} / \mathrm{L}$ de fenol. A mistura foi acondicionada em um banho termostático à temperatura de $40^{\circ} \mathrm{C}$, mantida a partir de então sob constante e vigorosa agitação magnética, e deixada estabilizar na temperatura desejada por $10 \mathrm{~min}$. À mistura foram então adicionados $8 \mu \mathrm{L}$ de solução $22 \%(\mathrm{~m} / \mathrm{m})$ de $\mathrm{H}_{2} \mathrm{O}_{2}$, iniciando-se a contagem de tempo de reação. As alíquotas foram retiradas em intervalos de 20 min, utilizado pipeta de Pasteur, e a filtração dessa foi realizada utilizando-se filtro acoplado em seringa.

\subsection{Instrumentação}

O monitoramento do $\mathrm{pH}$ do meio reacional foi realizado utilizando-se um pHmetro da marca Digimed, modelo DM-20, calibrado utilizando-se soluções tampão com pH 6,98 e 4,00.

Para a separação dos materiais sólidos obtidos em suspensão foi utilizada uma centrífuga da marca Hermle, modelo Z383, com raio de rotor de $10,3 \mathrm{~cm}$.

Os DRX foram registrados em um difratômetro de raios $X$ da marca Rigaku, modelo Miniflex, equipado com fonte de radiação de $\mathrm{Cu} K_{\alpha}(30 \mathrm{kV}$ e $15 \mathrm{~mA}$ ) e filtro de Ni. As amostras foram colocadas em porta-amostras de quartzo. Os DRXs foram registrados para valores de $2 \theta$ de $2^{\circ}$ até $70^{\circ}$, com contagem a cada $0,02^{\circ}$ e velocidade de $1 \%$ min. Para determinação dos ângulos 
das reflexões e das respectivas larguras à meia altura foi utilizado o software "Peak Search", fornecido pela Rigaku.

Os espectros vibracionais na região do infravermelho (espectros FTIR) foram registrados em um equipamento da marca Bomen, modelo MB-102, equipado com um acessório de reflectância difusa da marca Pike Technologies. As amostras foram preparadas triturando-se em almofariz uma mistura de $\mathrm{KBr}$ e o material a ser analisado, numa proporção de 100:1 em massa. Os espectros foram registrados na região entre 4000 e $400 \mathrm{~cm}^{-1}$, utilizando-se resolução de $4 \mathrm{~cm}^{-1}$ e 32 acumulações.

A análise termogravimétrica (TGA) foi realizada em um equipamento da marca Shimadzu, modelo TGA-50, sob fluxo de $50 \mathrm{~mL} / \mathrm{min}$ de ar sintético, com rampa de aquecimento de $10^{\circ} \mathrm{C} / \mathrm{min}$ até $900^{\circ} \mathrm{C}$. A derivada da curva termogravimétrica foi calculada pelo software Origin, versão 6.0, distribuído pela Microcal.

Os espectros de ressonância paramagnética eletrônica foram registrados pela Prof. ${ }^{a}$ Dr. ${ }^{a}$ Ana Maria da Costa Ferreira, em um equipamento da marca Bruker, modelo EMX, em temperatura de nitrogênio líquido, operando a $9,34 \mathrm{GHz}$, com freqüência de modulação de $100 \mathrm{MHz}$ e $20 \mathrm{~mW}$ de potência. As amostras foram preparadas acondicionando-se uma quantidade conhecida de cada material em tubos de polietileno. Os espectros foram registrados na região entre 2500 e 3700 G, com modulação de amplitude de 12G, utilizandose DPPH ( $\alpha, \alpha^{\prime}$-difenil- $\beta$-picril hidrazil) como referência.

As análises de carbono, nitrogênio, hidrogênio (equipamento da Perkin Elmer, modelo 2400) e de metais por ICP-AES (equipamento da Spectro Analytical Instruments) foram realizadas pela Central Analítica do Instituto de 
Química da USP. As amostras para análise de metais foram preparadas dissolvendo-se uma determinada quantidade de cada material (ca. 50mg) em 100 mL de solução de ácido nítrico 1\% (v/v).

A área superficial dos materiais foi determinada por dessorção de nitrogênio em um equipamento da marca Quantachrome, modelo Quantasorb, utilizando uma mistura de $\mathrm{N}_{2}$ e He na proporção 0,3 (Air Liquide). As amostras foram degaseificadas em temperatura ambiente, mantendo-as sob fluxo de 80 $\mathrm{mL} / \mathrm{min}$ de $\mathrm{N}_{2}$ (Air Liquide, 99,999\%) por $24 \mathrm{~h}$.

Os espectros de espalhamento Raman foram registrados em um equipamento da marca Renishaw, empregando laser de excitação de 514,5 nm para a HT e laser de $633 \mathrm{~nm}$ para as demais amostras. Nos experimentos de registro in situ dos espectros Raman das amostras em diferentes temperaturas (até $500^{\circ} \mathrm{C}$ ), foi empregado o porta amostra modelo TS-600, operando com rampa de aquecimento de $5^{\circ} \mathrm{C} / \mathrm{min}$ e tempo de estabilização de temperatura no patamar de 5 minutos. Os experimentos de espectroscopia Raman foram realizados sob a supervisão do Prof. Dr. Carlos J. Leopoldo Constantino (Departamento de Física, Química e Biologia da UNESP, campus de Presidente Prudente).

Os espectros eletrônicos foram registrados em um espectrofotômetro da marca Shimadzu, modelo UV-1650 PC, utilizando-se uma cubeta de caminho óptico de 0,1 cm. A janela espectral utilizada foi de 240 a $350 \mathrm{~nm}$.

A água utilizada em todos os experimentos foi desionizada em um equipamento Máxima Analytical MK3.

Para a filtração das alíquotas dos testes catalíticos foram utilizados filtros Millipore, de diâmetro de poro $0,22 \mu \mathrm{m}$, conectados em seringas de $3 \mathrm{~mL}$. 


\section{Resultados e Discussão}

\subsection{Síntese e Caracterização dos Materiais}

Nos primeiros experimentos, os parâmetros reacionais empregados no preparo das amostras contendo $\mathrm{Cu}^{2+}$ foram os mesmos utilizados na síntese da HT. Para a amostra HT-Cu0,3, as condições de síntese se mostraram adequadas, uma vez que o DRX, apresentado na Figura 5, mostra que houve a formação de uma única fase cristalina e do tipo $\mathrm{HT}^{[74]}$. Além disso, o material obtido apresentou coloração azul e não a coloração azul-acinzentada ou cinza. A coloração cinza ou preta indica a formação de $\mathrm{CuO}$ que, dependendo da concentração na amostra, não é detectado por difratometria de raios $X^{[88]}$.

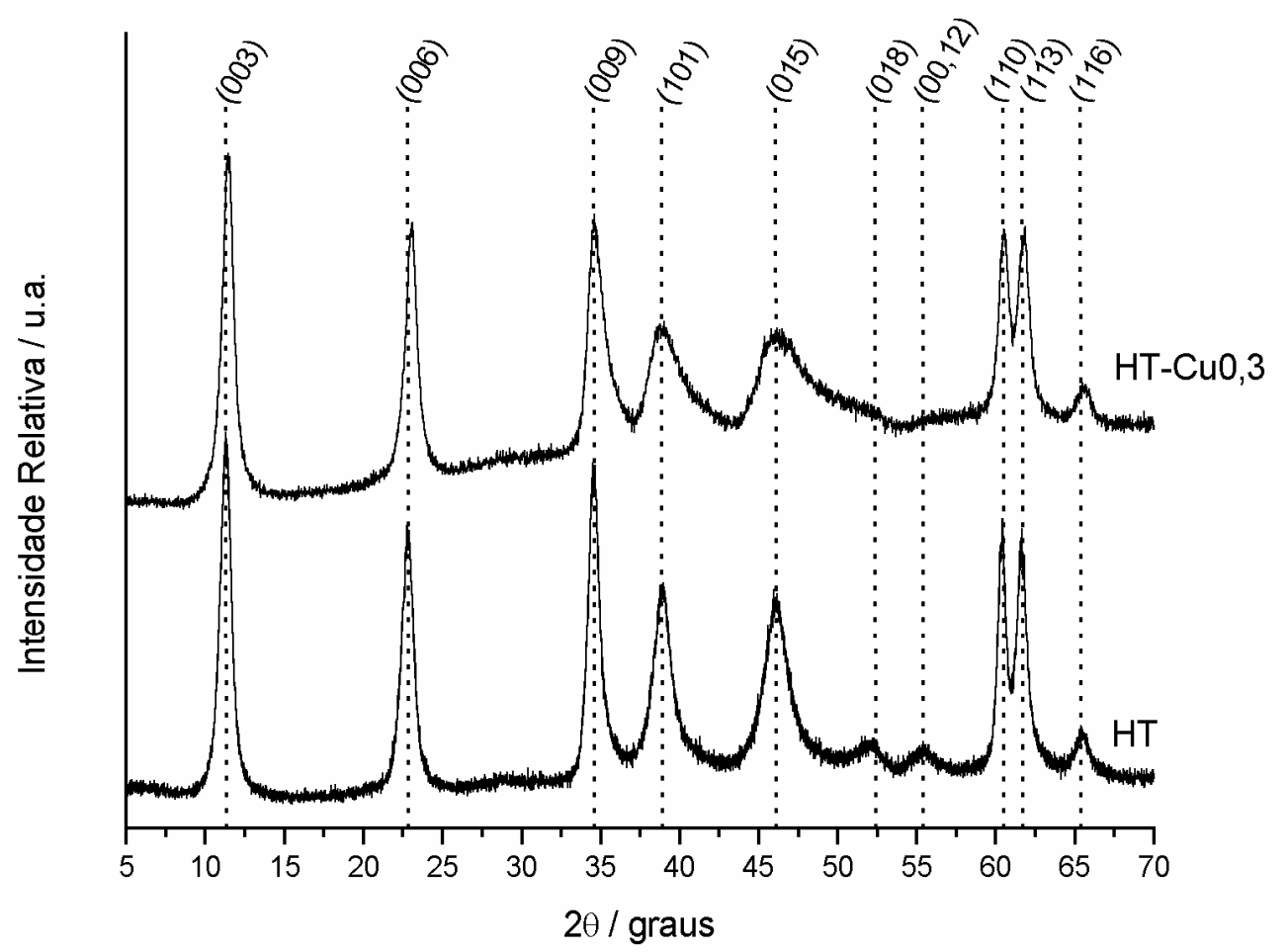

Figura 5 - DRX das amostras HT e HT-Cu0,3 
Por sua vez, nas mesmas condições de sínteses da HT, a amostra HTCu0,6 apresentou alteração de coloração, de azul claro para azul acinzentado, ao término do processo de secagem por $48 \mathrm{~h}$ a $80^{\circ} \mathrm{C}$ em estufa. Tal mudança na coloração foi atribuída à formação de $\mathrm{CuO}^{[75]}$,conforme atestam os $\mathrm{DRX}$ da Figura 6, no qual podem ser observados os picos de difração do óxido de cobre da amostra seca em estufa, não observados naquela seca em dessecador. Portanto, a fim de evitar a formação de tal óxido, os materiais passaram a ter o seu processo de secagem realizado à temperatura ambiente e sob vácuo, em dessecador contendo sílica gel como agente secante.

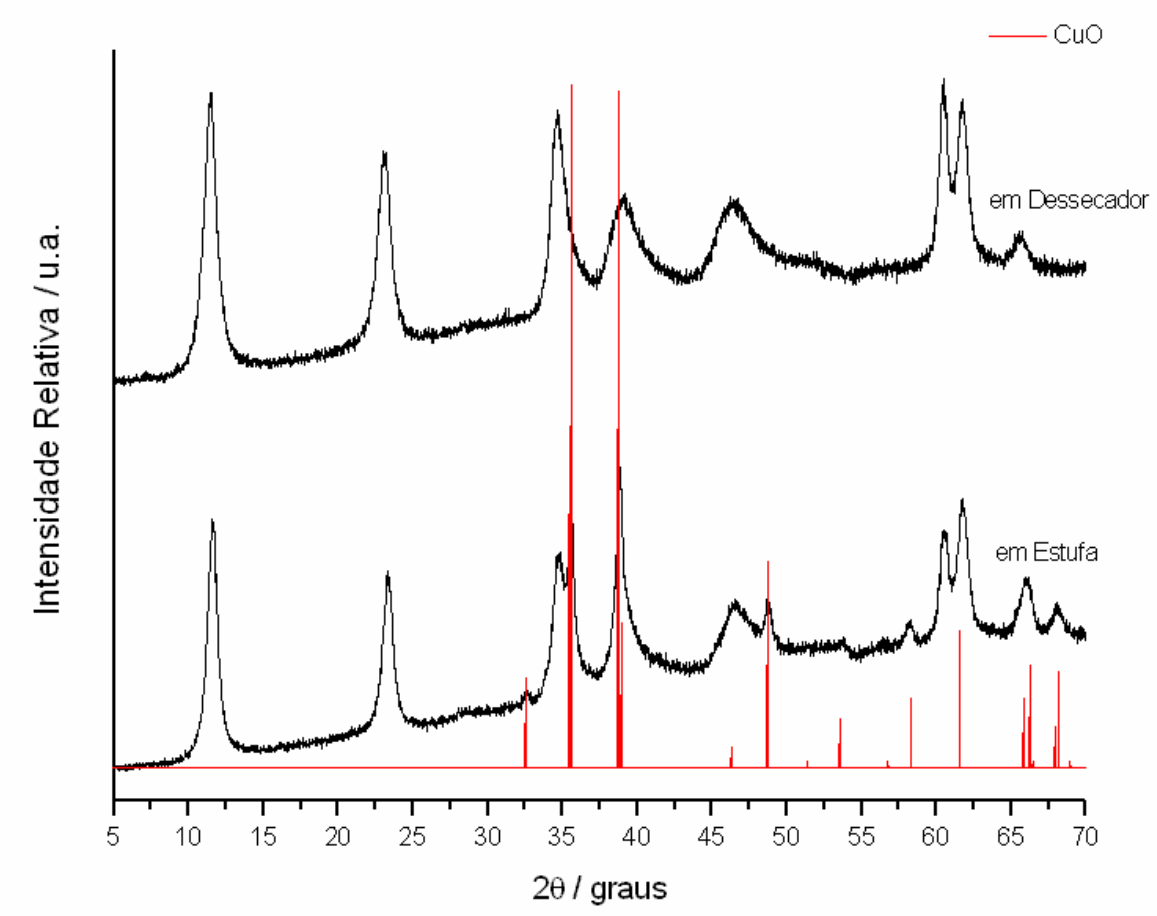

Figura 6 - DRX da amostra HT-Cu0,6 obtida por secagem em estufa a 80ㄷ e em dessecador sob vácuo

Durante a síntese da amostra HT-Cu0,9, observou-se que a suspensão obtida alterava sua coloração de azul claro para cinza, em intervalo inferior a 4h. Alterou-se, então, a temperatura de envelhecimento de $80^{\circ} \mathrm{C}$ para $70^{\circ} \mathrm{C}$, o 
que ainda não foi o suficiente para prevenir o escurecimento da suspensão. Apenas quando a temperatura de envelhecimento foi ajustada para $50^{\circ} \mathrm{C}$ é que foi possível obter o produto de coloração azul, sem contaminantes cristalinos, como $\mathrm{CuO}$, conforme pode ser observado nos difratogramas de raios $\mathrm{X}$ mostrados na Figura 7.

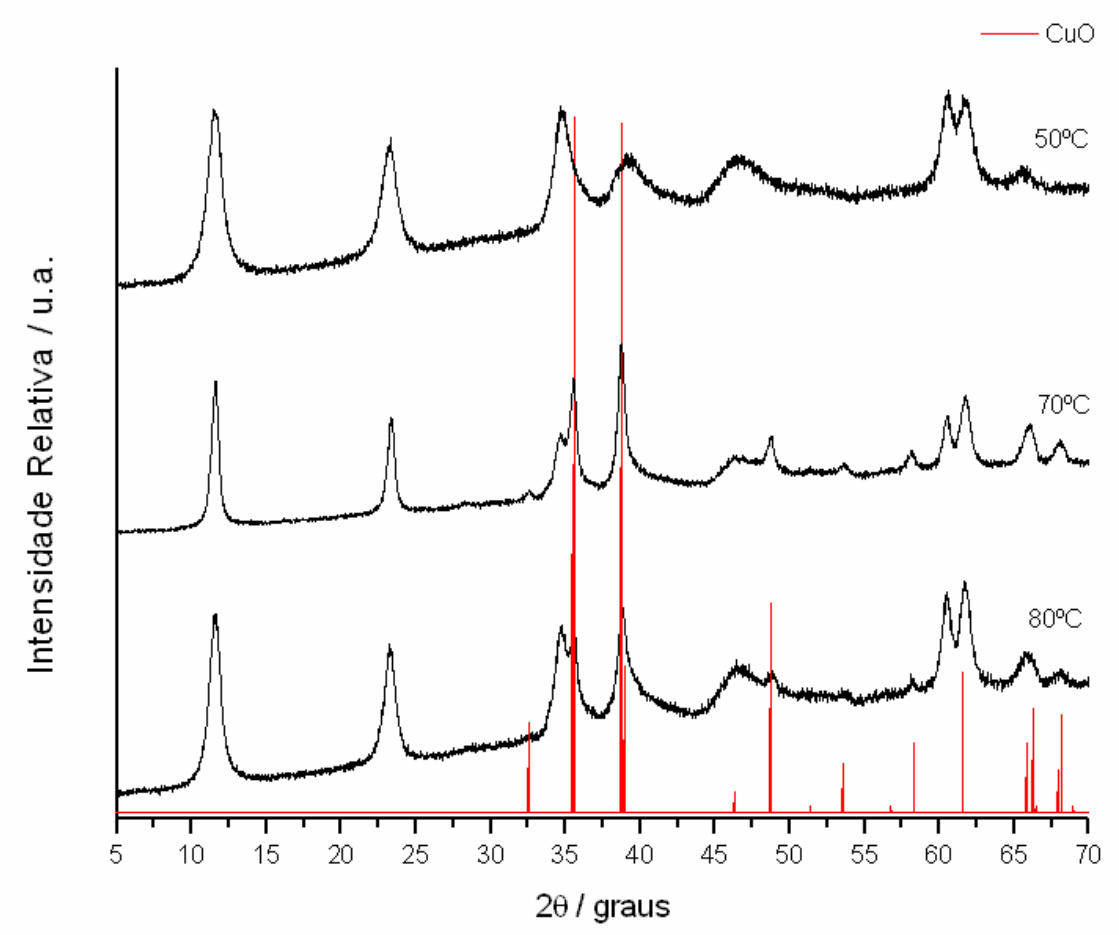

Figura 7 - DRX da amostra HT-Cu0,9 preparada com tratamento térmico a 50, 70 e 80ㄷ.

Ao sintetizar o composto HT-Cu1,2, observou-se, ao longo do período de envelhecimento, o mesmo escurecimento da suspensão observado no caso do HT-Cu0,9. O processo de envelhecimento passou a ser feito, então, à temperatura ambiente e por um período de $24 \mathrm{~h}$. Depois de tal alteração no procedimento de síntese, foi possível obter a amostra HT-Cu1,2 na coloração adequada e sem a presença de $\mathrm{CuO}$. 
Na síntese do composto HT-Cu1,5, foi visualizado novamente o mesmo escurecimento da suspensão observada anteriormente. Nesse caso, porém, optou-se pela diminuição do $\mathrm{pH}$ de síntese de 10 para 9,0. Tal alteração de pH mostrou-se eficiente para a síntese tanto do HT-Cu1,5 como para as amostras HT-Cu1,8 e HT-Cu2,1.

Uma última alteração nos parâmetros de síntese dos compostos fez-se necessária durante a síntese do HT-Cu2,4, na qual foi novamente necessário reduzir o pH de síntese de 9,0 para 8,0, a fim de evitar o escurecimento da suspensão durante o processo de envelhecimento. Porém, não se observa nenhuma diferença entre os DRXs das amostras sintetizadas a pH 8,0 e 9,0. No entanto, baseando-se nos resultados anteriores, a coloração cinza da amostra sintetizada em pH 9,0 é atribuída à presença de $\mathrm{CuO}$.

$\mathrm{Na}$ Tabela 6 estão mostradas as condições experimentais que foram utilizadas nas diversas tentativas de síntese dos hidróxidos ternários e as fases cristalinas observadas por difratometria de raios $\mathrm{X}$.

A transformação dos hidróxidos lamelares de composição $\mathrm{Mg}^{2+} / \mathrm{Cu}^{2+} / \mathrm{Al}^{3+}$ em $\mathrm{CuO}$ deve estar relacionada ao fato do $\mathrm{Cu}(\mathrm{II})$ não formar compostos com geometria octaédrica regular como a observada para a brucita (Figura 1). Em compostos lamelares como o mineral gerhardtita, um hidroxo-nitrato de coloração verde e composição $\mathrm{Cu}_{2}(\mathrm{OH})_{3} \mathrm{NO}_{3}$, os íons cobre(II) se encontram em sítios octaédricos distorcidos e é possível distinguir dois centros distintos de coordenação: em um sítio, o Cu(II) está coordenado a quatro íons hidroxila mais próximos, nas posições equatoriais, e a dois íons nitrato mais afastados nas posições axiais (coordenação do tipo 4+2) enquanto no outro sítio, o íon metálico se coordena a quatro íons hidroxila e, nas posições axiais, a um íon 
nitrato e uma hidroxila em ligações alongadas (coordenação do tipo $4+1+1)^{[76]}$. A síntese desse compostos também requer o controle do $\mathrm{pH}$ e da temperatura a fim de se evitar a formação do CuO.

O próprio hidróxido de cobre, $\mathrm{Cu}(\mathrm{OH})_{2}$, é dificilmente encontrado na natureza em virtude de sua instabilidade ${ }^{3,}{ }^{[77]}$. Esse composto é considerado metaestável, transformando-se facilmente no composto mais estável CuO quando aquecido ou em suspensão aquosa alcalina a temperatura ambiente. $\mathrm{O}$ $\mathrm{Cu}(\mathrm{OH})_{2}$ possui estrutura lamelar na qual as camadas sobrepostas apresentam, ao contrário da brucita, ondulações em virtude das distorções ao redor do íon metálico. Nesse composto, o íon $\mathrm{Cu}^{2+}$ possui número de coordenação cinco. O íon hidroxila de uma possível sexta posição em um octaedro está tão afastado em relação aos demais ligantes $\mathrm{OH}^{-}$, que a geometria do sítio metálico é de uma pirâmide de base quadrada (Figura 8-A). Acredita-se que um dos fatores da baixa estabilidade do $\mathrm{Cu}(\mathrm{OH})_{2}$ seja a presença desse íon hidroxila ligado a apenas dois centros metálicos e um átomo de hidrogênio (indicado como 01 na Figura 8-A). Em soluções alcalinas ou quando aquecido a $150^{\circ} \mathrm{C}$, o $\mathrm{Cu}(\mathrm{OH})_{2}$ se transforma no $\mathrm{CuO}$, um composto no qual o íon metálico apresenta número de coordenação quatro (geometria quadrado planar) e os átomos de oxigênio estão ligados a quatro íons $\mathrm{Cu}^{2+} \mathrm{em}$ uma geometria tetraédrica (Figura 8-B $)^{[3]}$.

Podemos propor que nos hidróxidos lamelares de composição $\mathrm{Mg}^{2+} / \mathrm{Cu}^{2+} / \mathrm{Al}^{3+}$ os íons cobre também estejam em um sítio octaédrico distorcido, com coordenação do tipo 4+2, e que a energia necessária para transformá-los em CuO (número de coordenação 4) seja pequena. Embora os DRXs das amostras sintetizadas neste trabalho não apresentem picos de 
reflexão de $\mathrm{Cu}(\mathrm{OH})_{2}$, não acreditamos que essa fase esteja presente na forma de um sólido não cristalino. Esse ponto voltará a ser discutido adiante, mas, lembrando que o meio de reação continha grande quantidade de íons carbonato, uma possível fase contaminante seria a malaquita, e não o hidróxido de $\mathrm{Cu}(\mathrm{II})$. A malaquita é um sólido verde estável de composição $\mathrm{Cu}_{2}(\mathrm{OH})_{2}\left(\mathrm{CO}_{3}\right)$. Segundo os dados da Tabela 1, a malaquita tem sido observada nos difratogramas de raios $\mathrm{X}$ de hidróxidos mistos lamelares que apresentam quantidades de cobre(II) semelhantes àquelas empregadas neste trabalho.

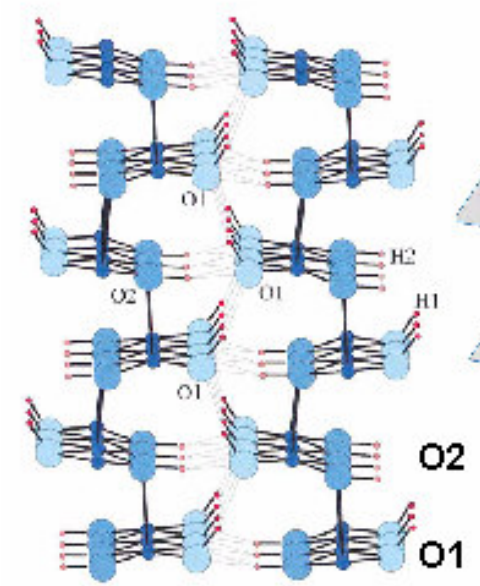

(A)

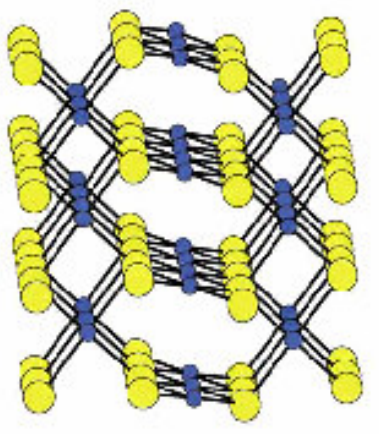

(B)

Figura 8 - Esquema das estruturas dos compostos (a) $\mathrm{Cu}(\mathrm{OH})_{2}$ e (B) $\mathrm{CuO}^{[3]}$.

$\mathrm{Na}$ Tabela 7, por sua vez, estão listadas as condições experimentais empregadas na síntese dos materiais que foram utilizados para a realização do presente trabalho, cujos DRXs encontram-se representados na Figura 9. As principais informações sobre as reflexões obtidas estão listadas na Tabela 8. 


\begin{tabular}{|c|c|c|c|c|c|}
\hline \multicolumn{3}{|c|}{ Razão Molar } & \multirow{2}{*}{$\mathrm{pH}$} & \multirow{2}{*}{$\begin{array}{c}\text { Temp. }^{\text {a) }} \\
\text { / 으 }\end{array}$} & \multirow{2}{*}{ Fases Cristalinas Obtidas } \\
\hline $\mathrm{Mg}^{2+}$ & $\mathrm{Cu}^{2+}$ & $\mathrm{Al}^{3+}$ & & & \\
\hline 3,0 & 0,0 & 1 & 10 & 80 & HT \\
\hline 2,7 & 0,3 & 1 & 10 & 80 & HT \\
\hline 2,4 & 0,6 & 1 & 10 & 80 & HT \\
\hline 2,1 & 0,6 & 1 & 10 & 80 & $\mathrm{HT}+\mathrm{CuO}$ \\
\hline 2,1 & 0,9 & 1 & 10 & 70 & $\mathrm{HT}+\mathrm{CuO}$ \\
\hline 2,1 & 0,9 & 1 & 10 & 50 & HT \\
\hline 1,8 & 1,2 & 1 & 10 & 50 & $\mathrm{HT}+\mathrm{CuO}$ \\
\hline 1,8 & 1,2 & 1 & 10 & TA & $\mathrm{HT}$ \\
\hline 1,5 & 1,5 & 1 & 10 & TA & $\mathrm{HT}+\mathrm{CuO}$ \\
\hline 1,5 & 1,5 & 1 & 9,0 & TA & HT \\
\hline 1,2 & 1,8 & 1 & 9,0 & TA & HT \\
\hline 0,9 & 2,1 & 1 & 9,0 & TA & $\mathrm{HT}$ \\
\hline 0,6 & 2,4 & 1 & 9,0 & TA & $\mathrm{HT}+\mathrm{CuO}$ \\
\hline 0,6 & 2,4 & 1 & 8,0 & TA & $\mathrm{HT}$ \\
\hline 0,3 & 2,4 & 1 & 8,0 & TA & HT \\
\hline 0,0 & 3,0 & 1 & 8,0 & TA & HT \\
\hline
\end{tabular}

a) temperatura de envelhecimento

Tabela 7 - Condições experimentais empregadas na síntese por co-precipitação dos hidróxidos ternários que resultaram apenas em fase do tipo HT

\begin{tabular}{ccc}
\hline Amostra & $\mathrm{pH}$ & Temp / ${ }^{\circ} \mathrm{C}$ \\
\hline HT & 10,0 & 80,0 \\
HT-Cu0,3 & 10,0 & TA \\
HT-Cu0,6 & 10,0 & TA \\
HT-Cu0,9 & 10,0 & TA \\
HT-Cu1,2 & 10,0 & TA \\
HT-Cu1,5 & 9,0 & TA \\
HT-Cu1,8 & 9,0 & TA \\
HT-Cu2,1 & 9,0 & TA \\
HT-Cu2,4 & 8,0 & TA \\
HT-Cu2,7 & 8,0 & TA \\
HT-Cu3,0 & 8,0 & TA \\
\hline
\end{tabular}




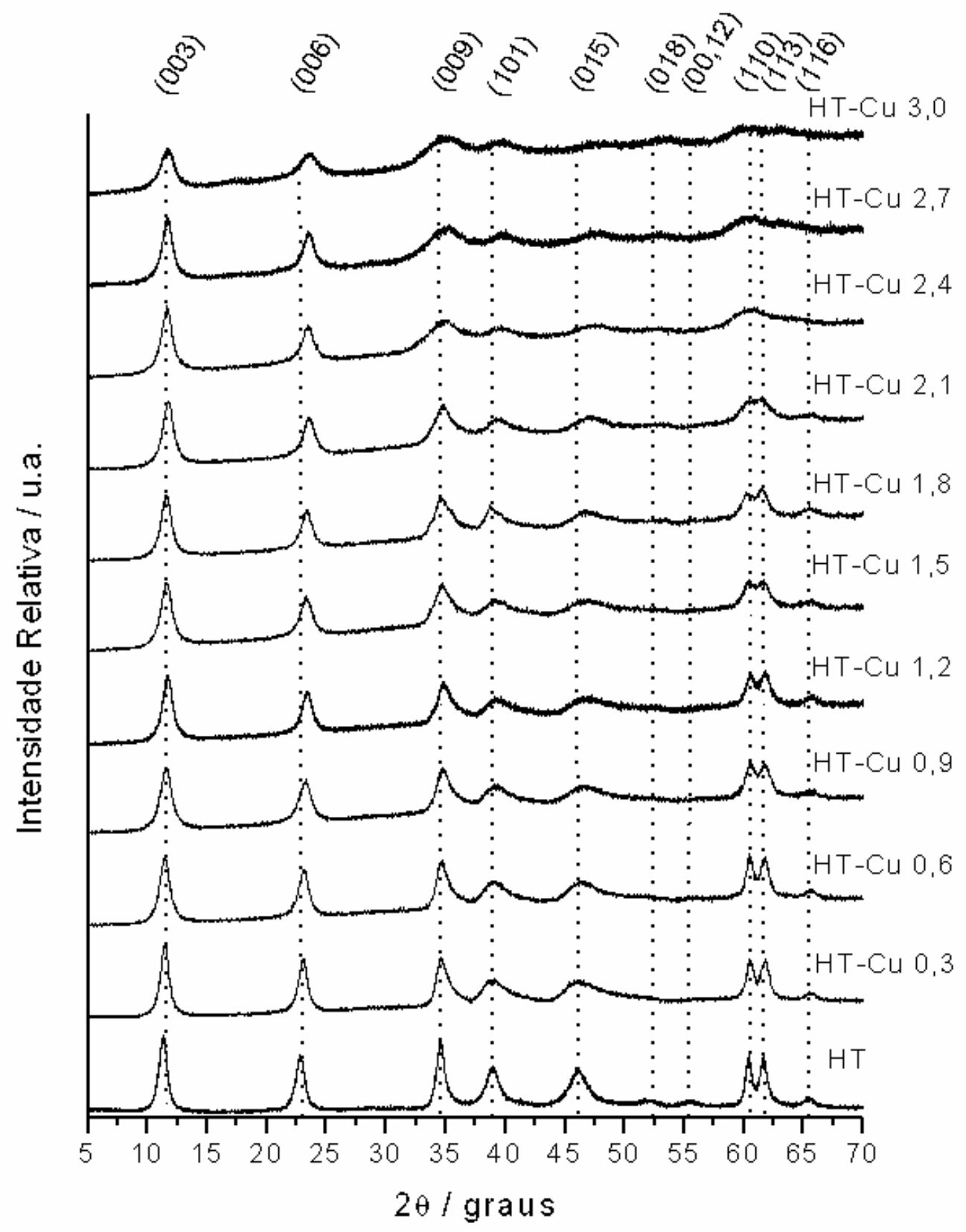

Figura 9 - DRX das amostras HT e HT-Cux 
Tabela 8 - Alguns valores cristalográficos para as amostras HT e HT-Cux, obtidos a partir dos DRXs da Figura 9

\begin{tabular}{lccccccc}
\hline Amostra & $\mathrm{d}_{003} / \AA$ & $\mathrm{c}^{\mathrm{a})} / \AA$ & $\begin{array}{c}\mathrm{FWHH}^{\mathrm{b}} / \\
2 \theta^{\circ}(003)\end{array}$ & $\mathrm{D}_{110} / \AA$ & $\mathrm{a}^{\mathrm{c}} / \AA$ & $\begin{array}{c}\mathrm{FWHH}^{\mathrm{b}} / \\
29^{\circ}(110)\end{array}$ & $\begin{array}{c}\text { Tamanho de } \\
\text { Cristalito } / \mathrm{nm}^{\mathrm{d})}\end{array}$ \\
\hline HT & 7,56 & 22,8 & 0,800 & 1,53 & 3,05 & 0,540 & 17,7 \\
HT-Cu0,3 & 7,73 & 23,1 & 0,824 & 1,53 & 3,06 & 0,541 & 17,2 \\
HT-Cu0,6 & 7,72 & 23,1 & 0,800 & 1,53 & 3,06 & 0,612 & 17,7 \\
HT-Cu0,9 & 7,70 & 23,0 & 0,800 & 1,53 & 3,05 & 0,612 & 17,7 \\
HT-Cu1,2 & 7,61 & 22,9 & 0,941 & 1,52 & 3,05 & 0,772 & 15,0 \\
HT-Cu1,5 & 7,64 & 22,8 & 0,871 & 1,54 & 3,07 & 0,635 & 16,2 \\
HT-Cu1,8 & 7,64 & 22,8 & 0,941 & 1,54 & 3,07 & 0,776 & 15,0 \\
HT-Cu2,1 & 7,56 & 22,6 & 0,941 & 1,53 & 3,06 & 0,988 & 15,0 \\
HT-Cu2,4 & 7,58 & 22,7 & - & 1,54 & 3,07 & - & - \\
HT-Cu2,7 & 7,57 & 22,7 & - & 1,54 & 3,07 & - & - \\
HT-Cu3,0 & 7,56 & 22,7 & - & 1,55 & 3,06 & - & - \\
\hline
\end{tabular}

a) $c=\left(3 d_{003}+6 d_{006}\right) / 2$

b) largura à Meia Altura (Full Width at Half Height)

c) $\mathrm{a}=2 \mathrm{~d}_{110}$

d) Calculado pela fórmula de Debye-Scherrer

Os valores de área superficial obtidos encontram-se na Tabela 9. Para a determinação da área superficial, conforme descrição já apresentada na parte experimental, as amostras foram degaseificadas sob fluxo de $\mathrm{N}_{2}$ à temperatura ambiente por 24h. Optou-se por não aquecer as amostras durante esse processo uma vez que ao realizá-lo com a amostra HT-Cu3,0 com aquecimento a $50^{\circ} \mathrm{C}$ por um período de $2 \mathrm{~h}$, observou-se o escurecimento da amostra. Portanto, mesmo sendo possível degaseificar as amostras HT e HTCu0,3, mantendo-as por $2 \mathrm{~h}$ a $200^{\circ} \mathrm{C}$ sob fluxo de nitrogênio, optou-se por padronizar o procedimento. Os resultados mostram que as áreas superficiais das amostras não apresentam valores significativamente diferentes, mas é perceptível uma tendência de diminuição da área à medida que os íons $\mathrm{Mg}^{2+}$ são substituídos por íons $\mathrm{Cu}^{2+}$. 
Tabela 9 - Dados de medidas de área superficial para as amostras HT e HT-Cux

\begin{tabular}{cc}
\hline Amostra & Área Superficial $/ \mathrm{m}^{2} / \mathrm{g}$ \\
\hline HT & 99,6 \\
HT-Cu0,3 & 90,2 \\
HT-Cu0,6 & 88,3 \\
HT-Cu0,9 & 87,1 \\
HT-Cu1,2 & 84,9 \\
HT-Cu1,5 & 85,6 \\
HT-Cu1,8 & 84,5 \\
HT-Cu2,1 & 86,6 \\
HT-Cu2,4 & 81,2 \\
HT-Cu2, & 83,4 \\
HT-Cu3,0 & 80,4 \\
\hline
\end{tabular}

Pode-se verificar a semelhança entre os valores do parâmetro de célula unitária a das diversas amostras. Tal fato deve-se à semelhança de raio iônico (para número de coordenação 6) entre os íons $\mathrm{Mg}^{2+}(86,0 \mathrm{pm})$, que estão sendo gradativamente substituídos pelos íons $\mathrm{Cu}^{2+}(87,0 \mathrm{pm})$. O parâmetro de célula unitária $c$, por sua vez, apresenta uma ligeira discrepância entre os valores obtidos para cada uma das amostras, devido principalmente à diferença de densidade de carga da lamela obtida para cada material. Observa-se também uma perda de cristalinidade conforme ocorre o aumento da quantidade de íons $\mathrm{Cu}^{2+}$, provavelmente devido ao efeito Jahn-Teller. Tal perda de cristalinidade pode ser notada nos dados de FWHH da Tabela 8, onde observa-se justamente o aumento da largura à meia altura conforme $\mathrm{o}$ aumento da quantidade de cobre(II) no material. Portanto, o aumento da quantidade de $\mathrm{Cu}^{2+}$ também aumenta a quantidade de octaedros distorcidos dentro da estrutura lamelar, o que acaba prejudicando a formação de um material de maior cristalinidade. Eventualmente, um maior tempo de envelhecimento poderia vir a melhorar a cristalinidade do material obtido, porém tal 
procedimento pode também aumentar a probabilidade de que parte dos íons de cobre(II) formem $\mathrm{CuO}$.

A curva termogravimética, juntamente com a respectiva derivada, de cada uma das amostras de hidróxido ternário, encontra-se na Figura 10. Observa-se uma tendência de abaixamento da temperatura necessária para que cada evento ocorra, conforme há um aumento da quantidade de $\mathrm{Cu}^{2+}$. Outro fenômeno é que mesmo na amostra contendo a menor quantidade de $\mathrm{Cu}^{2+}$, pode-se observar o surgimento de um terceiro evento na região de temperatura de $600^{\circ} \mathrm{C}$. A temperatura dos picos DTG, bem como a perda de massa envolvida no evento encontram-se na Tabela 10 e ilustrados na Figura 11.

O evento I está associado à perda de água interlamelar e superficial da matriz, sendo por isso utilizado para o cálculo da quantidade de água presente no material. O evento II, no caso da amostra HT, está associado à descarbonatação e à desidroxilação do material. Após o evento II, ocorre a formação de uma solução sólida de materiais amorfos, composta pelos óxidos dos metais. No caso da amostra HT aquecida até $500^{\circ} \mathrm{C}$, o contato com água promove a reestruturação da fase lamelar. Conforme já discutido na literatura, tal fenômeno recebe o nome de efeito memória e pode ser utilizado para que seja trocado o ânion interlamelar ${ }^{[4]}$. Para as amostras HT-Cux, não existem referências na literatura de que seja possível haver tal regeneração da fase lamelar após calcinação em temperaturas acima do evento II. 
Na Figura 11 estão apresentados os valores dos picos DTG para as amostras HT e HT-Cux em cada um dos eventos associados, mostrando visivelmente a tendência de diminuição de temperatura para o pico DTG conforme o aumento da quantidade de íons $\mathrm{Cu}^{2+}$. 


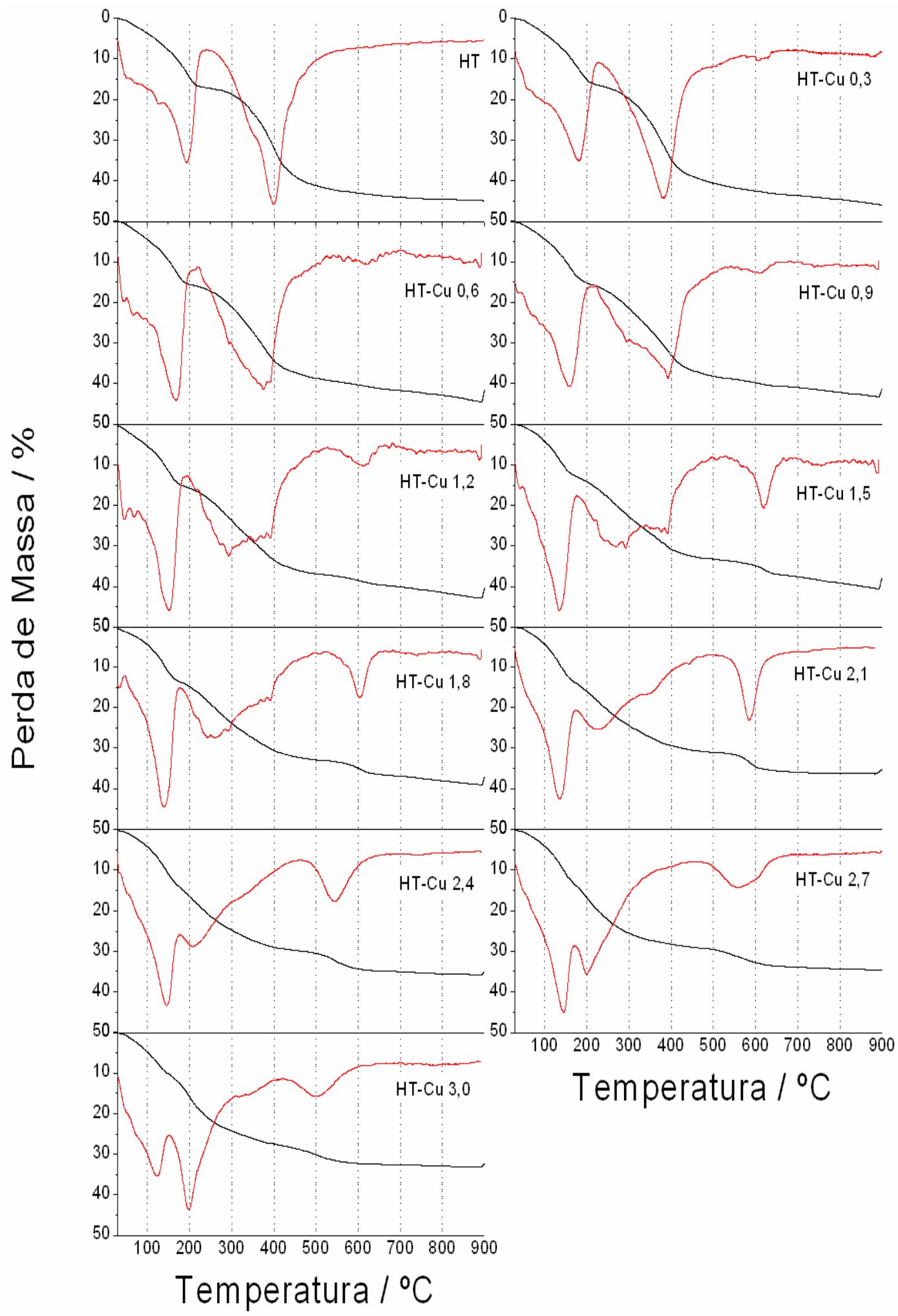

Figura 10 - Curvas TGA (-) e DTG (-) para as amostras HT e HT-Cu x 
Tabela 10 - Temperaturas e porcentagens de perda de massa, conforme TGA

\begin{tabular}{lcccccc}
\hline \multirow{2}{*}{ Amostra } & \multicolumn{2}{c}{ Evento I } & \multicolumn{2}{c}{ Evento II } & \multicolumn{2}{c}{ Evento III } \\
\cline { 2 - 7 } & $\Delta \mathrm{T} / \mathrm{o} \mathrm{C}$ & $\Delta \mathrm{m} / \%$ & $\Delta \mathrm{T} / \mathrm{o} \mathrm{C}$ & $\Delta \mathrm{m} / \%$ & $\Delta \mathrm{T} / \mathrm{O} \mathrm{C}$ & $\Delta \mathrm{m} / \%$ \\
\hline HT & $135-237$ & 17,1 & $239-535$ & 27,5 & - & - \\
HT-Cu0,3 & $82-230$ & 16,4 & $233-489$ & 25,5 & $567-650$ & 3,56 \\
HT-Cu0,6 & $86-216$ & 15,8 & $224-521$ & 23,6 & $522-701$ & 4,50 \\
HT-Cu0,9 & $48-214$ & 15,7 & $218-527$ & 23,0 & $535-673$ & 4,37 \\
HT-Cu1,2 & $55-194$ & 15,0 & $194-526$ & 21,4 & $527-679$ & 5,25 \\
HT-Cu1,5 & $48-178$ & 13,0 & $180-470$ & 20,5 & $529-690$ & 6,76 \\
HT-Cu1,8 & $44-176$ & 13,5 & $180-400$ & 19,3 & $522-663$ & 6,18 \\
HT-Cu2,1 & $44-178$ & 13,6 & $180-400$ & 17,1 & $502-703$ & 5,37 \\
HT-Cu2,4 & $35-178$ & 14,1 & $180-463$ & 15,5 & $464-688$ & 5,81 \\
HT-Cu2,7 & $30-172$ & 13,6 & $174-455$ & 15,5 & $470-692$ & 5,35 \\
HT-Cu3,0 & $30-152$ & 10,4 & $154-416$ & 17,5 & $421-645$ & 5,09 \\
\hline
\end{tabular}

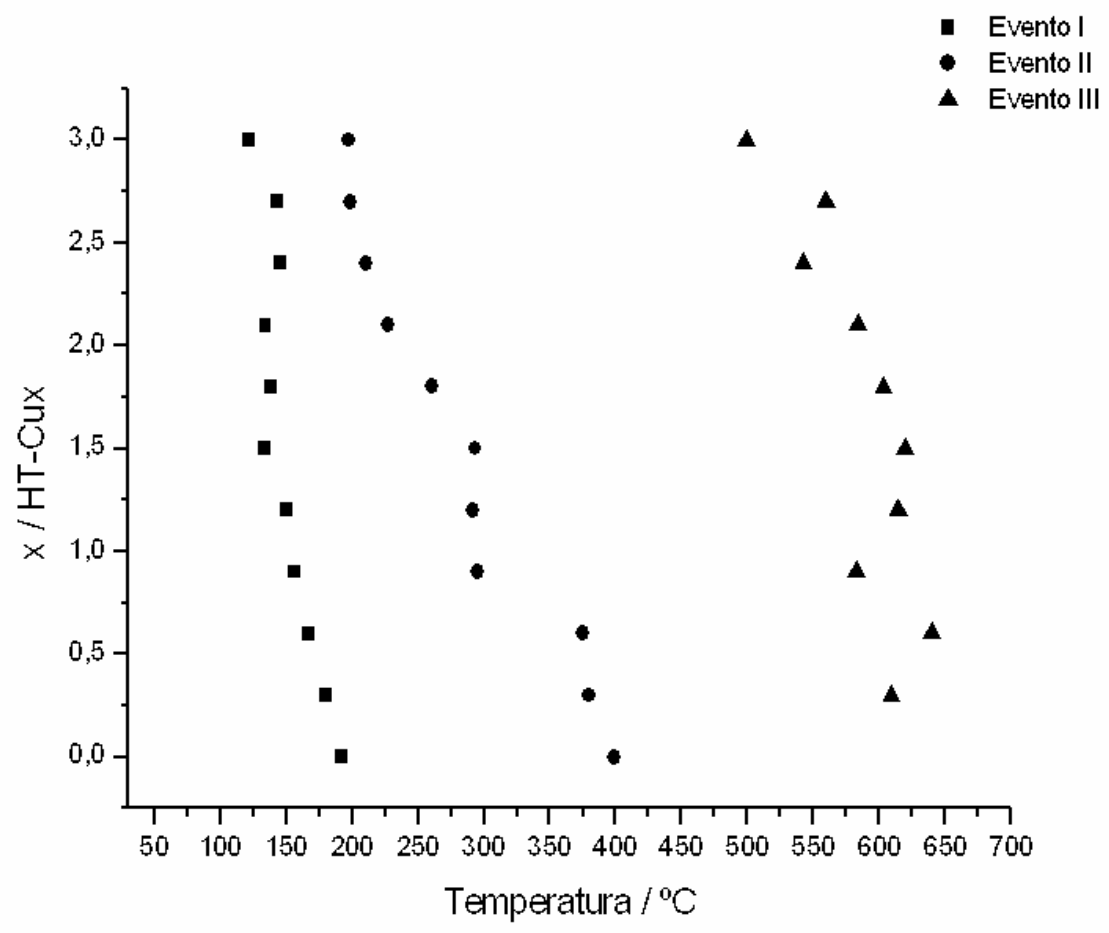

Figura 11 - Temperatura do pico DTG de cada evento térmico para as amostras HT e HTCux

NaTabela 11 se encontram listados os resultados das análises de metais e de $\mathrm{CHN}$, juntamente com os respectivos valores calculados. Os valores de $\mathrm{CHN}$ calculados foram obtidos considerando-se a fórmula $\left[\mathrm{Mg}_{x} \mathrm{Cu}_{y} \mathrm{Al}(\mathrm{OH})_{2+2 z}\right]\left(\mathrm{CO}_{3}\right)_{0,5} \cdot t \mathrm{H}_{2} \mathrm{O}$, onde $x, y$ e $z$ foram obtidos à partir dos 
resultados da análise de metais (sendo $z=x+y$ ), e $t$ foi obtido através da curva TGA (evento I). Nesse ponto, é interessante ressaltar que a diferença da porcentagem de água observada entre as amostras de acordo com a TGA, na verdade trata-se de uma diferença apenas na proporção e não na quantidade. Tal afirmativa justifica não apenas o fato do espaçamento c' observado nas reflexões 003 não variar de maneira significativa entre as amostras (Figura 9 e Tabela 8), mas também as quantidades semelhantes de água calculadas para cada amostra. Os pequenos desvios observados entre as amostras, portanto, não se deve a nenhuma diferença na interação entre os diferentes metais e as espécies interlamelares, mas sim às pequenas diferenças na densidade de carga obtidas entre os materiais devido à não manutenção da proporção $\mathrm{M}^{2+} / \mathrm{M}^{3+}$ nos materiais obtidos ao longo da série. 
Tabela 11 - Resultado de Análise de Metais por ICP e de CHN

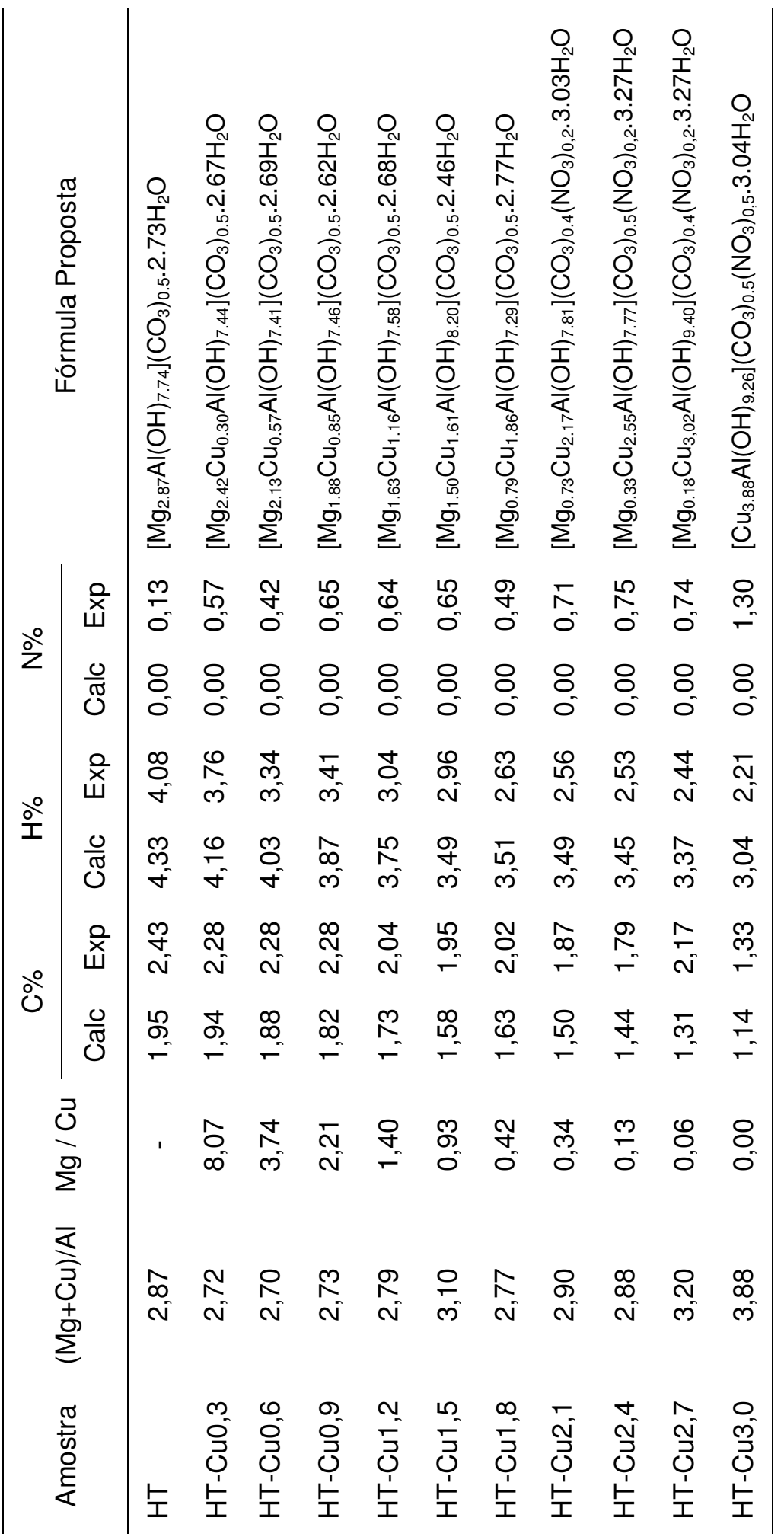


A discrepância entre os valores estimados de $\mathrm{CHN}$ e os valores obtidos experimentalmente podem ser justificados levando-se em consideração o pH de síntese utilizado e o diagrama de equilíbrio das espécies $\mathrm{H}_{2} \mathrm{CO}_{3}, \mathrm{HCO}_{3}{ }^{-}$e $\mathrm{CO}_{3}{ }^{2-}$, apresentado na Figura 12.

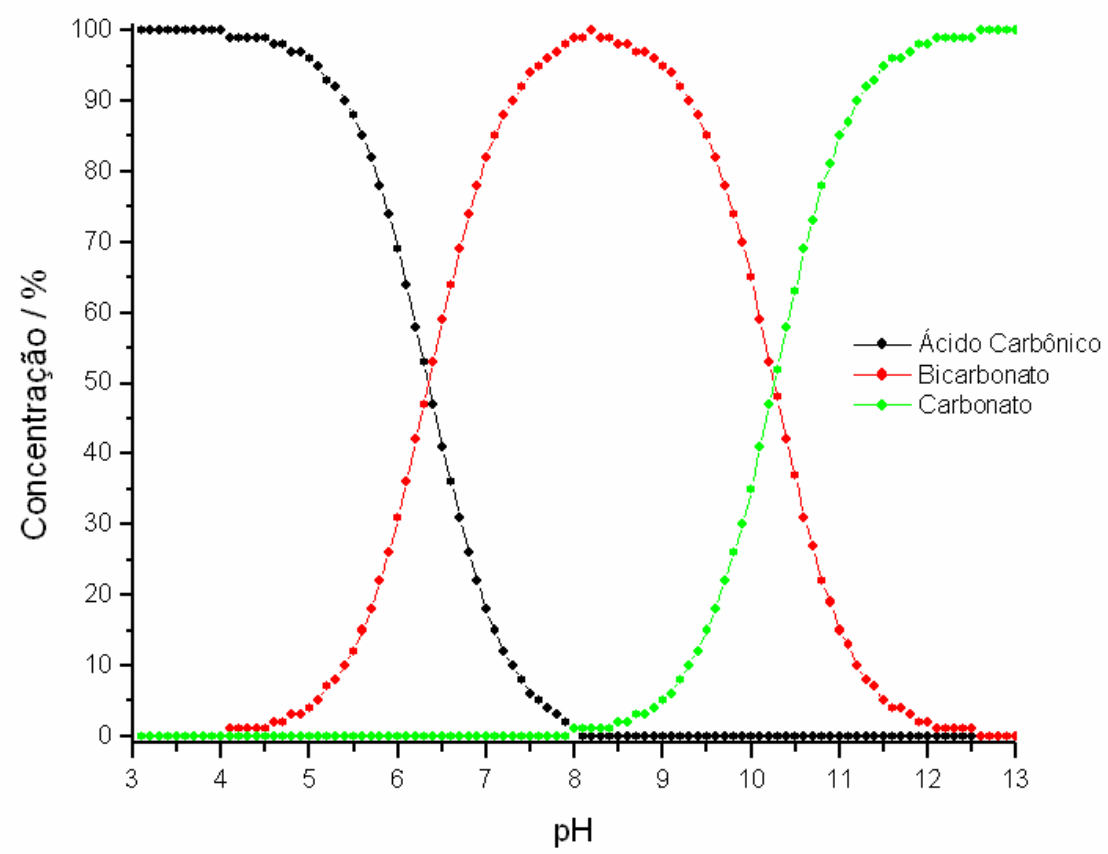

Figura 12 - Diagrama de Equilíbrio Ácido Carbônico - Bicarbonato - Carbonato

É interessante lembrar aqui que os materiais do tipo HT possuem a capacidade de trocar os íons interlamelares de acordo com uma determinada seletividade. Levando em consideração apenas os possíveis íons presentes nas misturas reacionais, temos a seguinte seqüência de prioridade de intercalação ${ }^{[78] \text { : }}$

$$
\mathrm{CO}_{3}{ }^{2-}>>\mathrm{NO}_{3}^{-}>\mathrm{HCO}_{3}^{-}
$$

Portanto, conforme observado na Figura 12, em pH igual a 8,0, a espécie predominante no meio reacional não é o ânion de interesse, $\mathrm{CO}_{3}{ }^{2-}$, 
mas sim o ânion $\mathrm{HCO}_{3}{ }^{-}$, que por sua vez, é trocado em parte pelos íons $\mathrm{NO}_{3}{ }^{-}$ oriundos dos nitratos metálicos utilizados para a síntese.

A espectroscopia vibracional no infravermelho e Raman também foram empregadas na caracterização dos hidróxidos mistos lamelares sintetizados. As principais regiões de absorção desses materiais estão relacionadas com as vibrações das unidades $\mathrm{M}-\mathrm{OH}$ e do íon $\mathrm{OH}^{-}$das lamelas, do ânion intercalado (neste trabalho, $\mathrm{O} \mathrm{CO}_{3}{ }^{2-}$ ) e das moléculas de água que ocupam a região interlamelar e a superfície externa das partículas ${ }^{[22]}$.

No espectro vibracional no IV de todas as amostras (Figura 14), observa-se na região de $3500 \mathrm{~cm}^{-1}$ uma banda intensa e larga atribuída ao estiramento $\mathrm{O}-\mathrm{H}$ dos grupos hidroxila das lamelas e, também, das moléculas de água presentes na superfície externa das partículas ${ }^{[22], ~[79]}$. Já na região de $3000 \mathrm{~cm}^{-1}$, a absorção se deve ao estiramento O-H das moléculas de água que ocupam a região entre as lamelas e interagem através de ligações de hidrogênio com os íons carbonato ${ }^{[22], ~[79] . ~}$

Os espectros vibracionais dos hidróxidos mistos (Figura 14) mostram ainda as bandas de absorção do ânion intercalado. O íon carbonato é uma espécie planar que possui simetria $D_{3 h}$ e os quatro modos de vibração mostrados na Figura $13^{[81]}$.
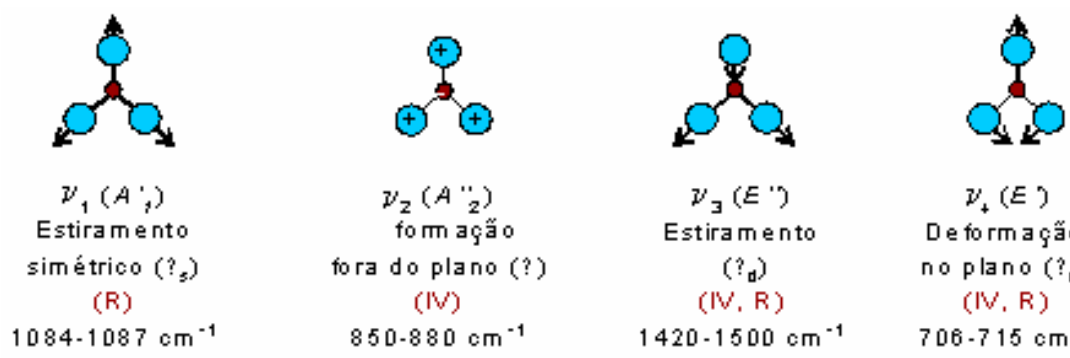

$$
\begin{gathered}
\nu_{+}(E) \\
\text { Deformação } \\
\text { noplano(?d) } \\
\text { (IV, R) } \\
700-715 \mathrm{~cm}^{-1}
\end{gathered}
$$

Figura 13 - Modos normais de vibração do íon carbonato. (R) : modo ativo no Raman; (IV): modo ativo no infravermelho. As regiões espectrais indicadas se referem à calcita e à aragonita $(\mathrm{CaCO} 3)^{[81]}$. 
$\mathrm{Na}$ Figura 14, a banda de absorção atribuída ao estiramento $v_{3}$ do íon carbonato é observada em $1360 \mathrm{~cm}^{-1}$ enquanto que aquelas relacionadas aos modos $v_{2}$ e $v_{4}$ não aparecem resolvidas em virtude de se sobreporem às bandas de vibração das unidades $\mathrm{M}(\mathrm{OH})_{6}$ das lamelas. À medida que aumenta a quantidade de cobre nas amostras, observa-se um aumento na intensidade de absorção entre $1400-1450 \mathrm{~cm}^{-1}$. Esse fato poderia ser interpretado como decorrência da quebra de degenerescência do modo duplamente degenerado $v_{3}$ em virtude de um abaixamento de simetria do íon carbonato. Se isso ocorresse, o modo $v_{1}$ passaria a ser observado no espectro no infravermelho do $\mathrm{CO}_{3}{ }^{2-}$ de menor simetria ${ }^{[81]}$. Como isso não ocorre, pode-se sugerir a presença de dois tipos de íons carbonato (simetria $D_{3 h}$ ), estabelecendo ligações de hidrogênio mais fortes (espécie que absorve em $1360 \mathrm{~cm}^{-1}$ ) e mais fracas (espécie que absorve em ca. $1410 \mathrm{~cm}^{-1}$ ) com as moléculas de água. $\mathrm{O}$ espectro vibracional no IV do mineral estichitita, um HDL de composição $\left[\mathrm{Mg}_{6} \mathrm{Cr}_{2}(\mathrm{OH})_{16}\right] \mathrm{CO}_{3} \cdot 4 \mathrm{H}_{2} \mathrm{O}$, também apresenta duas bandas de absorção na região referente ao modo de vibração $v_{3}$ do íon carbonato $\left(1457 \text { e } 1381 \mathrm{~cm}^{-1}\right)^{[80]}$.

Para as amostras sintetizadas em menor valor de $\mathrm{pH}(\mathrm{HT}-\mathrm{Cu} 2,4 ; 2,7 \mathrm{e}$ 3,0), também há a contribuição da absorção dos íons nitrato na região de 1400 $\mathrm{cm}^{-1}$. Quando intercalados em HDLs, a banda referente ao estiramento $v_{3}$ do

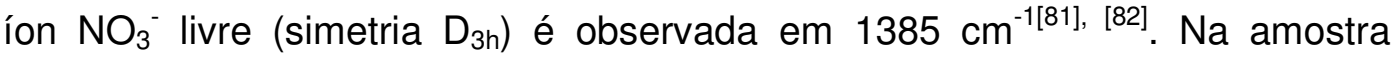
HT-Cu3,0 que, segundo os dados de análise elementar mostrados na Tabela 11, tem $50 \%$ das cargas das lamelas neutralizadas por íons nitrato, observa-se absorção mais nítida em $1385 \mathrm{~cm}^{-1}$ que nas amostras HT-Cu 2,7 e HT-Cu2,1. 
$\mathrm{Na}$ Tabela 12, estão listadas as principais bandas observadas em cada uma das amostras, juntamente com as respectivas atribuições.

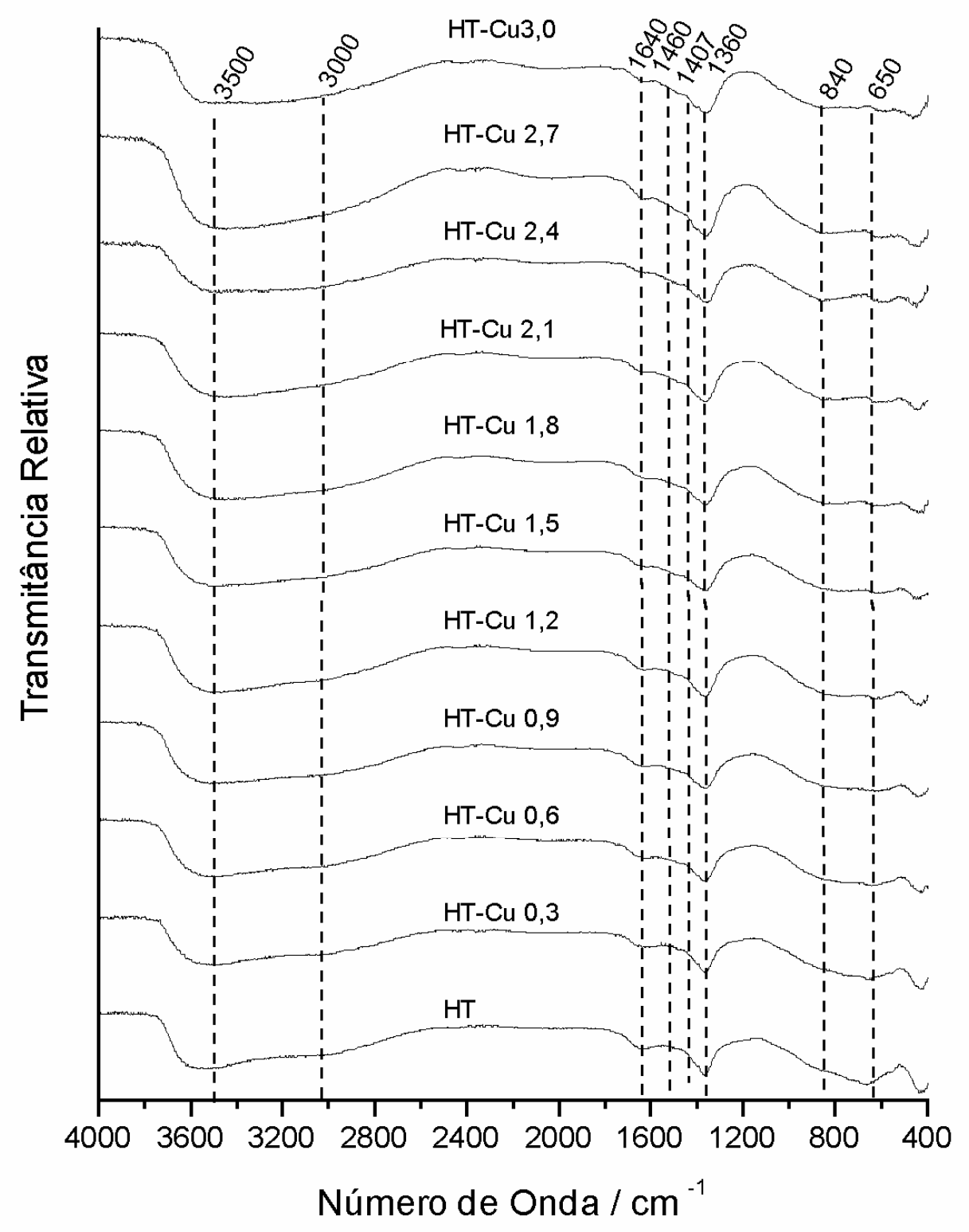

Figura 14 - Espectros FTIR das amostras HT e HT-Cux 
Tabela 12 - Principais bandas observadas nos espectros FTIR das amostras HT-Cux

\begin{tabular}{cc}
\hline $\begin{array}{c}\text { Número de Onda / } \\
\mathrm{cm}^{-1}\end{array}$ & Atribuição \\
\hline 430 & $\mathrm{M}-\mathrm{O}],[82]$ \\
650 & $\mathrm{M}-\mathrm{O}$ \\
840 & $\mathrm{v}_{2} \mathrm{CO}_{3}{ }^{-2}$ \\
1360 & $\mathrm{v}_{3} \mathrm{CO}_{3}{ }^{-2}$ \\
1460 & $\mathrm{v}_{3} \mathrm{CO}_{3}^{-2}$ \\
1640 & $\delta \mathrm{H}_{2} \mathrm{O}^{2-}$ \\
3000 & $v \mathrm{O}-\mathrm{H} \mathrm{CO}_{3}{ }^{2-}$ \\
3500 & $v \mathrm{OH}$ \\
\hline
\end{tabular}

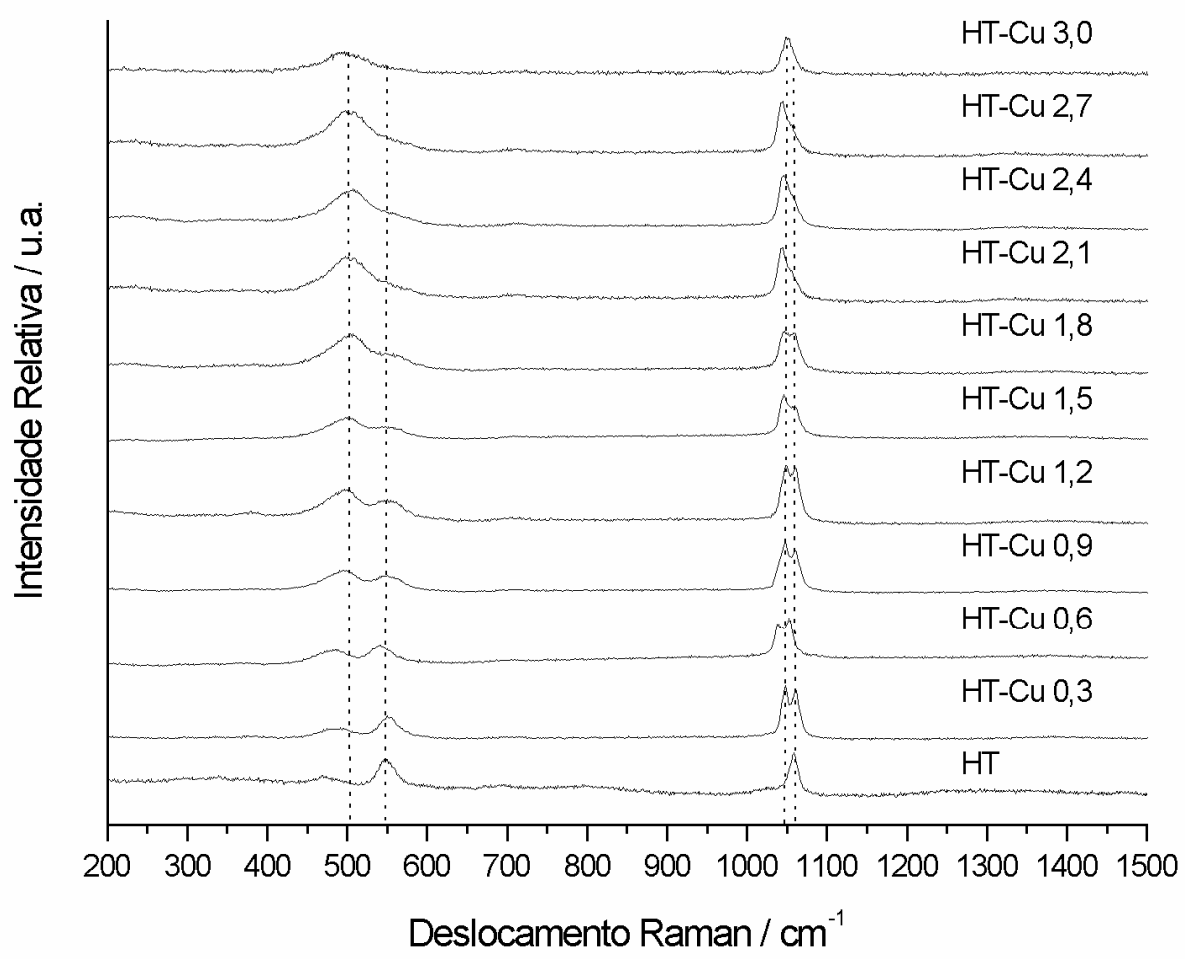

Figura 15 - Espectro de espalhamento Raman para as amostras HT-Cux e HT

A Figura 15 mostra os espectros vibracionais Raman das amostras de hidróxidos mistos lamelares. Observa-se uma banda intensa na região de 
$1040-1060 \mathrm{~cm}^{-1}$ da $\mathrm{HT}$, referente ao estiramento simétrico $v_{1}$ do $\mathrm{CO}_{3}{ }^{2-}$, que não é um modo de vibração ativo no infravermelho. Quando o íon magnésio é parcialmente substituído por íons cobre, duas bandas são observadas nessa região, indicando, assim como os espectros FTIR, a presença de dois tipos de íons carbonato. As bandas referentes aos modos ativos $v_{3}$ e $v_{4}$ não são observadas nos espectros Raman (bandas muito pouco intensas). Na região de baixa energia, onde são observadas as bandas referentes à translação $\mathrm{M}$ $\mathrm{OH}^{83}$, a banda em ca. $550 \mathrm{~cm}^{-1}$ diminui de intensidade à medida que diminui a quantidade de íons magnésio na amostra enquanto a banda em ca. $460 \mathrm{~cm}^{-1}$ aumenta de intensidade e se desloca para valores maiores de número de onda. Podemos propor que a primeira banda tem maior contribuição da ligação Mg$\mathrm{OH}$, e a segunda, da ligação $\mathrm{Cu}-\mathrm{OH}$.

Os espectros de EPR apresentados na Figura 16 são anisotrópicos, ou seja, os parâmetros $g_{/ /}$e $g_{\perp}$ são bem definidos, indicando que os íons cobre(II) se encontram em sítio com simetria axial (coordenação do tipo 4+2). À medida que a quantidade de $\mathrm{Cu}^{2+}$ nas amostras aumenta, ocorre uma diminuição no sinal do metal de transição, que pode ser interpretada como decorrência de um acoplamento antiferromagnético entre os íons cobre. Na Tabela 13 estão indicados os dados obtidos dos espectros EPR. 


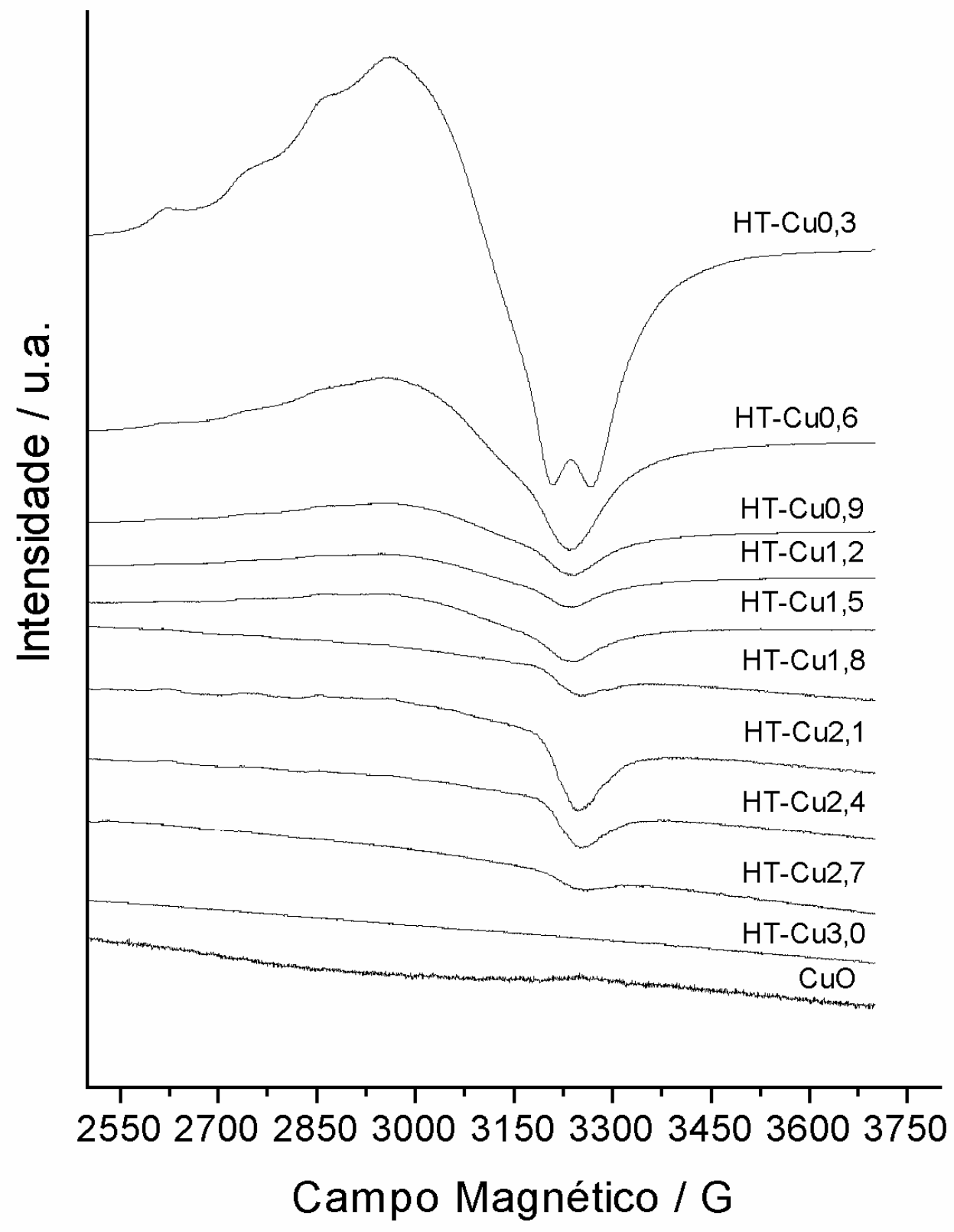

Figura 16 - Espectros EPR para as amostras HT-Cux e CuO na temperatura de $\mathrm{N}_{2}$ líquido.

Na Figura 17 estão mostradas as áreas do sinal dos espectros EPR em relação ao conteúdo de cobre nos hidróxidos mistos. Observa-se que a intensidade do sinal diminui da amostra HT-Cu0,3 até HT-Cu1,5. Para as 
amostras com maior conteúdo de cobre que a Cu1,5, o aumento do metal de transição não altera o sinal paramagnético.

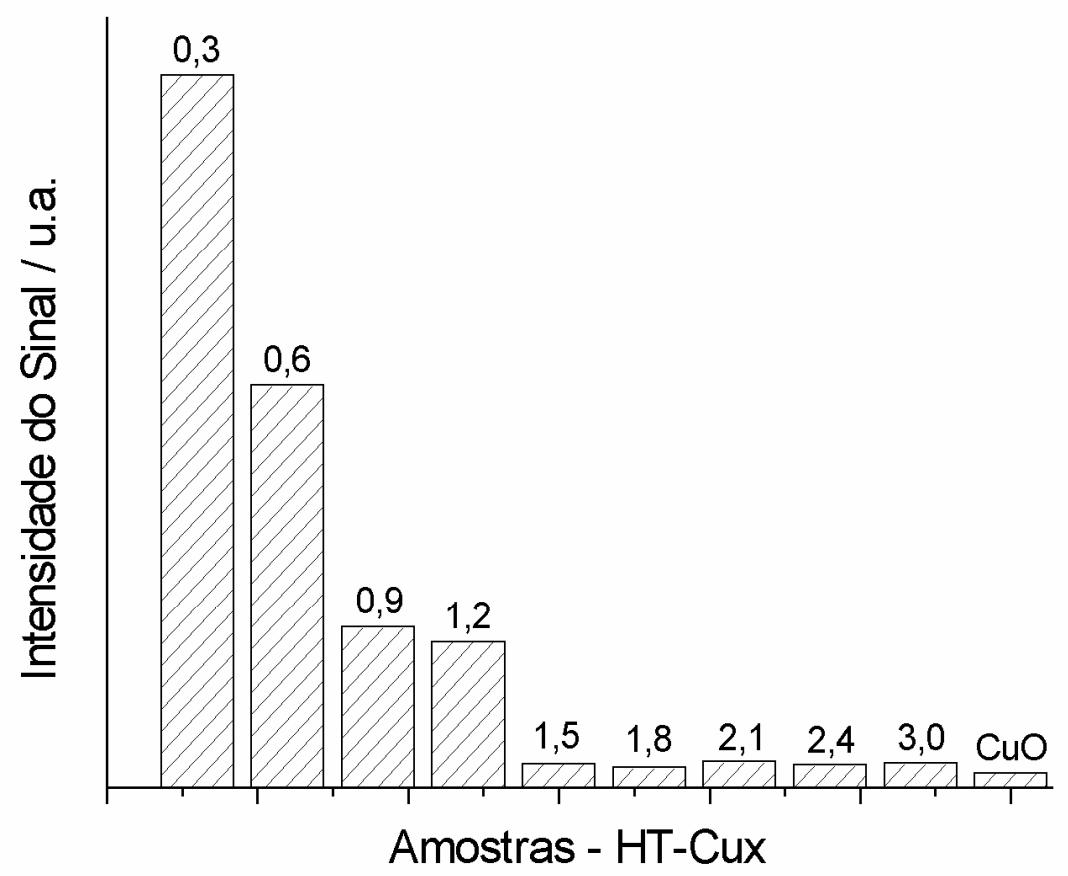

Figura 17 - Histograma de intensidade do sinal EPR para as amostras HT-Cux e CuO

Tabela 13 - Parâmetros de EPR para as amostras HT-Cu0,3; 0,6; 0,9; 1,2 e 1,5

\begin{tabular}{lccccc}
\hline \multicolumn{1}{c}{ Amostra } & $\mathbf{g}_{\perp}$ & $\mathbf{g}_{\|}$ & $\mathbf{A}_{\|}(\mathbf{G})$ & $\mathbf{A}_{\|} \times \mathbf{x 1 0}^{-4}\left(\mathbf{c m}^{-1}\right)$ & $\mathbf{g}_{\|} / \mathbf{A}_{\|}(\mathbf{c m})$ \\
\hline HT-Cu0,3 & 2,147 & 2,382 & 122 & 135,7 & 176 \\
HT-Cu0,6 & 2,152 & 2,378 & 124 & 137,7 & 173 \\
HT-Cu0,9 & 2,152 & 2,376 & 124 & 137,5 & 173 \\
HT-Cu01,2 & 2,156 & 2,377 & 122 & 135,4 & 176 \\
HT-Cu01,5 & 2,153 & 2,378 & 122 & 135,4 & 176 \\
\hline
\end{tabular}

A partir da razão $g_{\|} / A \|$ (Tabela 13) é possível estimar o grau de distorção tetraédrica de espécies quadrado planares de cobre(II) ${ }^{[84]}$. Os valores de $g_{\|} / A \|$ entre 110-120 são típicos de complexos planares, enquanto no 
intervalo 130-150 são característicos de pequena para moderada distorção, e de 180-250 indica considerável distorção tetraédrica. Os valores dessa razão para o íon $\mathrm{Cu}^{2+}$ nos hidróxidos mistos lamelares são aproximadamente 173176, indicando que os íons $\mathrm{OH}^{-}$equatoriais ligados ao íon metálico não se encontram no mesmo plano, mas distorcidos tetraedricamente. Esses dados evidenciam a baixa simetria ao redor do íon de transição quando comparado aos sítios octaedros regulares contendo $\mathrm{Mg}^{2+}$ e $\mathrm{Al}^{3+}$.

Se as amostras com alto conteúdo de cobre apresentassem sinal no espectro EPR, seria possível avaliar a geometria ao redor dos centros metálicos e o número de sítios distintos de $\mathrm{Cu}^{2+}$. Leroux et al. ${ }^{[44]}$ usaram a espectroscopia de absorção de raios X (EXAFS) para caracterizar um HDL de composição $\mathrm{Cu}_{2} \mathrm{Al}_{-} \mathrm{Cl}^{-}$. Observou-se que esse material não possui similaridade estrutural com o $\mathrm{Cu}(\mathrm{OH})_{2}$ mas apresenta estrutura local do tipo da botalaquita, um mineral lamelar de composição $\mathrm{Cu}_{2}(\mathrm{OH})_{3} \mathrm{Cl}$, com íons $\mathrm{Al}^{3+}$ substituindo alguns sítios de cobre(II). Assim como a gerhardtita, a botalaquita possui dois centros de cobre ${ }^{[85]}$ : um com coordenação do tipo $4+2$ e outro com coordenação $4+1+1$. Nesse último sítio, os íons hidroxila nas posições equatoriais não estão no mesmo plano, apresentando distorção.

Ao término da análise termogravimétrica das amostras contendo menor quantidade de $\mathrm{Cu}^{2+}$, a coloração observada da amostra calcinada a $900^{\circ} \mathrm{C}$ diferia da coloração cinza característica do CuO. Para a amostra HT-Cu0,3, a coloração observada foi verde; para a amostra HT-Cu0,6, foi ocre. Para as demais amostras, observou-se uma coloração cinza, que ia se tornando de matiz mais escuro conforme se aumentava a quantidade de íons cobre(II). Considerando-se o alto valor da temperatura de calcinação, uma fase esperada 
seria o espinélio de composição $\mathrm{CuAl}_{2} \mathrm{O}_{4}$, que apresenta coloração marrom ${ }^{86}$. Esse óxido não apresenta estrutura de espinélio normal (Figura 18), mas 66,5\% dos íons $\mathrm{Cu(II)} \mathrm{se} \mathrm{encontram} \mathrm{em} \mathrm{sítios} \mathrm{tetraédricos} \mathrm{e} \mathrm{o} \mathrm{restante,} \mathrm{em}$ sítios octaédricos ${ }^{[87]}$. Os DRX das amostras calcinadas a $900^{\circ} \mathrm{C}$ por um período de $1 \mathrm{~h}$, mostrados na Figura 19, revelam a presença das fases cristalinas $\mathrm{CuO}$, $\mathrm{MgO}^{[88]}, \mathrm{MgAl}_{2} \mathrm{O}_{4}{ }^{[89]}$ e $\mathrm{CuAl}_{2} \mathrm{O}_{4}{ }^{[90]}$. Nenhuma dessas fases é responsável pela coloração verde da amostra HT-Cu0,3 calcinada a $900^{\circ} \mathrm{C}$.

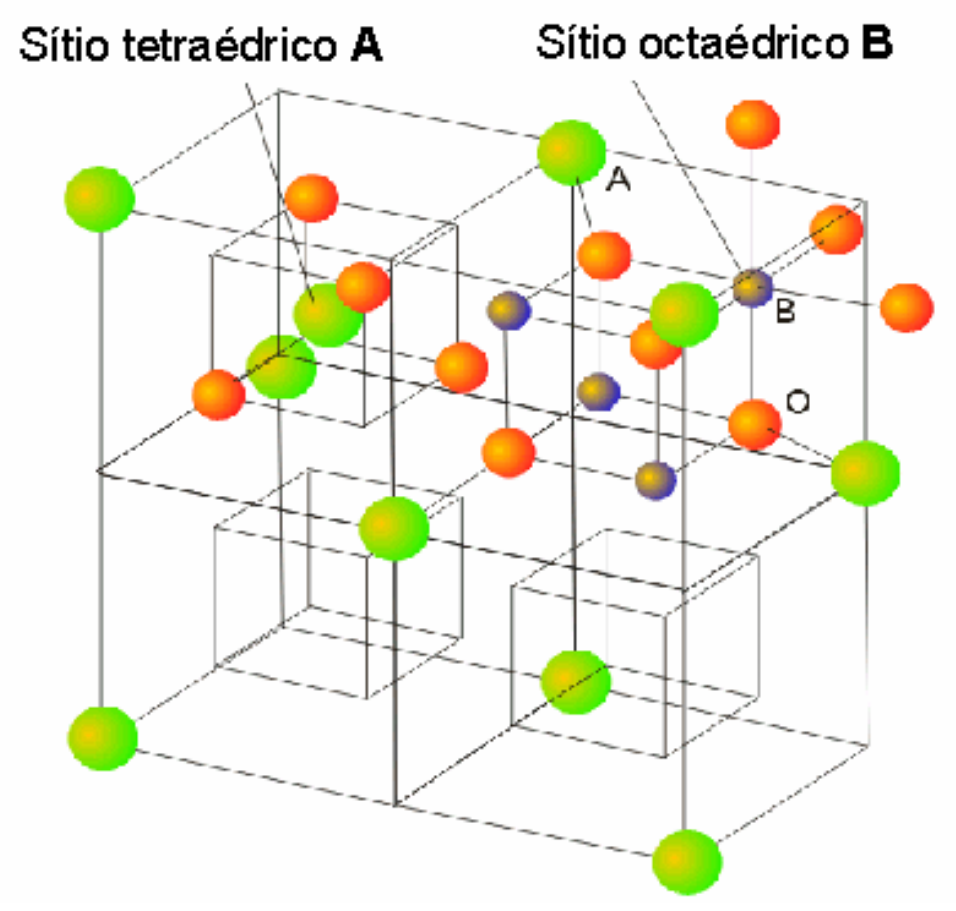

Figura 18 - Estrutura de espinélio normal $\mathrm{M}^{\prime \prime} \mathrm{M}^{\mathrm{II \prime}}{ }_{2} \mathrm{O}_{4}\left(\mathrm{ou} \mathrm{AB}_{2} \mathrm{O}_{4}\right)$ [25] 


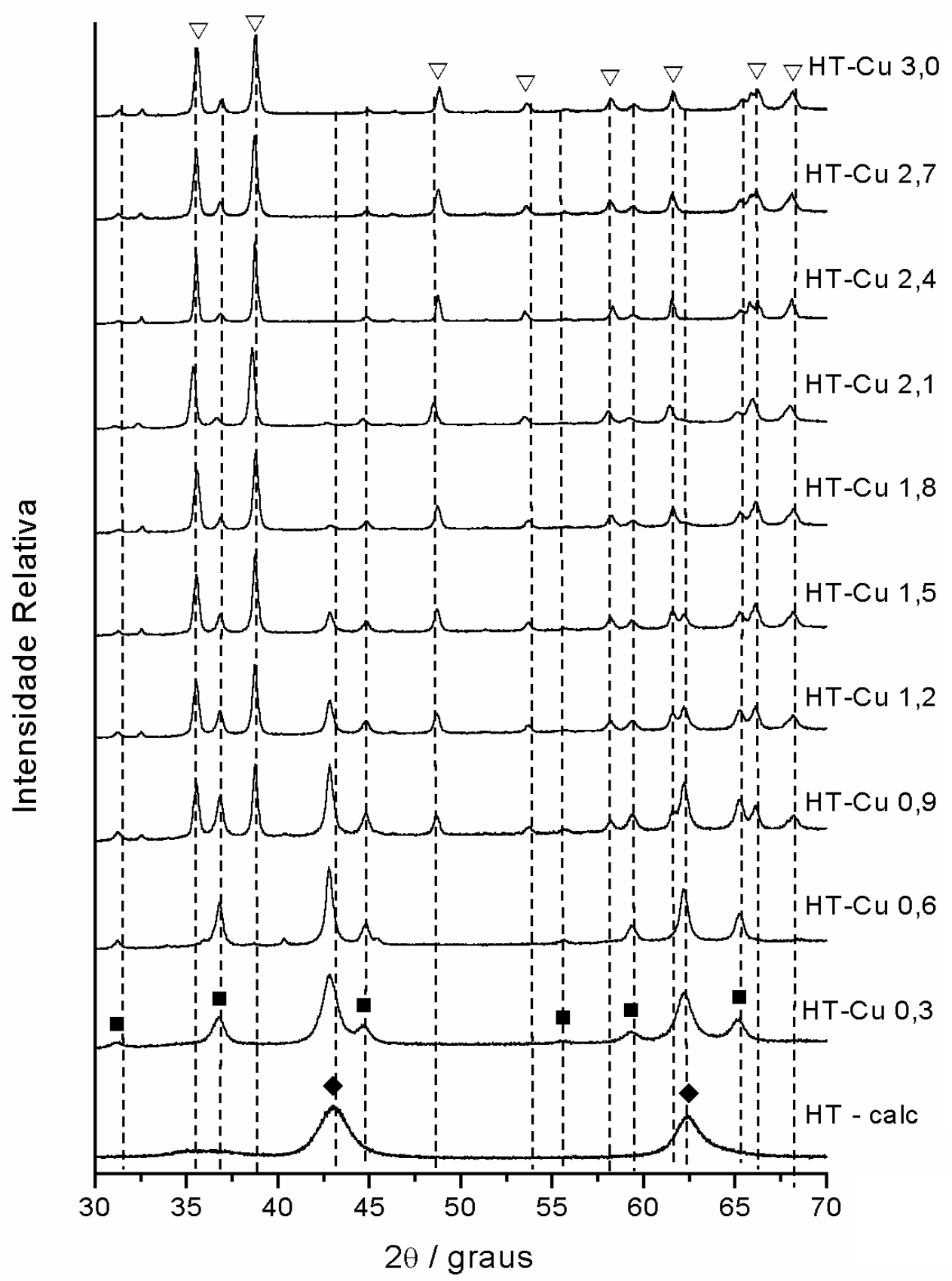

Figura 19 - DRX das amostras calcinadas em forno a $900 \circ \mathrm{C}$ por 1 hora: $\diamond \mathrm{MgO}$; $\square \mathrm{MgAl}_{2} \mathrm{O}_{4}$ e/ou $\mathrm{CuAl}_{2} \mathrm{O}_{4} ; \nabla \mathrm{CuO}$

Uma fase verde estável de Cu(II) é a malaquita (ou hidroxo-carbonato de cobre). Para refutar-se a hipótese de formação de malaquita, foi levado em consideração não apenas a alta cristalinidade dessa fase, o que geraria 
reflexões observáveis no DRX mesmo em baixa quantidade, mas também a discrepância entre os espectros vibracionais das amostras calcinadas, mostrados na Figura 20, e o obtido por Frost et al. ${ }^{[1]}$ para amostras de malaquita. Além disso, de acordo com a análise termogravimétrica mostrada no artigo supracitado, a presença de malaquita em material calcinado a $900^{\circ} \mathrm{C}$ (temperatura em que as amostras foram calcinadas neste trabalho), é pouco provável. O espectro de espalhamento Raman para as mesmas amostras também foi registrado e encontra-se na Figura 21. 


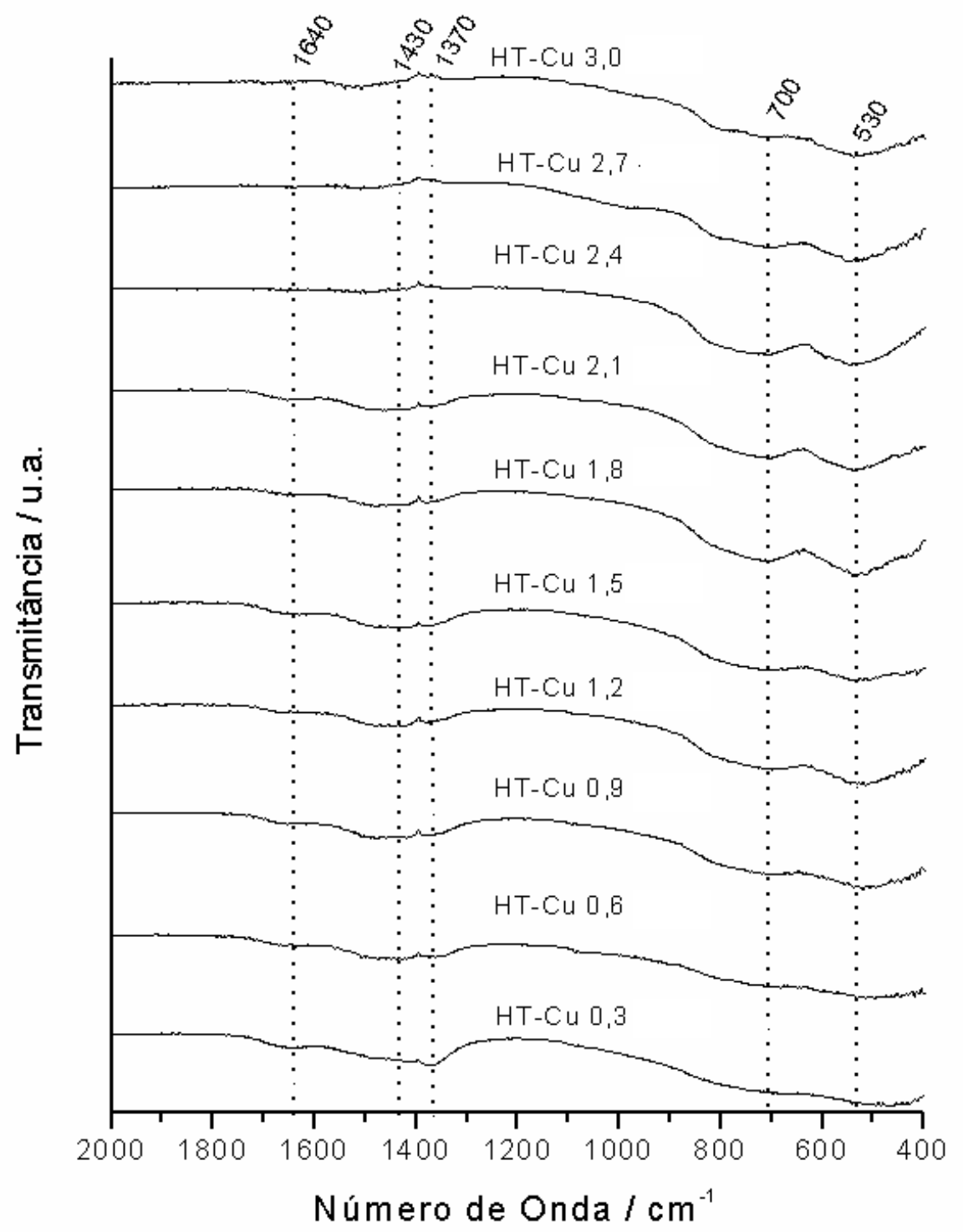

Figura 20 - Espectros FTIR das amostras HT-Cux, calcinadas em forno a $900^{\circ} \mathrm{C}$ por $1 \mathrm{~h}$ (calcinação ex-situ) 


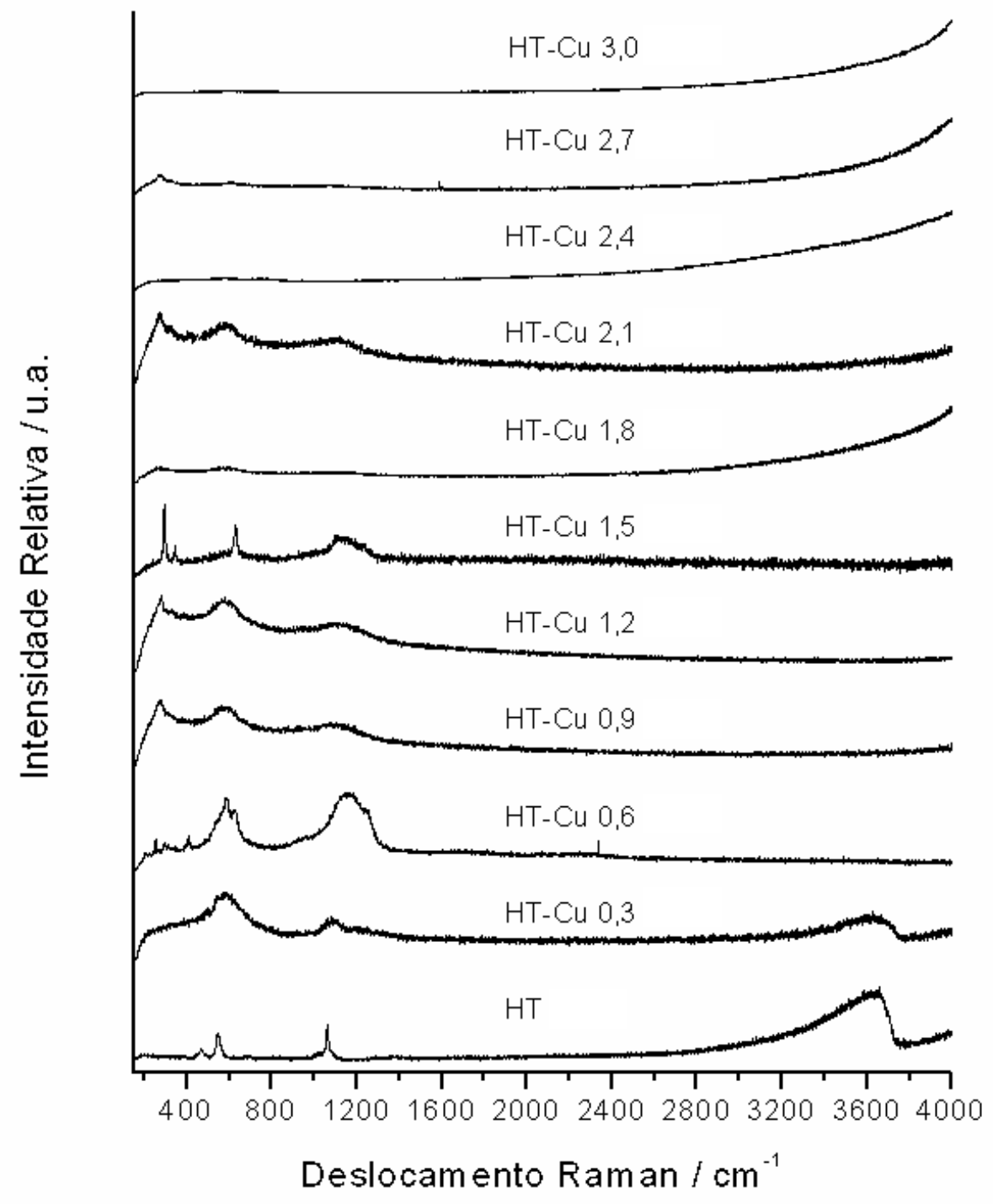

Figura 21 - Espectros de Espalhamento Raman das amostras HT-Cu x, calcinadas em forno a $900^{\circ} \mathrm{C}$ por $1 \mathrm{~h}$ (calcinação ex-situ)

Os espectros apresentados na Figura 21 podem não serem os ideais para se discutir acerca da estrutura dos materiais, uma vez que esses espectros foram registrados mais de 90 dias após a calcinação do material. Por isso, acredita-se que ocorreu rehidratação do sólido, explicando a presença de 
bandas na região de $3600 \mathrm{~cm}^{-1}$, e recarbonatação, responsável pelas bandas na região de $1100 \mathrm{~cm}^{-1}$, através da reação de íons óxido na estrutura do sólido calcinado com $\mathrm{CO}_{2}$ da atmosfera, conforme descrito na equação abaixo:

$$
\mathrm{CO}_{2}+\mathrm{O}^{2-} \rightarrow \mathrm{CO}_{3}{ }^{2-}
$$

Assim sendo, com a finalidade de melhor entender a estrutura dos materiais obtidos através de calcinação, foram selecionadas as amostras HT e HT-Cu0,6; 1,2; 1,8; 2,4 e 3,0, para calcinação por 30 min nas temperaturas de $80^{\circ} \mathrm{C}, 115^{\circ} \mathrm{C}, 150^{\circ} \mathrm{C}, 185^{\circ} \mathrm{C}, 220^{\circ} \mathrm{C}$ e $300^{\circ} \mathrm{C}$ em forno. Em cada uma das temperaturas, foi observada a coloração do material obtido e registrado o respectivo espectro FTIR, apresentados nas Figura 22, Figura 23, Figura 24, Figura 25, Figura 26 e Figura 27. 


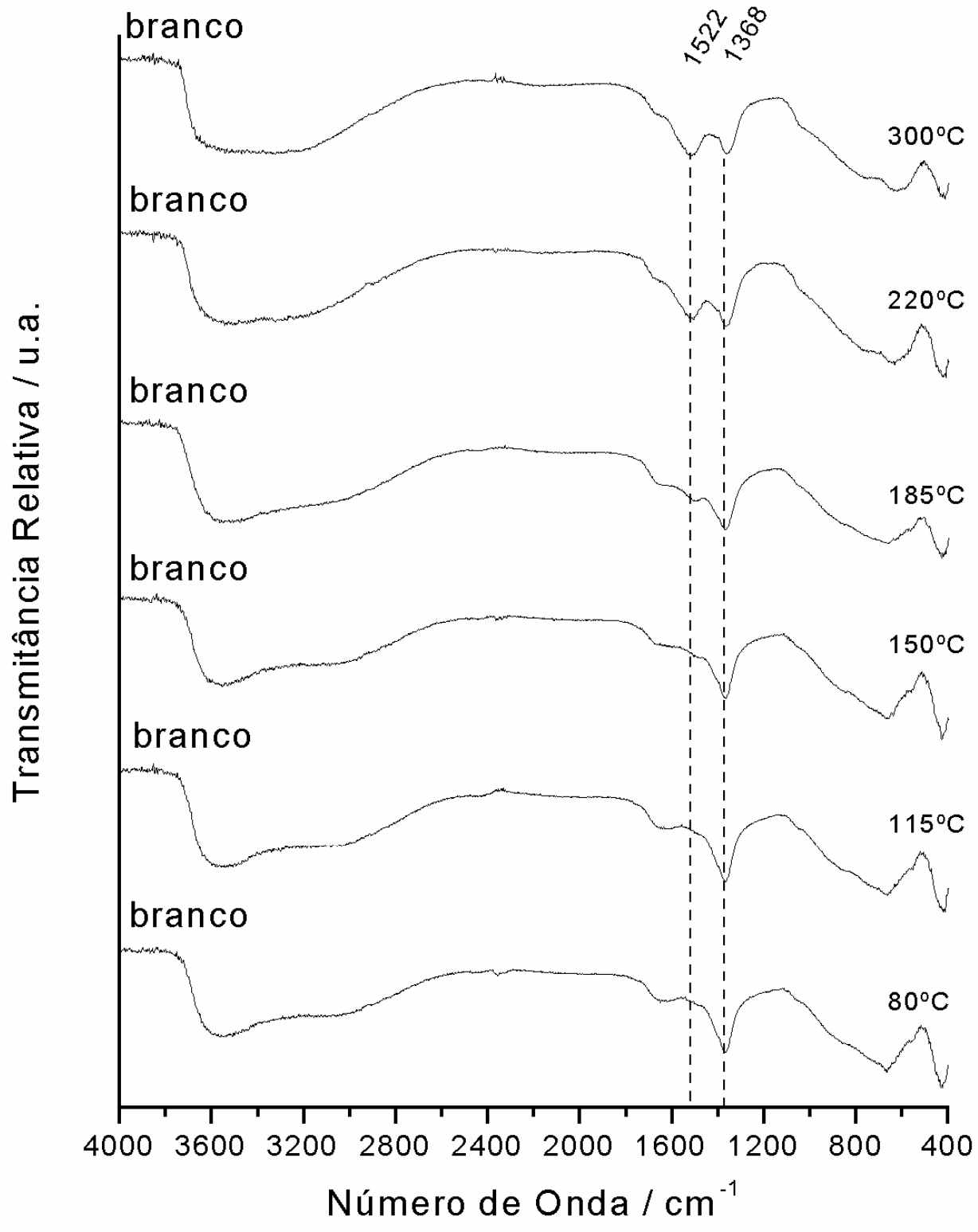

Figura 22 - Espectros FTIR da amostra HT calcinada em diferentes temperaturas 


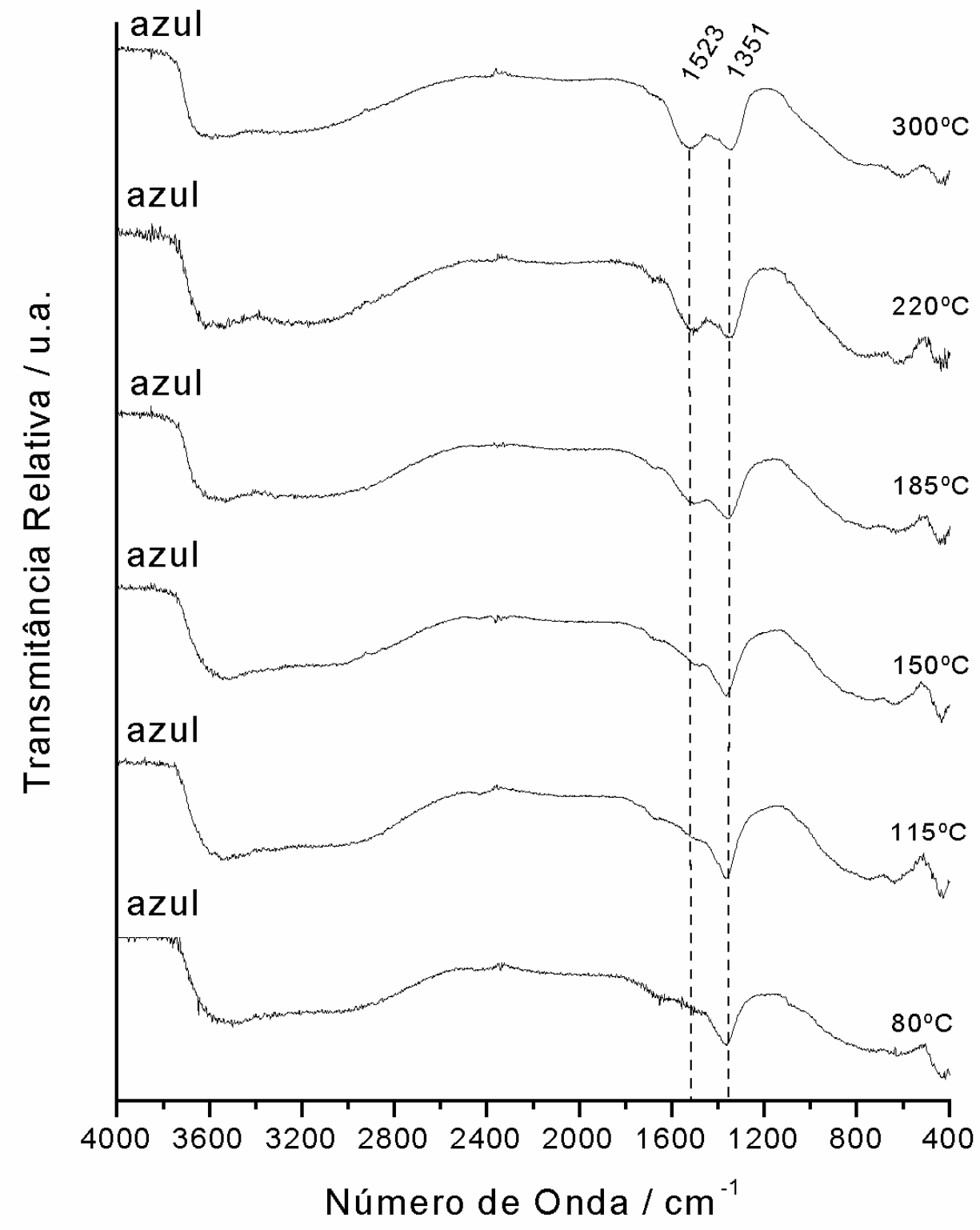

Figura 23 - Espectros FTIR da amostra HT-Cu0,6 calcinada em diferentes temperaturas (à esquerda está indicada a cor da amostra após aquecimento) 


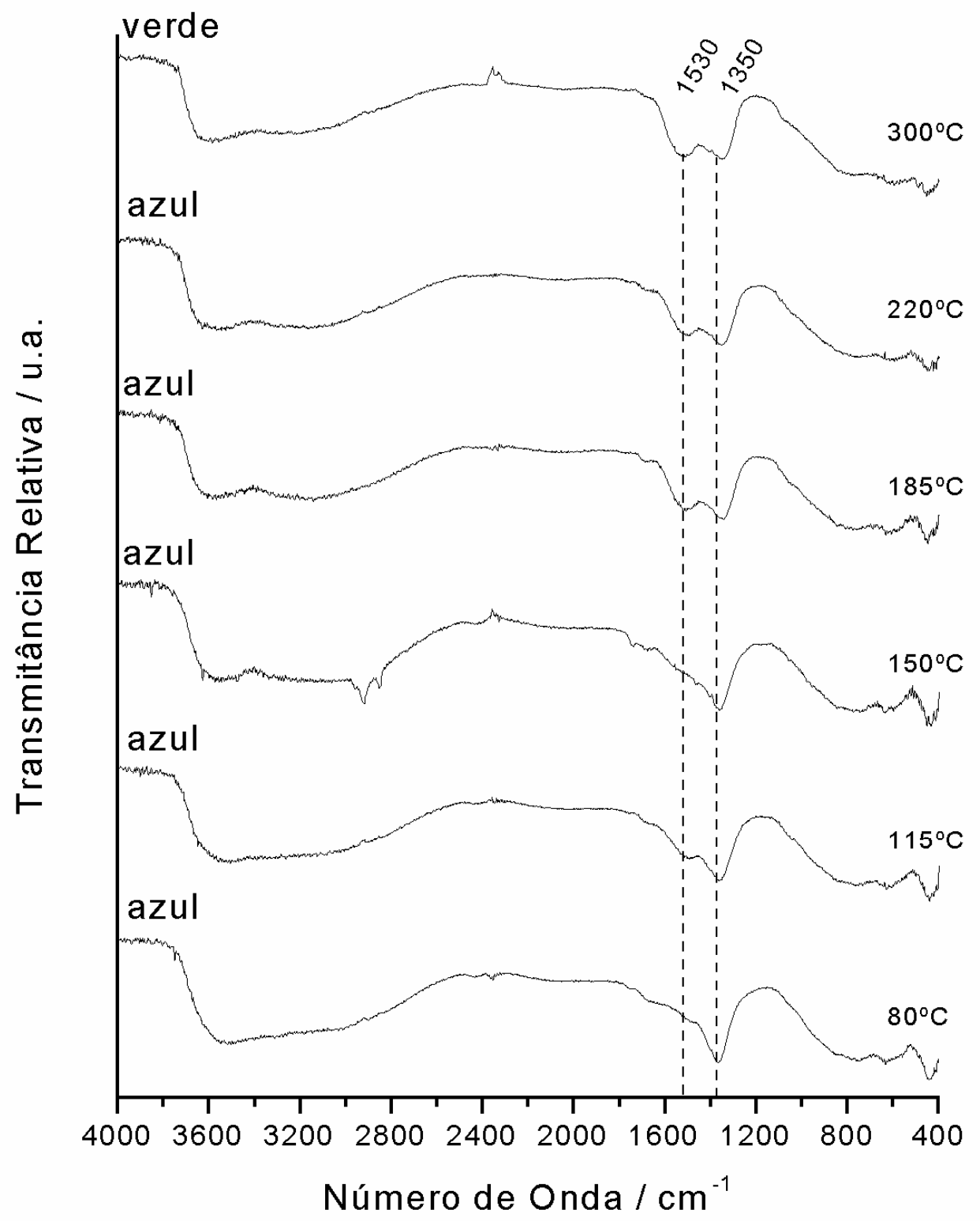

Figura 24 - Espectros FTIR da amostra HT-Cu1,2 calcinada em diferentes temperaturas 


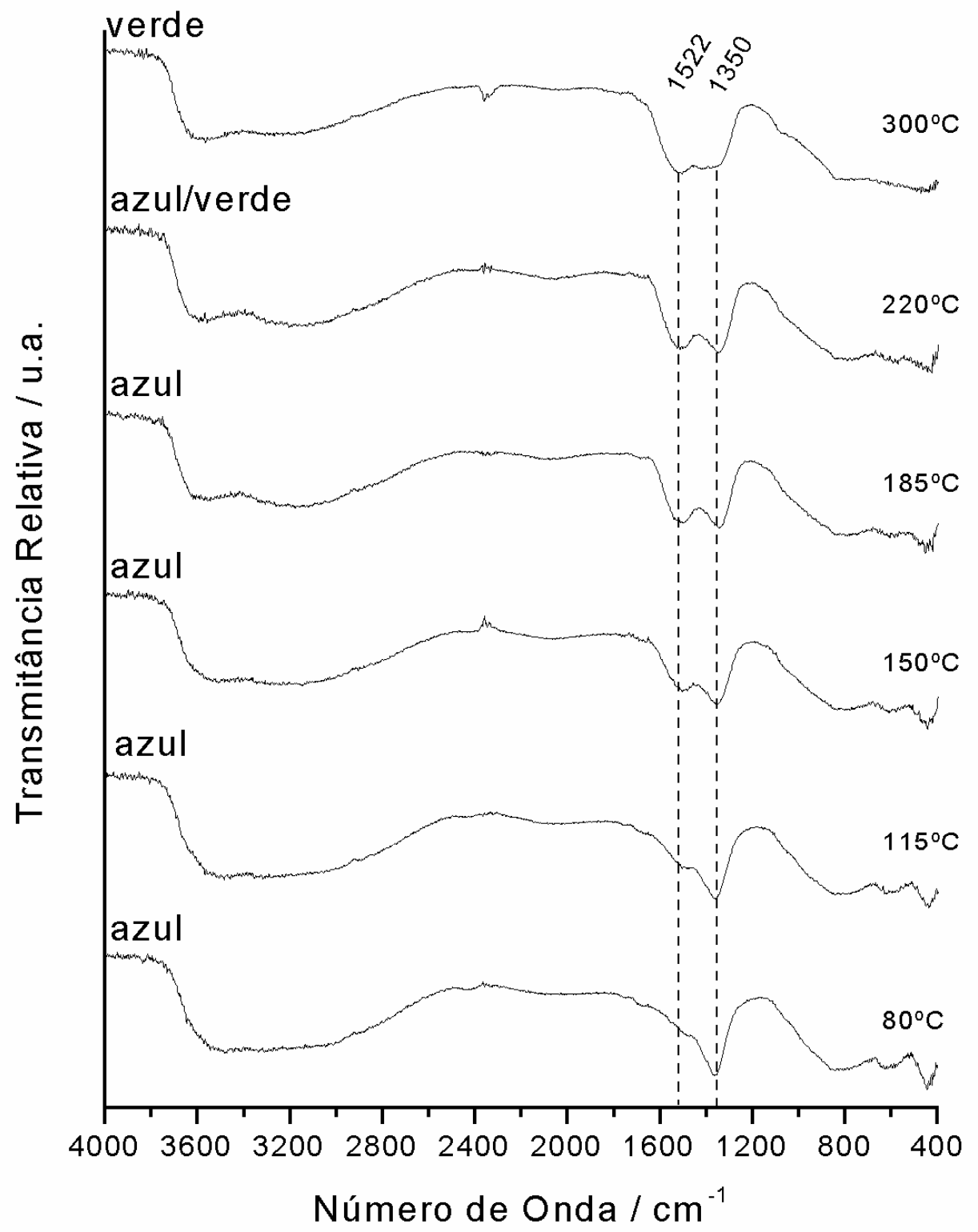

Figura 25 - Espectros FTIR da amostra HT-Cu1,8 calcinada em diferentes temperaturas 


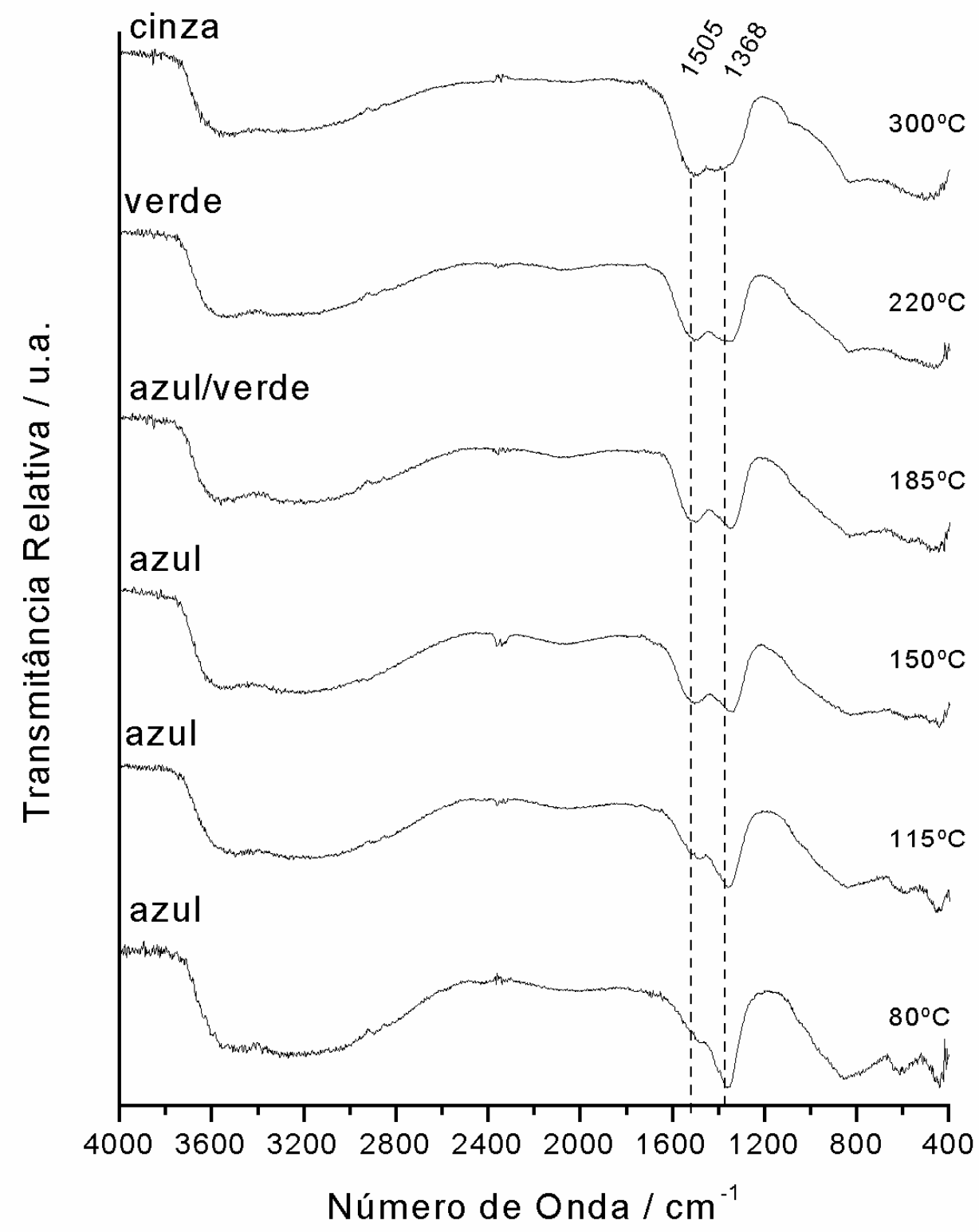

Figura 26 - Espectros FTIR da amostra HT-Cu2,4 calcinada em diferentes temperaturas 


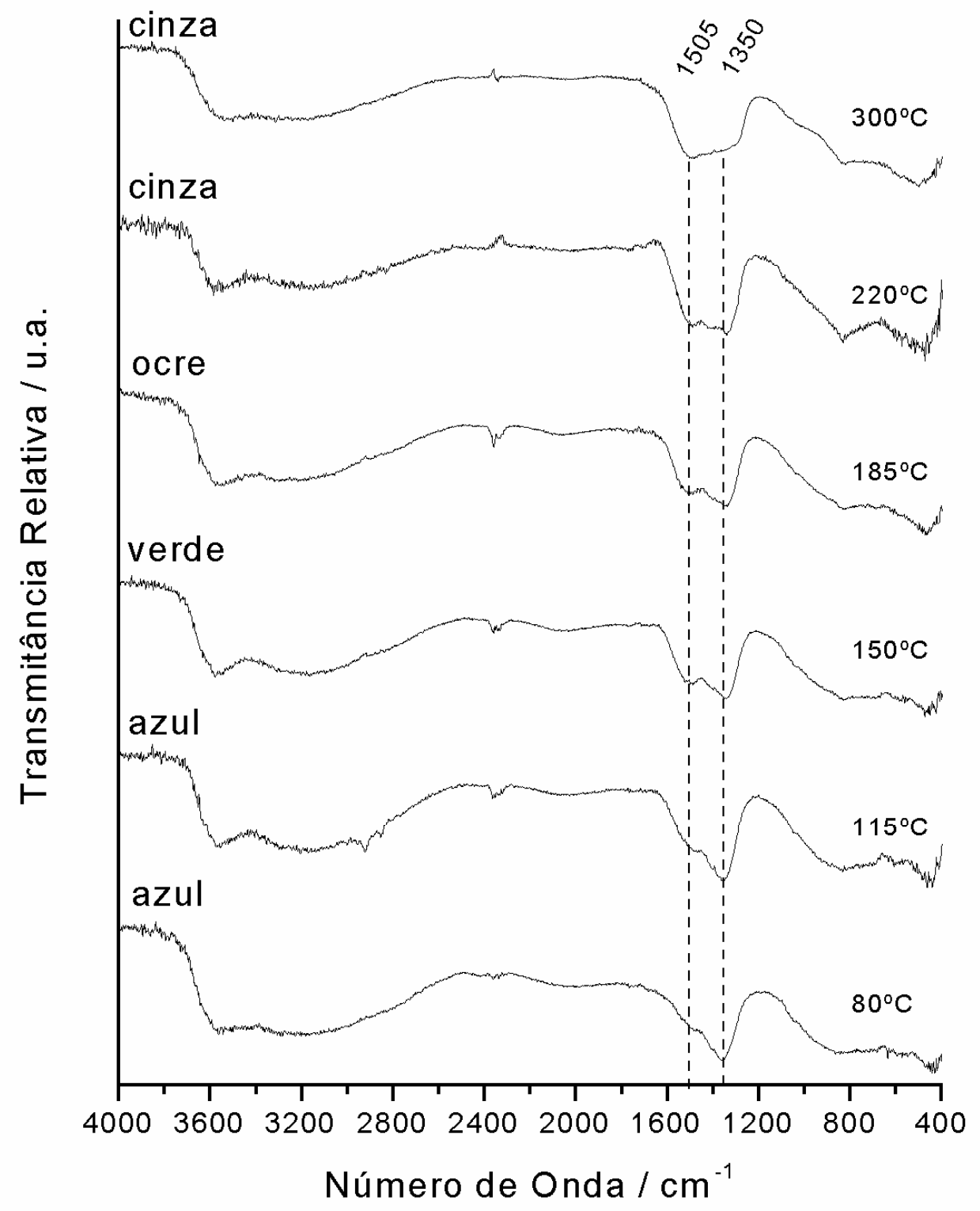

Figura 27 - Espectros FTIR da amostra HT-Cu3,0 calcinada em diferentes temperaturas

Em todos os espectros vibracionais das amostras calcinadas em diferentes temperaturas, observa-se a diminuição da banda da região de 1360 $\mathrm{cm}^{-1}$, atribuída ao modo vibracional $v_{3}$ do carbonato (modo ativo no IV), e o 
aparecimento seguido de aumento de uma banda em $1460 \mathrm{~cm}^{-1}$, atribuída ao desdobramento do modo $v_{3}$ do carbonato, presente apenas no caso de íon carbonato mono ou bidentado ${ }^{[81]}$. Conforme já apresentado na Tabela 12 , cada uma dessas bandas é referente a um modo vibracional do íon carbonato. Porém, o íon carbonato em sua simetria $D_{3 h}$ (íon livre) possui o seu modo vibracional $v_{1}$, na região de $1050 \mathrm{~cm}^{-1}$, inativo no infravermelho. Esse modo vibracional só se torna ativo quando ocorre um abaixamento de simetria de $D_{3 h}$ para $\mathrm{C}_{\mathrm{s}}$ ou $\mathrm{C}_{2 \mathrm{v}}$, referentes ao íon carbonato bi ou monodentado (Figura 28). Observa-se uma banda de absorção fraca em 1050-1100 $\mathrm{cm}^{-1}$ nos espectros FTIR das amostras aquecidas, confirmando o abaixamento de simetria do íon carbonato.

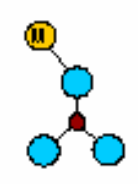

Unidentado

(Cs)

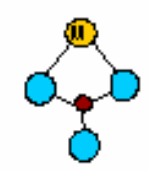

Bidentado

$\left(\mathrm{C}_{\mathbf{z u}}\right)$

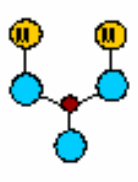

Ponte

$\left(\mathrm{C}_{\mathbf{z u}}\right)$

(A)
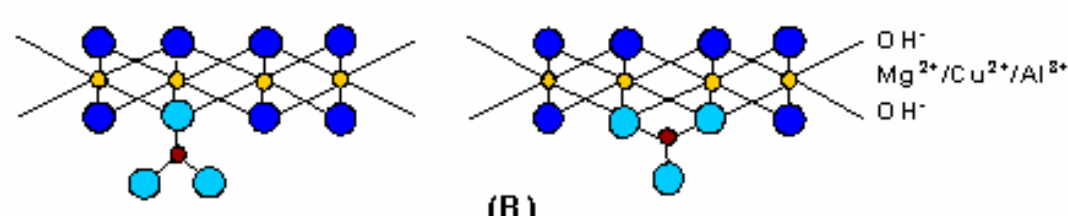

(B)

Figura 28 - (A) Modos de coordenação do íon carbonato aos centros metálicos[59]; (B) Modos de coordenação (ou enxertia) dos íons carbonato aos centros metálicos das lamelas de hidróxidos mistos.

Além do espectro vibracional no infravermelho, registrou-se também o espectro Raman das amostras aquecidas in situ às temperaturas de 50, 80, $115,150,185,220,250,300,350,400,450$ e 500ํ (espectros apresentados no Anexo C). Nas Figura 29, Figura 30, Figura 31, Figura 32, Figura 33 e Figura 34, estão apresentados os espectros Raman para as mesmas amostras calcinadas que tiveram seus espectros de FTIR registrados ex situ. 


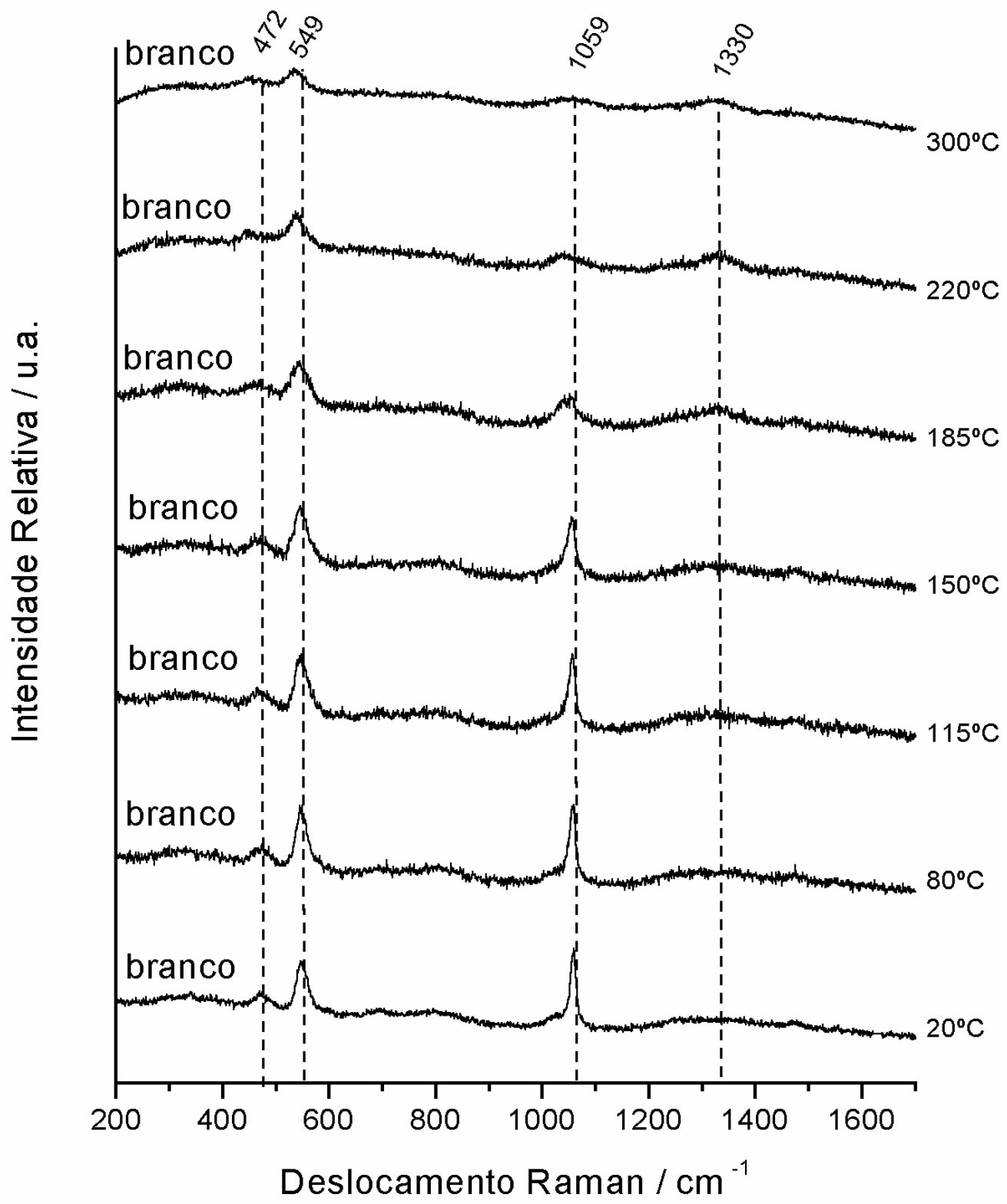

Figura 29 - Espectros de Espalhamento Raman da amostra HT calcinada em diferentes temperaturas 


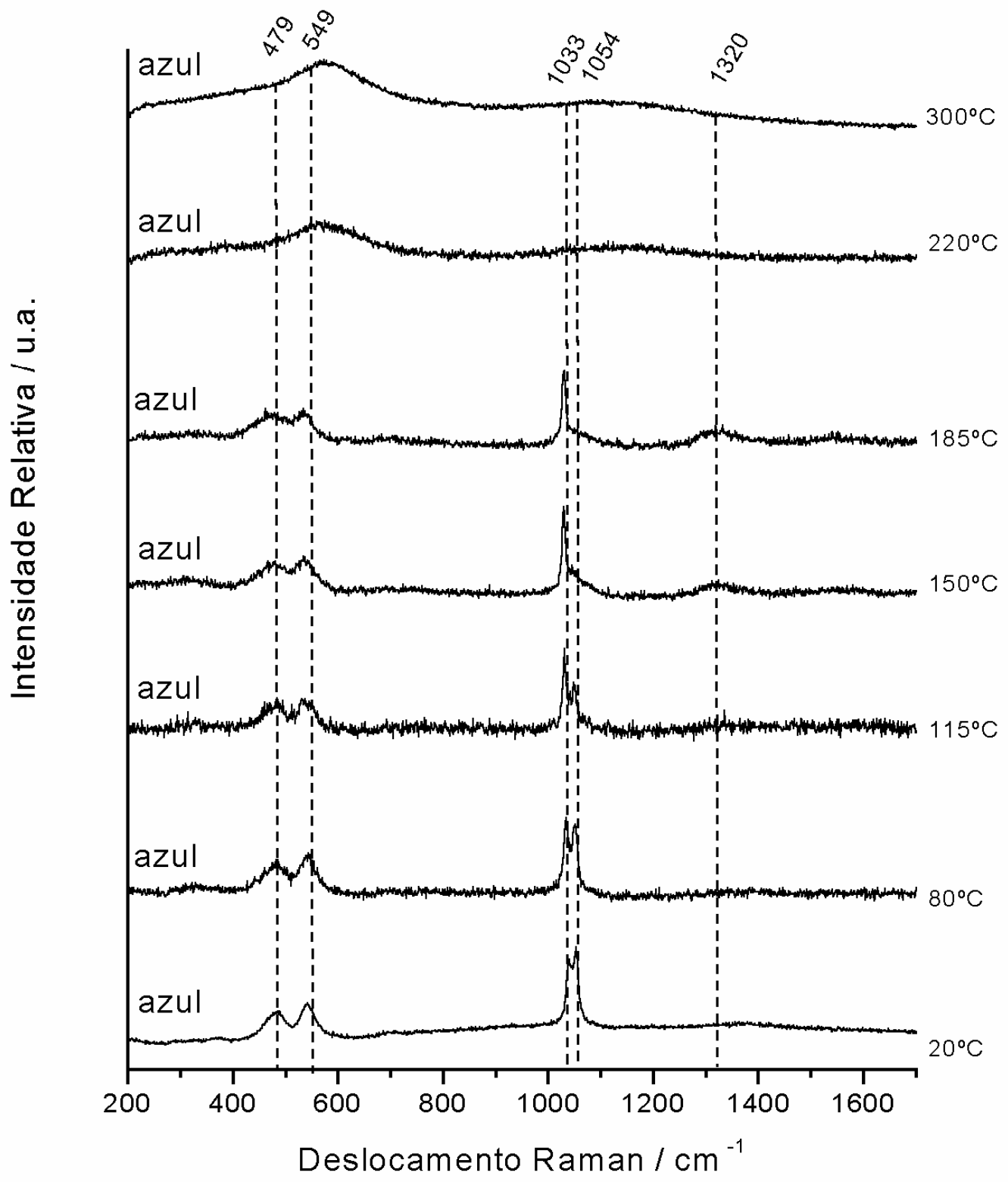

Figura 30 - Espectros de Espalhamento Raman da amostra HT-Cu0,6 calcinada em diferentes temperaturas 


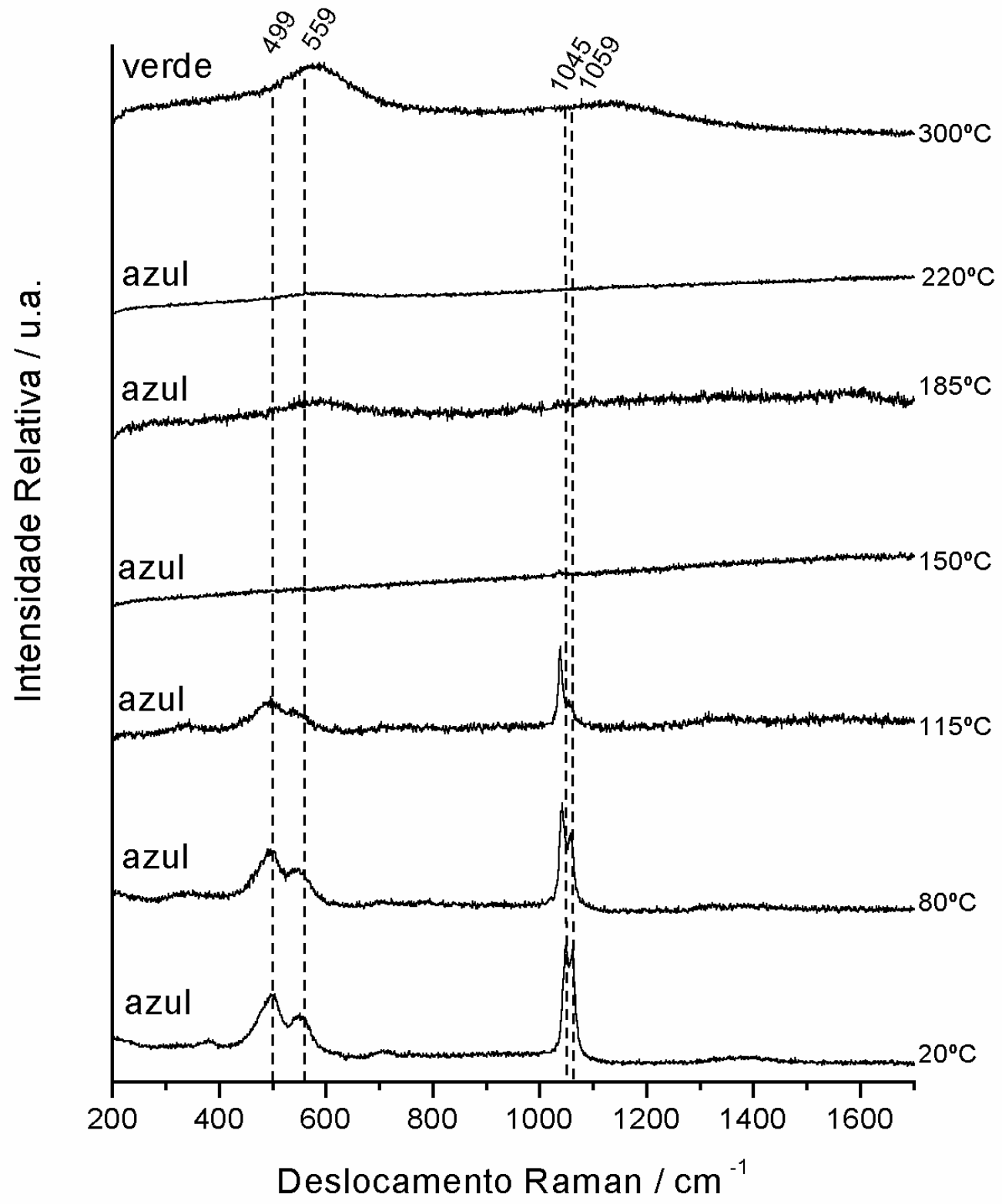

Figura 31 - Espectros de Espalhamento Raman da amostra HT-Cu1,2 calcinada em diferentes temperaturas 


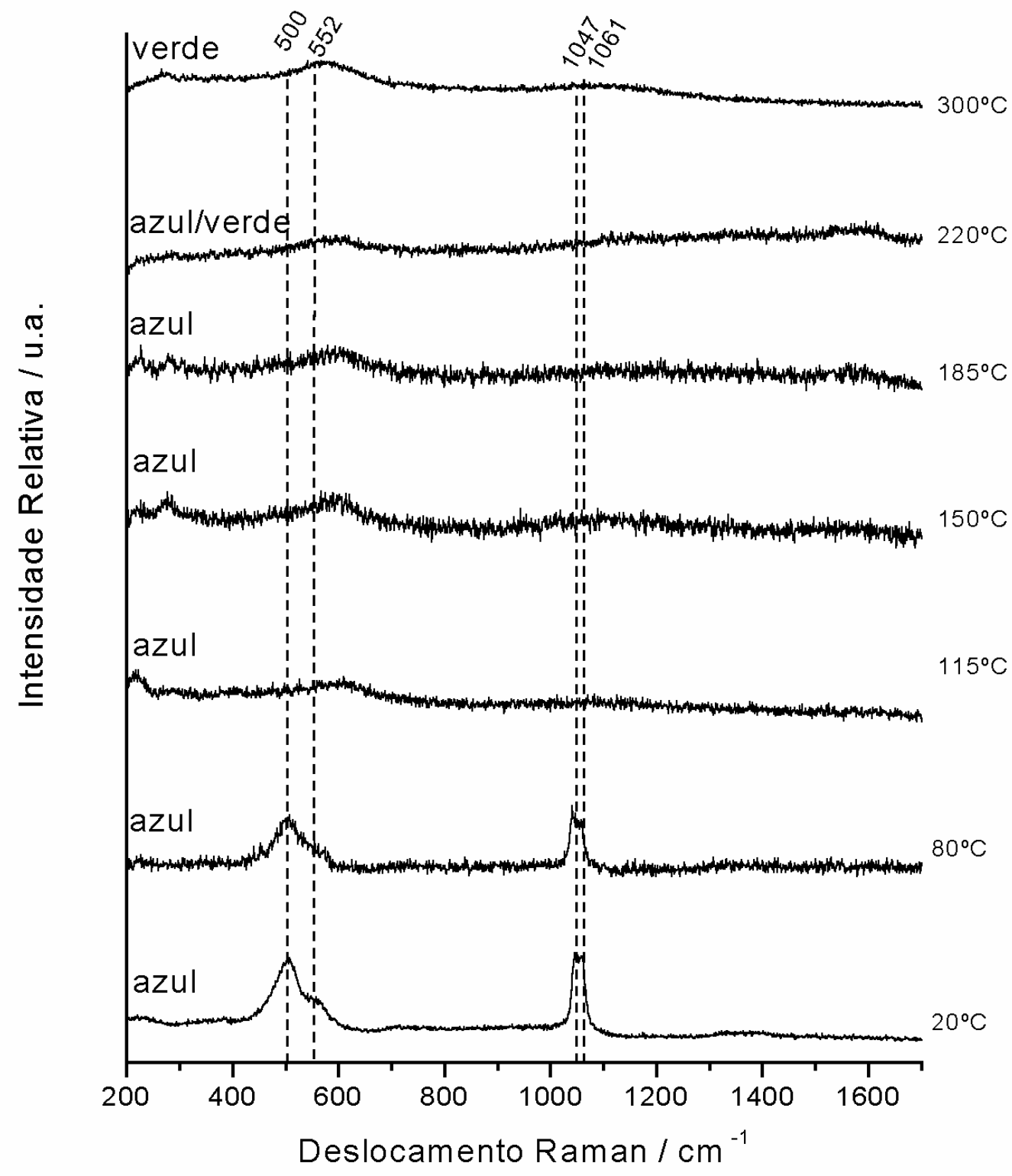

Figura 32 - Espectros de Espalhamento Raman da amostra HT-Cu1,8 calcinada em diferentes temperaturas 


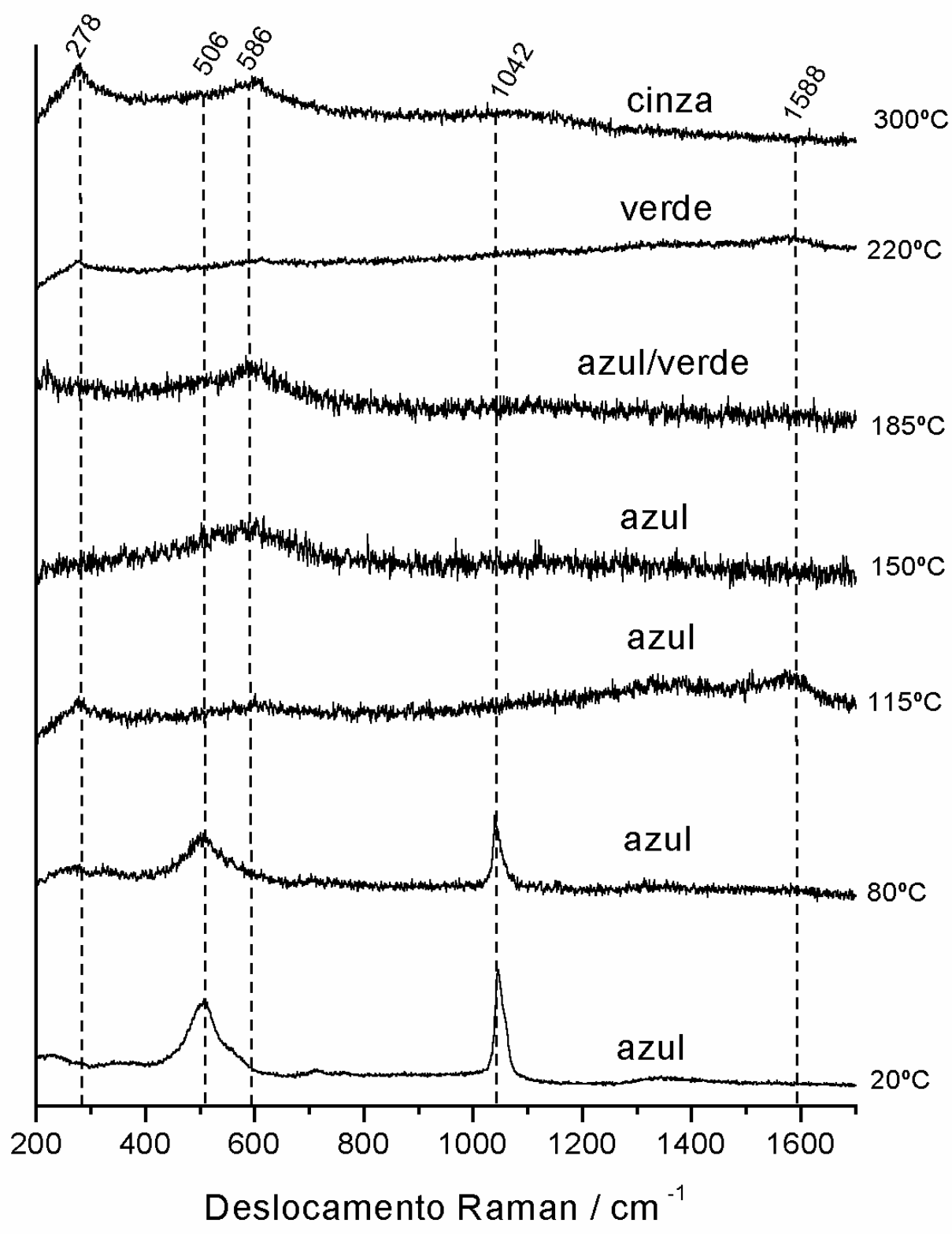

Figura 33 - Espectros de Espalhamento Raman da amostra HT-Cu2,4 calcinada em diferentes temperaturas 


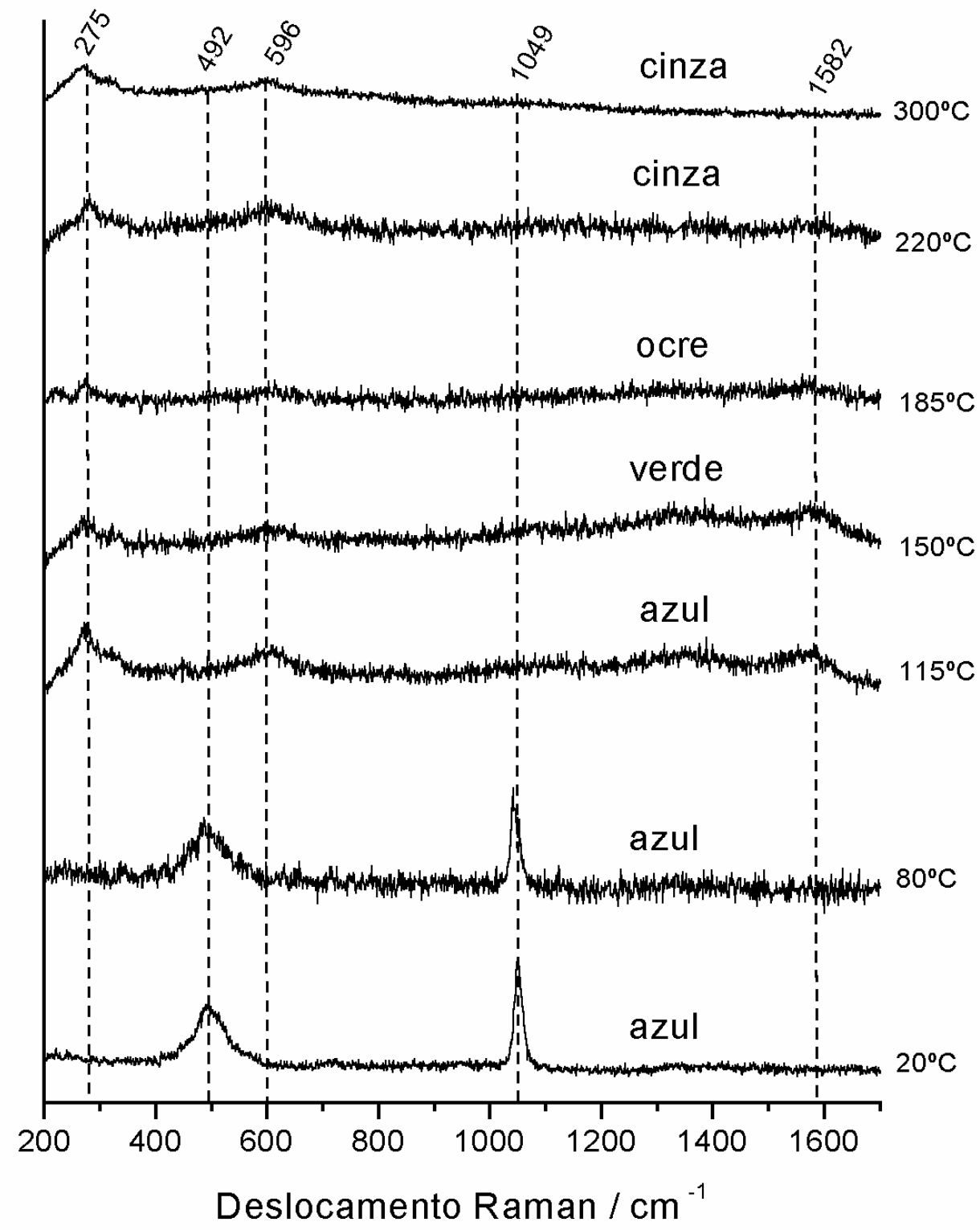

Figura 34 - Espectros de Espalhamento Raman da amostra HT-Cu3,0 calcinada em diferentes temperaturas

As principais bandas observadas nos espectros Raman para a amostra HTCu1,2 seguem na Tabela 14. 
Tabela 14 - Principais bandas observadas nos espectros de espalhamento Raman para as amostras HT e HT-Cux em diferentes temperaturas

\begin{tabular}{|c|c|c|c|c|c|c|c|c|}
\hline \multirow{2}{*}{ Amostra } & \multicolumn{7}{|c|}{ Temperatura / ${ }^{\circ} \mathrm{C}$} & \multirow{2}{*}{${ }_{[91],[92]}^{\text {Atribuição }}{ }^{[81],}$} \\
\hline & 20 & 80 & 115 & 150 & 185 & 220 & 300 & \\
\hline \multirow{4}{*}{ HT } & 471 & 476 & 465 & 463 & 466 & 440 & 456 & Transl. M-OH \\
\hline & 546 & 548 & 546 & 544 & 43 & 537 & 533 & Transl. M-OH \\
\hline & 1057 & 1057 & 1057 & 1057 & 1050 & 1044 & 1059 & $v_{1} \mathrm{CO}_{3}^{2-}$ \\
\hline & - & - & - & - & 1328 & 1333 & 1330 & $v_{3} \mathrm{CO}_{3}{ }^{2-}$ \\
\hline \multirow{7}{*}{ HT-Cu0,3 } & 487 & 487 & 487 & 487 & 469 & - & - & $\mathrm{M}-\mathrm{OH}$ \\
\hline & 547 & 547 & 553 & 547 & 547 & 553 & - & $\mathrm{M}-\mathrm{OH}$ \\
\hline & 1047 & 1041 & 1039 & 1041 & 1051 & 1032 & 1041 & $v_{1} \mathrm{CO}_{3}^{2-}$ \\
\hline & 1060 & 1058 & 1059 & - & - & - & - & $v_{1} \mathrm{CO}_{3}^{2-}$ \\
\hline & - & - & - & - & - & 1318 & - & $v_{3} \mathrm{CO}_{3}^{2-}$ \\
\hline & 3508 & - & - & - & - & - & - & $\mathrm{H}_{2} \mathrm{O}$ \\
\hline & 3583 & 3540 & 3557 & 3675 & - & 3675 & 3658 & $v_{\mathrm{s}} \mathrm{OH}$ \\
\hline \multirow{8}{*}{ HT-Cu0,6 } & 482 & 482 & 479 & 475 & 475 & - & - & $\mathrm{M}-\mathrm{OH}$ \\
\hline & 540 & 540 & 543 & 537 & 533 & - & - & $\mathrm{M}-\mathrm{OH}$ \\
\hline & - & - & - & - & - & 575 & 570 & $\mathrm{M}-\mathrm{OH}$ \\
\hline & 1037 & 1033 & 1029 & 1026 & 1029 & - & - & $v_{1} \mathrm{CO}_{3}^{2-}$ \\
\hline & 1050 & 1050 & 1059 & 1047 & - & - & - & $v_{1} \mathrm{CO}_{3}^{2-}$ \\
\hline & - & - & - & - & - & 1146 & 1143 & - \\
\hline & - & - & - & 1320 & 1320 & - & - & $v_{3} \mathrm{CO}_{3}{ }^{2-}$ \\
\hline & 3563 & 3563 & 3563 & 3562 & 3660 & - & - & $\mathrm{v}_{\mathrm{s}} \mathrm{OH}$ \\
\hline \multirow{7}{*}{ HT-Cu0,9 } & 487 & 487 & 479 & - & - & - & - & $\mathrm{M}-\mathrm{OH}$ \\
\hline & 545 & 553 & 545 & - & - & - & - & $\mathrm{M}-\mathrm{OH}$ \\
\hline & - & - & - & - & 579 & 527 & 588 & $\mathrm{M}-\mathrm{OH}$ \\
\hline & 1047 & 1049 & 1049 & - & - & - & - & $v_{1} \mathrm{CO}_{3}{ }^{2-}$ \\
\hline & 1060 & - & - & - & - & - & - & $v_{1} \mathrm{CO}_{3}^{2-}$ \\
\hline & - & - & - & - & 1107 & 1058 & 1142 & - \\
\hline & 3557 & 3557 & 3566 & 3641 & 3632 & 3641 & - & $v_{s} \mathrm{OH}$ \\
\hline \multirow{6}{*}{ HT-Cu1,2 } & 490 & 600 & 605 & - & 750 & 762 & 775 & $\mathrm{M}-\mathrm{OH}$ \\
\hline & 550 & 560 & 575 & - & - & - & - & $\mathrm{M}-\mathrm{OH}$ \\
\hline & 1050 & 1045 & 1052 & - & - & - & - & $v_{1} \mathrm{CO}_{3}^{2-}$ \\
\hline & 1060 & 1055 & 1058 & - & - & - & - & $v_{1} \mathrm{CO}_{3}^{2-}$ \\
\hline & 1415 & 1405 & - & - & - & - & - & $v_{3} \mathrm{CO}_{3}^{2-}$ \\
\hline & 3600 & 3600 & 3600 & - & - & - & - & $\mathrm{v}_{\mathrm{s}} \mathrm{OH}$ \\
\hline \multirow{7}{*}{ HT-Cu1,5 } & 495 & 503 & 487 & - & - & - & - & $\mathrm{M}-\mathrm{OH}$ \\
\hline & 547 & 547 & 557 & - & - & - & - & $\mathrm{M}-\mathrm{OH}$ \\
\hline & - & - & - & 566 & 574 & 574 & 574 & $\mathrm{M}-\mathrm{OH}$ \\
\hline & 1046 & 1041 & 1039 & 1031 & - & - & - & $v_{1} \mathrm{CO}_{3}{ }^{2-}$ \\
\hline & 1060 & 1058 & - & - & - & - & - & $v_{1} \mathrm{CO}_{3}^{2-}$ \\
\hline & - & - & - & - & 1118 & 1093 & 1110 & - \\
\hline & 3546 & 3546 & 3590 & 3625 & - & - & - & $v_{\mathrm{s}} \mathrm{OH}$ \\
\hline \multirow{6}{*}{ HT-Cu1,8 } & 506 & 506 & 506 & - & - & - & - & $\mathrm{M}-\mathrm{OH}$ \\
\hline & 549 & - & - & - & - & - & - & $\mathrm{M}-\mathrm{OH}$ \\
\hline & - & - & - & 592 & 576 & 601 & 566 & $\mathrm{M}-\mathrm{OH}$ \\
\hline & 1045 & 1046 & 1041 & - & - & - & - & $v_{1} \mathrm{CO}_{3}^{2-}$ \\
\hline & - & - & - & - & 1118 & 1093 & 1110 & $v_{1} \mathrm{CO}_{3}^{2-}$ \\
\hline & 3546 & 3546 & 3590 & 3625 & - & - & - & $\mathrm{v}_{\mathrm{s}} \mathrm{OH}$ \\
\hline
\end{tabular}




\begin{tabular}{|c|c|c|c|c|c|c|c|c|}
\hline \multirow{7}{*}{ HT-Cu2,1 } & 504 & 504 & 487 & - & - & - & - & $\mathrm{M}-\mathrm{OH}$ \\
\hline & - & - & - & 570 & 562 & 562 & 553 & $\mathrm{M}-\mathrm{OH}$ \\
\hline & 712 & - & - & - & - & - & - & $v_{4} \mathrm{NO}_{3}^{-}$ \\
\hline & 1047 & 1041 & 1041 & - & - & - & - & $v_{1} \mathrm{CO}_{3}{ }^{2-}$ \\
\hline & - & - & - & 1139 & - & 1090 & 1099 & $v_{1} \mathrm{CO}_{3}{ }^{2-}$ \\
\hline & 1333 & - & - & - & - & - & - & $v_{3} \mathrm{CO}_{3}{ }^{2-}$ \\
\hline & 3549 & 3540 & 3589 & - & - & - & - & $\mathrm{v}_{\mathrm{s}} \mathrm{OH}$ \\
\hline \multirow{4}{*}{ HT-Cu2,4 } & 504 & 504 & - & - & - & - & - & $\mathrm{M}-\mathrm{OH}$ \\
\hline & - & - & 620 & 588 & 594 & 603 & 603 & $\mathrm{M}-\mathrm{OH}$ \\
\hline & 1041 & 1041 & - & - & - & - & - & $v_{1} \mathrm{CO}_{3}{ }^{2-}$ \\
\hline & 3531 & 3557 & - & - & - & - & - & $v_{\mathrm{s}} \mathrm{OH}$ \\
\hline \multirow{7}{*}{ HT-Cu2,7 } & 510 & 504 & 495 & - & - & - & - & $\mathrm{M}-\mathrm{OH}$ \\
\hline & - & - & 562 & - & - & - & - & $\mathrm{M}-\mathrm{OH}$ \\
\hline & - & - & - & 579 & 588 & - & - & $\mathrm{M}-\mathrm{OH}$ \\
\hline & 703 & - & - & - & - & - & - & $\mathrm{v}_{4} \mathrm{NO}_{3}^{-}$ \\
\hline & 1041 & 1041 & 1041 & 1032 & - & - & - & $v_{1} \mathrm{NO}_{3}^{-}$ \\
\hline & 2911 & 2902 & - & - & - & - & - & $\mathrm{H}_{2} \mathrm{O}_{\text {def }}$ \\
\hline & 3549 & 3566 & 3572 & 3589 & - & - & - & $v_{\mathrm{s}} \mathrm{OH}$ \\
\hline \multirow{5}{*}{ HT-Cu3,0 } & 487 & 487 & - & - & - & - & - & $\mathrm{M}-\mathrm{OH}$ \\
\hline & - & - & 603 & 603 & 588 & 594 & 594 & $\mathrm{M}-\mathrm{OH}$ \\
\hline & 1047 & 1041 & - & - & - & - & - & $\mathrm{v}_{1} \mathrm{NO}_{3}^{-}$ \\
\hline & - & - & 1569 & 1592 & - & - & - & - \\
\hline & 3566 & 3566 & - & - & - & - & - & $v_{s} \mathrm{OH}$ \\
\hline
\end{tabular}

Observa-se, tanto nos espectros Raman quanto nos vibracionais FTIR das amostras, uma maior complexidade de bandas referentes à estrutura inorgânica do material (bandas na região de $550 \mathrm{~cm}^{-1}$ ) conforme a diminuição da quantidade de íons $\mathrm{Cu}^{2+}$, devido provavelmente à distorção que esse causa na estrutura da matriz, conforme previsto pelo efeito Jahn-Teller.

Ao registrar-se os espectros de espalhamento Raman, esperava-se obter maior número de informações acerca do(s) ânion(s) interlamelar(es), uma vez que as bandas atribuídas aos estiramentos das moléculas de água não são intensas no Raman, o que acarreta em um espectro com menor quantidade de informações que podem dificultar ou até mesmo interferir na interpretação dos dados. 
Nos espectros Raman não se observa nenhuma evidência tão clara de abaixamento de simetria do íons $\mathrm{CO}_{3}{ }^{2-}$ como nos espectros no infravermelho. Porém, o fato dessas medidas terem sido feitas com aquecimento in situ permite observar com maior detalhamento o evento térmico de alteração de estrutura devido à desidroxilação, uma vez que o material calcinado, extremamente higroscópico, não é exposto em nenhum momento à umidade do ambiente. Assim, como já observado anteriormente nos espectros vibracionais FTIR, à medida que conteúdo de $\mathrm{Cu}^{2+}$ nas matrizes aumenta, as alterações nos espectros Raman passam a ocorrer em temperaturas menores.

Além dos espectros Raman, em cada temperatura também foi registrada a imagem da amostra, a fim de ilustrar a alteração de coloração que ocorre conforme aquecimento, de acordo com a imagem apresentada na Figura 35, para a amostra HT-Cu1,5, e no Apêndice C, para todas as demais. 


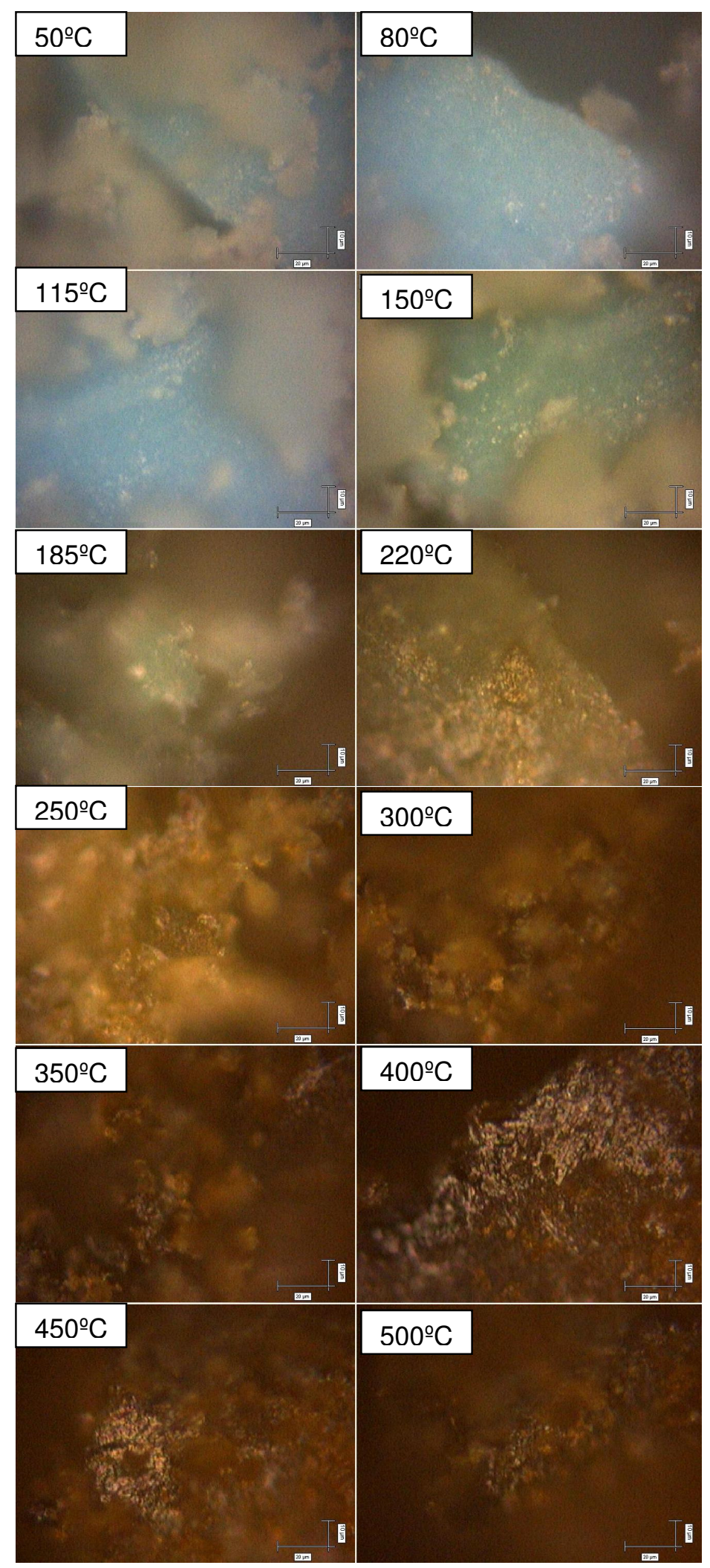

Figura 35 - Imagens em microscópio óptico, com lente de 50x, da amostra HT-Cu1,2 em diferentes temperaturas 
Observando-se apenas a coloração dos materiais obtidos, pode-se perceber que quanto maior a quantidade de íons $\mathrm{Cu}^{2+}$, menor a temperatura necessária para que ocorra uma alteração na cor das amostras. Através dos espectros FTIR, pode-se também observar o surgimento de uma nova banda, na região de $1500 \mathrm{~cm}^{-1}$, acompanhada nos espectros Raman pela diminuição das bandas em 3000, 1100 e $500 \mathrm{~cm}^{-1}$ e o aparecimento de bandas em 300 e $500 \mathrm{~cm}^{-1}$, que ocorre também em temperaturas cada vez menores conforme se aumenta a quantidade de íons $\mathrm{Cu}^{2+}$. Considerando-se novamente as curvas TGA dos materiais HT-Cux, tal tendência de diminuição de temperatura para ocorrência de eventos térmicos, inversamente proporcional à concentração de íons cobre(II), já havia sido observada anteriormente.

Atualmente, encontra-se na literatura duas vertentes para explicar tais transformações que ocorrem durante $\mathrm{o}$ aquecimento de amostras de HDL contendo íons cobre(II). Uma delas, primeiramente publicada por Velu et al. ${ }^{[93]}$, na qual se defende que a diminuição de simetria dos íons carbonato se deva à enxertia destes nas lamelas, formando ao longo do processo de calcinação, oxocarbonatos de composição química $\mathrm{M}^{2+} \mathrm{M}^{3+}{ }_{x} \mathrm{O}_{\mathrm{y}}\left(\mathrm{CO}_{3}\right)_{z}$. Tal hipótese foi confirmada por Starminova et al. ${ }^{[94]}$, e mais recentemente por Kanan et al. ${ }^{[95]}$, elucidando o processo de decomposição térmica ao mesmo tempo que propõe uma estrutura para o material obtido em cada uma das etapas. Por outro lado, Kloprogge et al. ${ }^{[96]}$, atribui tal abaixamento de simetria nos íons carbonato apenas à presença de um segundo tipo de íon carbonato livre (não coordenado ou enxertado) que teve sua simetria alterada devido à interações mais fortes com sua vizinhança. A única diferença entre os estudos realizados para defender uma ou outra hipótese reside na interpretação feita dos resultados 
obtidos; todos eles se basearam em medidas de espaçamento basal, oriunda de análise do DRX, termogravimetria e espectros vibracionais no FTIR. Mesmo tendo realizado, além das técnicas supracitadas, medidas de EPR, apoiar qualquer uma das duas hipóteses atuais pode ser considerada uma atitude precipitada. Baseando-se nos resultados obtidos ao longo do estudo realizado, ambas as hipóteses podem ser verdadeiras e estudos mais aprofundados devem ser realizados para afirmar a veracidade de uma em detrimento da outra.

Os dados de espectroscopia vibracional no infravermelho e Raman não permitem diferenciar as amostras azuis originais daquelas calcinadas de coloração verde. Essa transformação não parece estar associada à liberação de moléculas de água de hidratação ou a um possível processo de enxertia dos íons carbonato nas lamelas. Observa-se com clareza que o maior conteúdo de cobre promove a alteração de cor em temperaturas mais baixas. Como foi mencionado na parte introdutória, devido ao efeito Jahn-Teller, a geometria ao redor do íon $\mathrm{Cu}(\mathrm{II})$ está sujeita a distorções quando em um ambiente cúbico (octaedro regular ou tetraédrico). O íon cobre(II) nunca é observado em um geometria regular, com uma única exceção, o composto $\mathrm{K}_{2} \mathrm{~Pb}\left[\mathrm{Cu}\left(\mathrm{NO}_{2}\right)\right]^{[97]}$. Os compostos de cobre(II) são geralmente azuis ou verdes e apresentam bandas de absorção eletrônica na região de 600-900 nm. Essas bandas são geralmente assimétricas devido à sobreposição de várias bandas. A Figura 36 mostra o espectro eletrônico da amostra HT-Cu1,2 original (azul) e calcinada a $300^{\circ} \mathrm{C}$ (verde). A banda larga em 700-750 nm, nos dois espectros eletrônicos, é atribuída às transições $d-d$ do $\mathrm{Cu}^{2+}$. $\mathrm{O}$ composto verde apresenta absorção muito mais intensa na região abaixo de $500 \mathrm{~nm}$ que o composto precursor azul. 
Estudo de zeólita ZSM-Cu+2, para uso na decomposição de NO, mostra que no sólido há centros isolados de $\mathrm{Cu}^{2+}$ (parâmetros $\mathrm{g}_{\|}=2,37$ e $\mathrm{A}_{\|}=145 \mathrm{G}$, obtidos dos espectros EPR) e espécie dimérica $\mathrm{Cu}_{2}(\mathrm{OH})_{2}{ }^{2+}$ (hidroxo-pontes) que não apresenta sinal $\mathrm{EPR}^{[98]}$. Quando calcinada a $500^{\circ} \mathrm{C}$ em ar, a amostra se torna verde e, no espectro eletrônico, aprecem bandas em 320 e 440 nm atribuídas à formação de ligações $(\mathrm{Cu}-\mathrm{O}-\mathrm{Cu})^{2+}$. Assim, podemos propor que no presente trabalho, o aquecimento das amostras originais azuis provoca a desidroxilação de octaedros distorcidos vizinhos contendo $\mathrm{Cu}(\mathrm{II})$.A cor verde seria devida à transição de transferência de carga $\mathrm{O}^{2-} \rightarrow \mathrm{Cu}(\mathrm{II})^{[87]}{ }^{[98]}$. Essa proposta corrobora com os estudos de Stanimirova et al. ${ }^{[94]}$ sobre a decomposição térmica da $\mathrm{HT}$, que a $240-260^{\circ} \mathrm{C}$ perde água e formaria uma fase metaestável de composição $\left[\mathrm{Mg}_{6} \mathrm{Al}_{2}(\mathrm{OH})_{12} \mathrm{O}_{2}\left(\mathrm{CO}_{3}\right)\right]$. 


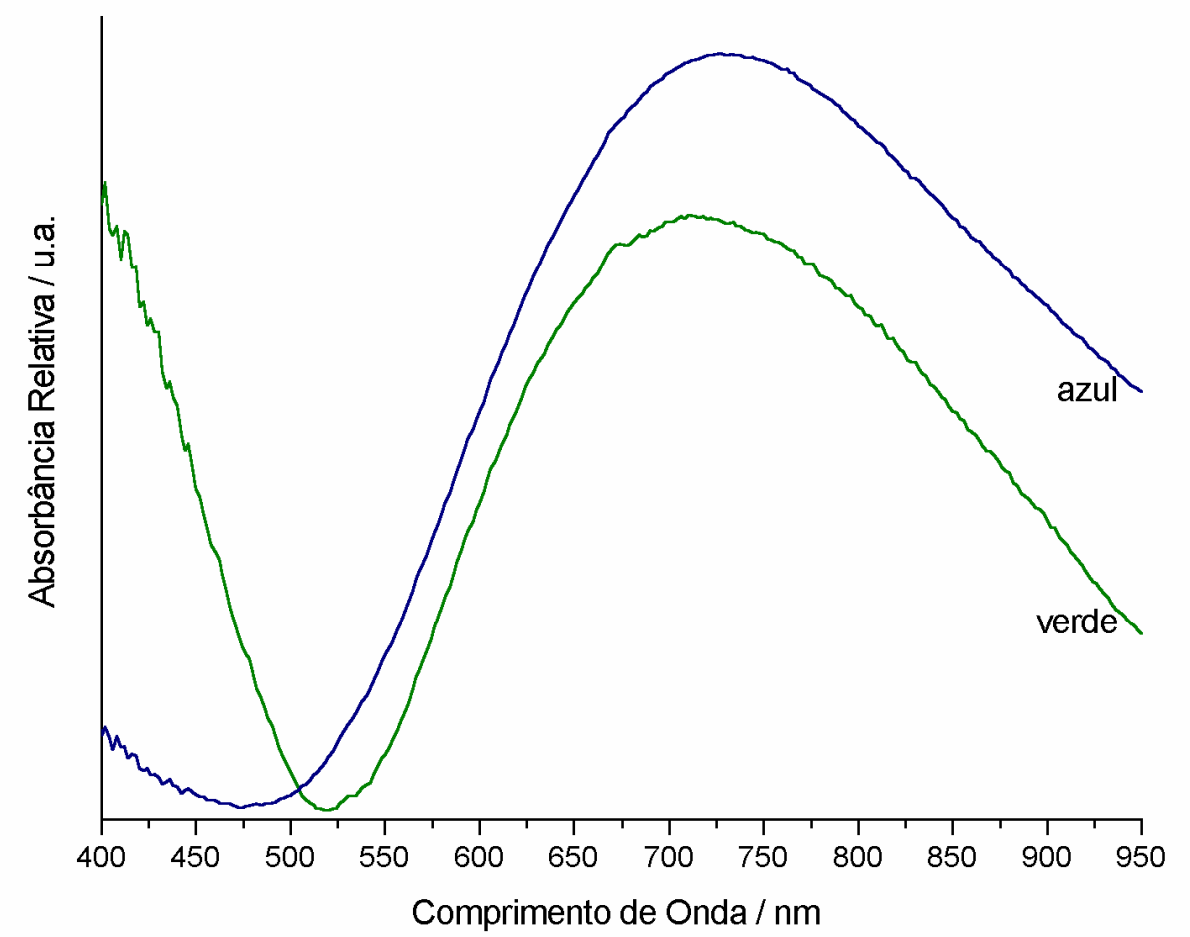

Figura 36 - Espectro eletrônico da amostra HT-Cu1,2 sem tratamento térmico (azul) e aquecida a $300^{\circ} \mathrm{C}$ (verde)

\subsection{Testes Catalíticos de Hidroxilação de Fenol}

Para a realização dos experimentos de reatividade catalítica foram realizados alguns testes preliminares. Primeiramente foram registrados os espectros eletrônicos das três espécies (fenol, catecol e hidroquinona) para a determinação da curva de calibração. Considerando-se que a solução $7.10^{-}$ ${ }^{4} \mathrm{~mol} / \mathrm{L}$ de fenol apresentou absorbância próxima a 1, optou-se por estipular que a concentração de fenol na mistura reacional deveria ser múltipla desse valor a fim de assegurar uma linearidade na absorbância em função da concentração de fenol na solução. A primeira reação, realizada a $60^{\circ} \mathrm{C}$, com concentração de fenol de $3,5.10^{-2} \mathrm{~mol} / \mathrm{L}$, proporções molares de fenol/ $\mathrm{H}_{2} \mathrm{O}_{2}$ e fenol $/ \mathrm{Cu}^{2+}$ iguais a 
1/1 e 35/1 respectivamente, levou à formação de uma mistura composta por uma solução de cor marrom e um precipitado de cor escura. Levando-se em consideração que o interesse inicial nessa reação era justamente a formação de hidroquinona e catecol, de coloração incolor e amarelada quando em solução, concluiu-se que essa primeira condição reacional estava levando a uma posterior oxidação dos produtos formados. O principal produto não esperado inicialmente que poderia estar sendo formado era a p-benzoquinona, produto da oxidação da hidroquinona. Na Figura 37 está representada a estrutura do fenol e dos três produtos obtidos para a reação.
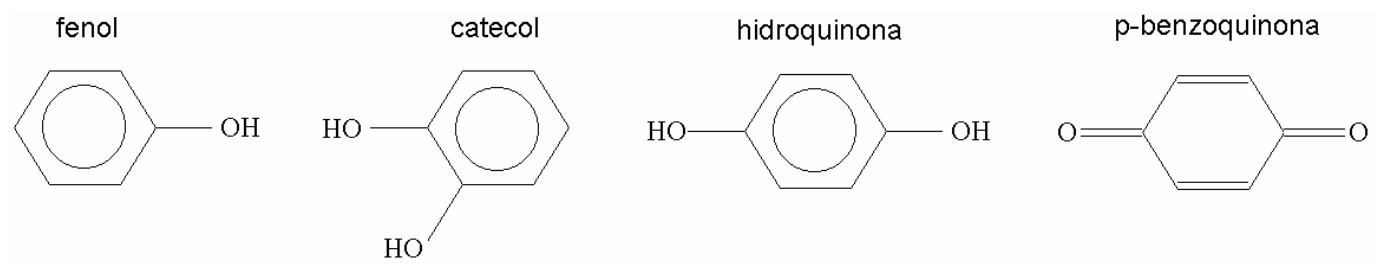

Figura 37 - Estruturas do fenol e dos compostos formados na reação

As quinonas compõem uma classe de compostos orgânicos caracterizados pela presença de ligações $\mathrm{C}=\mathrm{O}$ em anéis insaturados. Estes compostos, quando submetidos a aquecimento, podem polimerizar-se formando cadeias longas o suficiente para a formação de precipitados sólidos, conforme já observado por Dubey et al. ${ }^{[41]}$, referindo-se a tal fenômeno como formação de tar. Esse provavelmente é o principal motivo para a não detecção, ou detecção de valores extremamente baixos, de p-benzoquinona em estudos já publicados envolvendo hidroxilação de fenol monitorados por cromatografia gasosa. Além disso, a p-benzoquinona, em meio aquoso e sob luz, é capaz de clivar as moléculas de água, formando o radical hidroxila ${ }^{[99], ~[100], ~[101] ~}{ }^{\text {Estudos }}$ de foto-decomposição de p-benzoquinona em meio aquoso mostraram que 
diversos compostos podem ser formados. Por esse motivo, todos os demais testes catalíticos foram conduzidos em frascos reacionais cobertos com folhas de alumínio a fim de evitar não apenas a foto-decomposição da $p$ benzoquinona, mas também que os radicais hidroxila, responsáveis pela hidroxilação do fenol, pudessem ser formados pelo mesmo processo fotoquímico.

Além de evitar a foto-decomposição dos produtos formados, optou-se também pelo aumento da proporção fenol/ $\mathrm{Cu}^{2+}$ para $50 / 1$, porém ainda assim foi observada a formação de precipitado marrom e escurecimento da mistura reacional. Levando-se em consideração as dificuldades experimentais impostas pela temperatura de envelhecimento para a síntese dos materiais sem contaminantes, optou-se então pelo abaixamento da temperatura para $40^{\circ} \mathrm{C}$.

Outro fator que influenciou a alteração da temperatura foi o consumo de peróxido de hidrogênio. Conforme observado na Figura 38, para a temperatura de $60^{\circ} \mathrm{C}$, o consumo do peróxido se dá em menos de 40 min, enquanto que a $50^{\circ} \mathrm{C}$, ocorre em aproximadamente $100 \mathrm{~min}$. Levando-se em consideração que o escopo deste trabalho é o estudo da oxidação promovida pelo peróxido de hidrogênio, optou-se então pela temperatura de $40^{\circ} \mathrm{C}$, pois além de ser baixa $\mathrm{o}$ suficiente para não degradar o catalisador, apresentou uma taxa de consumo de $\mathrm{H}_{2} \mathrm{O}_{2}$ satisfatória em um intervalo de tempo razoável. 


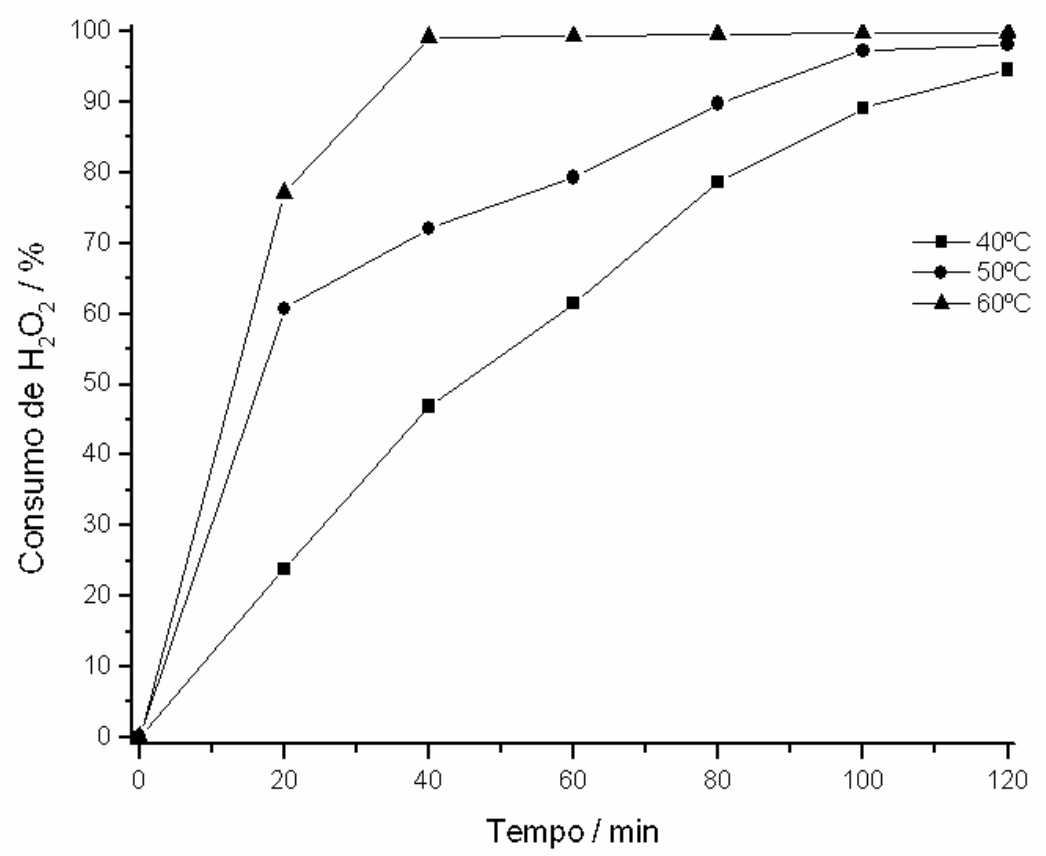

Figura 38 - Curva cinética de consumo de $\mathrm{H}_{2} \mathrm{O}_{2}$ para hidroxilação de fenol com HT-Cu1,5 como catalisador, em diferentes temperaturas

Ao efetuarem-se tais alterações no procedimento experimental, não mais foi observada a formação de precipitado escuro, provavelmente proveniente da polimerização termicamente induzida da p-benzoquinona, além do escurecimento da mistura reacional ocorrer de maneira mais lenta. Com a finalidade de otimizar ainda mais o processo, optou-se por alterar a concentração inicial de fenol, mantendo suas proporções em relação ao catalisador e ao agente oxidante. A diminuição da concentração reacional de $3,5.10^{-2}$ para $3,5.10^{-3} \mathrm{~mol} / \mathrm{L}$ ocasionou uma diminuição na velocidade de escurecimento do meio reacional, alterando o consumo de fenol em menos de $10 \%$ ao longo de 2 horas no caso da matriz HT-Cu1,5. Realizando-se a mesma reação, porém com concentração de fenol de $3,5.10^{-4} \mathrm{~mol} / \mathrm{L}$, observou-se a 
diminuição considerável da velocidade de reação. Portanto, optou-se por utilizar uma concentração de fenol de $3,5.10^{-3} \mathrm{~mol} / \mathrm{L}$ no meio reacional e, para a realização das medidas espectrofotométricas, uma cubeta de quartzo de caminho óptico de $0,1 \mathrm{~cm}$, para suprimir a necessidade de uma diluição, minimizando dessa forma o acúmulo de erro experimental devido à diluição da mistura reacional.

Seguiram-se então a realização dos testes catalíticos para hidroxilação seguindo as seguintes condições reacionais:

- temperatura igual a $40^{\circ} \mathrm{C}$

- concentração de fenol igual a $3,5.10^{-4} \mathrm{~mol} / \mathrm{L}$

- proporção molar fenol/Cu ${ }^{2+}$ igual a 50/1

- proporção molar fenol/ $\mathrm{H}_{2} \mathrm{O}_{2}$ igual a $1 / 1$

- ausência de luz no meio reacional

- tempo de reação de 2 horas

Com o objetivo de estudar a interferência da matriz contendo cobre no processo catalítico e não a influência da quantidade de $\mathrm{Cu}^{2+}$, optou-se por manter constante a quantidade de íons cobre(II) e não a massa de catalisador utilizado. Portanto, na Tabela 15 é mostrada a massa de material utilizado para a reação com $15 \mathrm{~mL}$ de fenol e $\mathrm{H}_{2} \mathrm{O}_{2} 3,5 \cdot 10^{-4} \mathrm{~mol} / \mathrm{L}$. 
Tabela 15 - Massa de cada catalisador utilizada para realização dos testes catalíticos

\begin{tabular}{lc}
\hline Amostra & Massa / mg \\
\hline HT & 6,00 \\
HT-Cu0,3 & 5,43 \\
HT-Cu0,6 & 3,26 \\
HT-Cu0,9 & 2,07 \\
HT-Cu1,2 & 1,75 \\
HT-Cu1,5 & 1,32 \\
HT-Cu1,8 & 0,85 \\
HT-Cu2,1 & 1,02 \\
HT-Cu2,4 & 0,85 \\
HT-Cu2,7 & 0,78 \\
HT-Cu3,0 & 0,87 \\
\hline
\end{tabular}

Em um primeiro instante, a análise dos espectros obtidos experimentalmente gerava valores incoerentes para as concentrações de cada um dos componentes da mistura. Observando-se os espectros eletrônicos obtidos, observava-se um aumento não linear da absorbância na região acima de $320 \mathrm{~nm}$, região na qual, conforme pode ser observado na Figura 39, nenhum dos prováveis componentes absorve. 


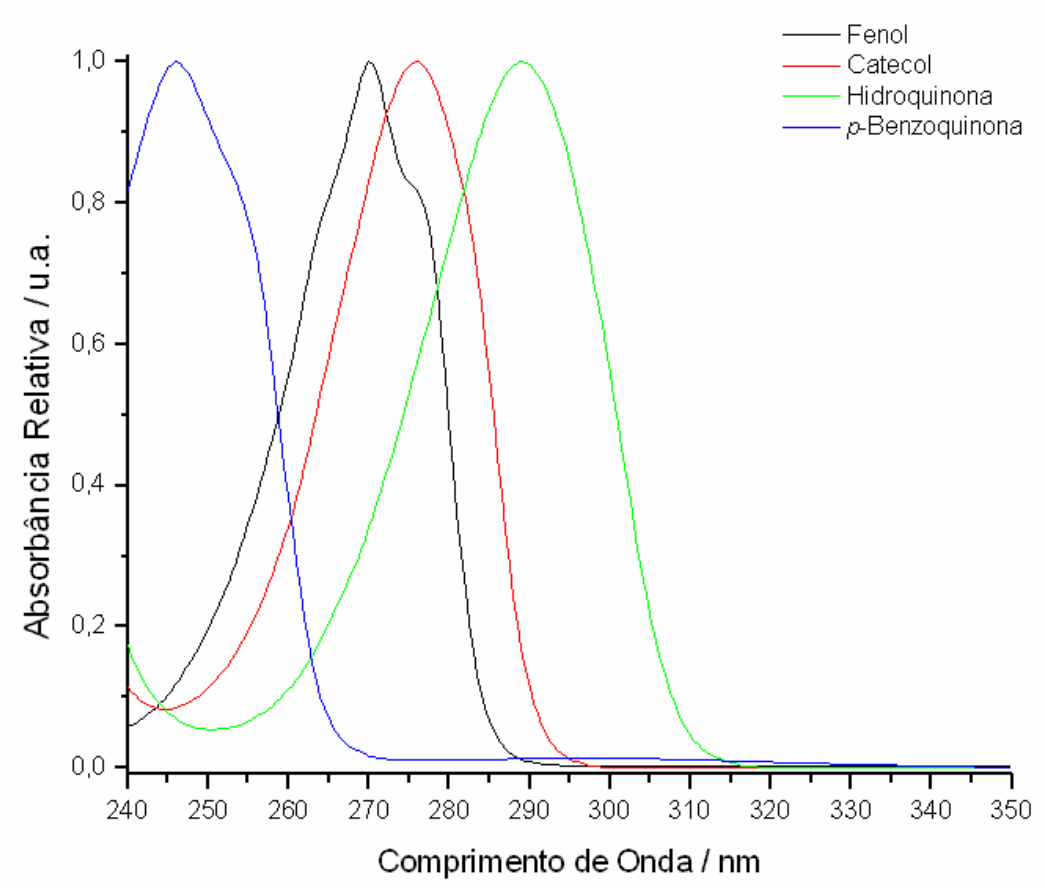

Figura 39 - Espectros eletrônicos de absorção normalizados das prováveis espécies existentes após a reação de hidroxilação do fenol

Considerando-se a ausência de um padrão de comportamento no aumento de absorbância da região acima de 320 nm nem em função do tempo ou da amostra utilizada, cogitou-se a hipótese de tal interferência ocorrer devido à ineficácia do filtro utilizado. Essa hipótese foi confirmada submetendose à filtração uma suspensão composta apenas por uma massa aleatória do catalisador em água deionizada. O espectro eletrônico obtido encontra-se na Figura 40. 


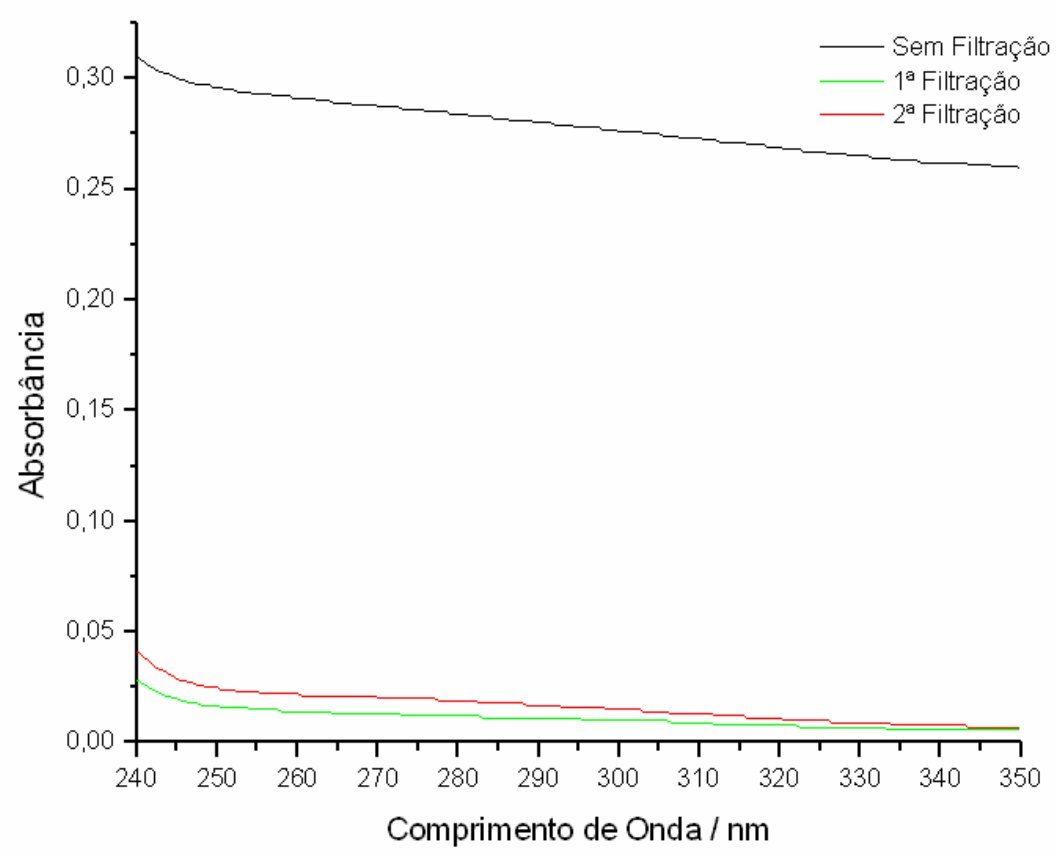

Figura 40 - Espectro eletrônico do filtrado obtido após separação do catalisador com filtro Millipore

Portando, ao efetuar a deconvolução dos espectros eletrônicos obtidos experimentalmente foi necessário incluir um termo referente aos interferentes sólidos $^{[102], ~[103]}$. Levando-se em consideração que é inviável a análise quantitativa do material retido no filtro ou até mesmo da fração sólida que esse não foi capaz de reter, não é possível determinar se o interferente sólido contido no filtrado é composto apenas de HDL ou se é uma mistura de HDL com derivados de $p$-benzoquinona polimerizada.

$\mathrm{Na}$ Figura 41, encontra-se a concentração de cada componente em solução em função do tempo, para o teste realizado com a amostra HT-Cu3,0 como catalisador. 


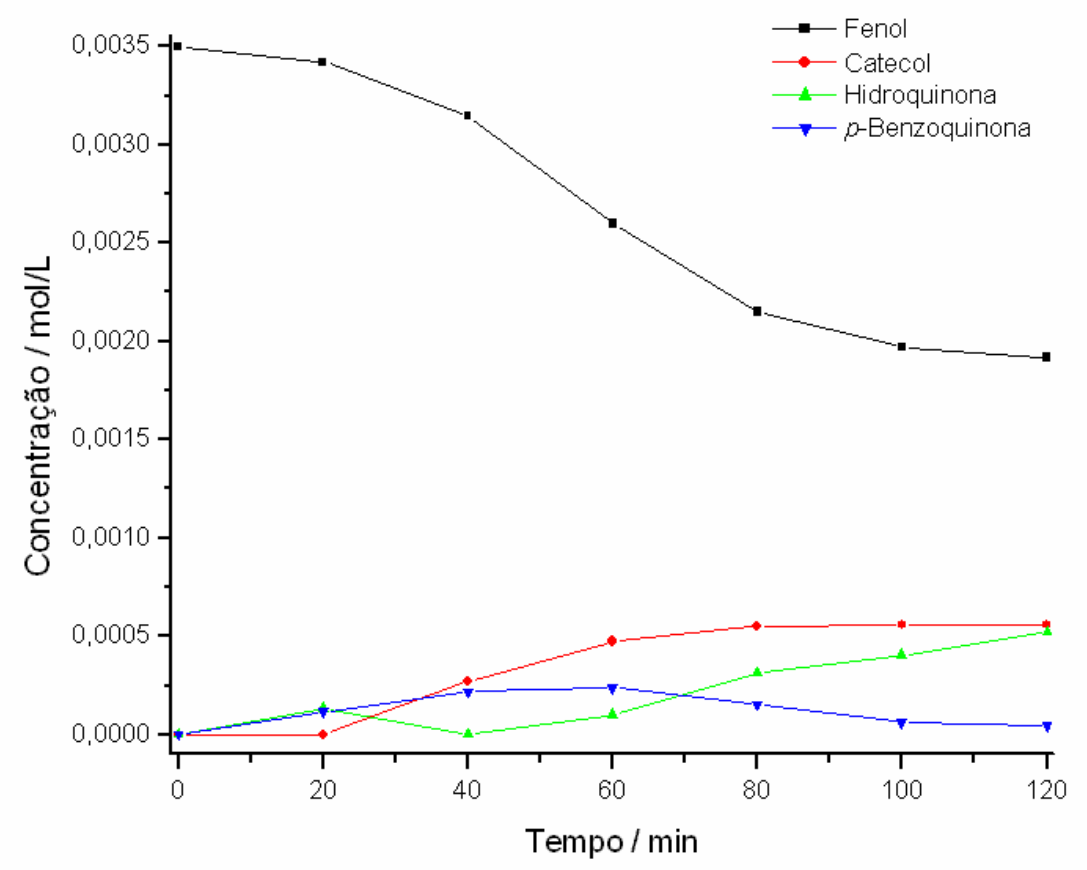

Figura 41 - Concentração dos componentes da mistura reacional em função do tempo, para reação com HT-Cu3,0 como catalisador

Observando-se os resultados dos testes catalíticos realizados, nota-se uma discrepância entre a diferença da soma da concentração dos componentes da solução e a concentração inicial de fenol. Outra observação interessante em tais resultados é a diminuição da concentração de $p$ benzoquinona em função do tempo. Tais fenômenos são explicáveis se for levada em consideração, conforme já discutido, a capacidade das quinonas de sofrerem polimerização termicamente induzida. Portanto, pode-se considerar que a quantidade de p-benzoquinona que sofre polimerização, e por isso não é detectada espectrofotometricamente, é igual à diferença entre as concentrações observadas na solução e a concentração inicial de fenol, conforme listado na Tabela 16. 
Tabela 16 - Concentrações finais obtidas para cada componente

\begin{tabular}{lccccc}
\hline Amostra & $\begin{array}{c}{[\mathrm{fenol}] /} \\
10^{-5} \mathrm{~mol} / \mathrm{L}\end{array}$ & $\begin{array}{c}{[\mathrm{CT}] /} \\
10^{-5} \mathrm{~mol} / \mathrm{L}\end{array}$ & $\begin{array}{c}{[\mathrm{HQ}] /} \\
10^{-5} \mathrm{~mol} / \mathrm{L}\end{array}$ & $\begin{array}{c}{[\mathrm{BQ}] /} \\
10^{-5} \mathrm{~mol} / \mathrm{L}\end{array}$ & $\begin{array}{c}{[\mathrm{BQ}] \mathrm{polim} .} \\
/ 10^{-5} \mathrm{~mol} / \mathrm{L}\end{array}$ \\
\hline HT & 350 & 0,0 & 0,0 & 0,0 & 0,0 \\
HT-Cu0,3 & 299 & 0,0 & 2,46 & 1,24 & 47,3 \\
HT-Cu0,6 & 317 & 0,0 & 3,34 & 1,38 & 28,3 \\
HT-Cu0,9 & 298 & 0,0 & 1,62 & 3,08 & 47,3 \\
HT-Cu1,2 & 211 & 30,6 & 6,02 & 14,0 & 88,4 \\
HT-Cu1,5 & 180 & 54,1 & 35,2 & 8,14 & 72,6 \\
HT-Cu1,8 & 177 & 33,4 & 11,3 & 11,7 & 116 \\
HT-Cu2,1 & 192 & 49,8 & 30,6 & 11,2 & 66,4 \\
HT-Cu2,4 & 179 & 33,2 & 37,6 & 6,16 & 94,0 \\
HT-Cu2,7 & 162 & 47,7 & 51,0 & 4,48 & 84,8 \\
HT-Cu3,0 & 192 & 55,9 & 52,1 & 4,89 & 45,1 \\
\hline
\end{tabular}

Conforme pode ser observado na Figura 42, a porcentagem total de conversão de fenol por quantidade de íons $\mathrm{Cu}^{2+}$ não varia linearmente. Tais dados mostram que, apesar de existir uma tendência do aumento da eficiência do catalisador em função da quantidade de íons cobre(II) presentes, existe uma quantidade limite à partir da qual uma maior quantidade de $\mathrm{Cu}^{2+}$ na matriz não resulta em aumento da eficiência do catalisador.

Lembrando-se que todas as amostras apresentaram valores de área superficial semelhantes, e considerando-se que todo o conteúdo de íons cobre(II) encontra-se homogeneamente distribuído pelo material, é possível entender tal não linearidade na relação entre quantidade de $\mathrm{Cu}^{2+}$ e eficiência do catalisador como uma provável interferência devido à grande proximidade de sítios ativos no material. É interessante ressaltar que os íons $\mathrm{Cu}^{2+}$ mais acessíveis no material são aqueles localizados na superfície externa (ou basal) e nas arestas das partículas do HDL. 


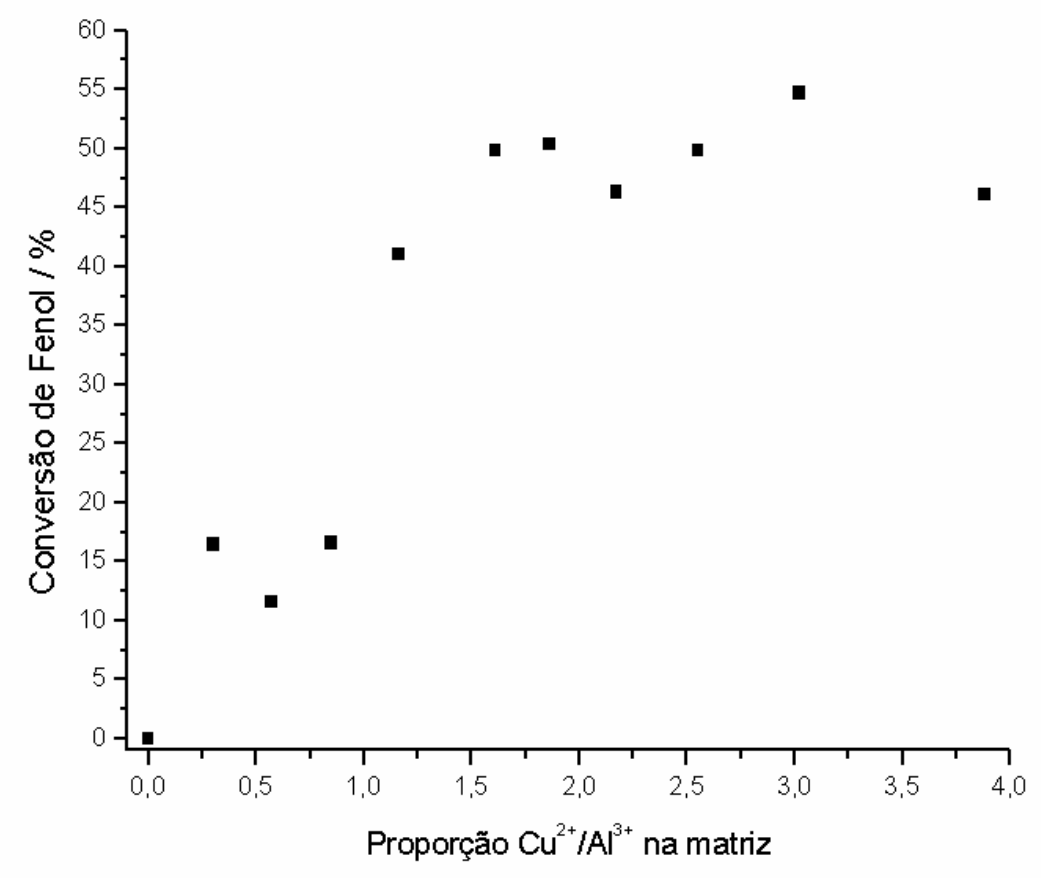

Figura 42 - Porcentagem de conversão de fenol por quantidade de íons $\mathrm{Cu}^{2+}$ presentes no catalisador

Outros dois parâmetros que devem ser levados em consideração na análise dos resultados dos testes catalíticos são: a proporção [catecol]/[hidroquinona] e $\quad[p$-benzoquinona $] /([$ catecol] $+[$ hidroquinona $])$, apresentados na Figura 43. 


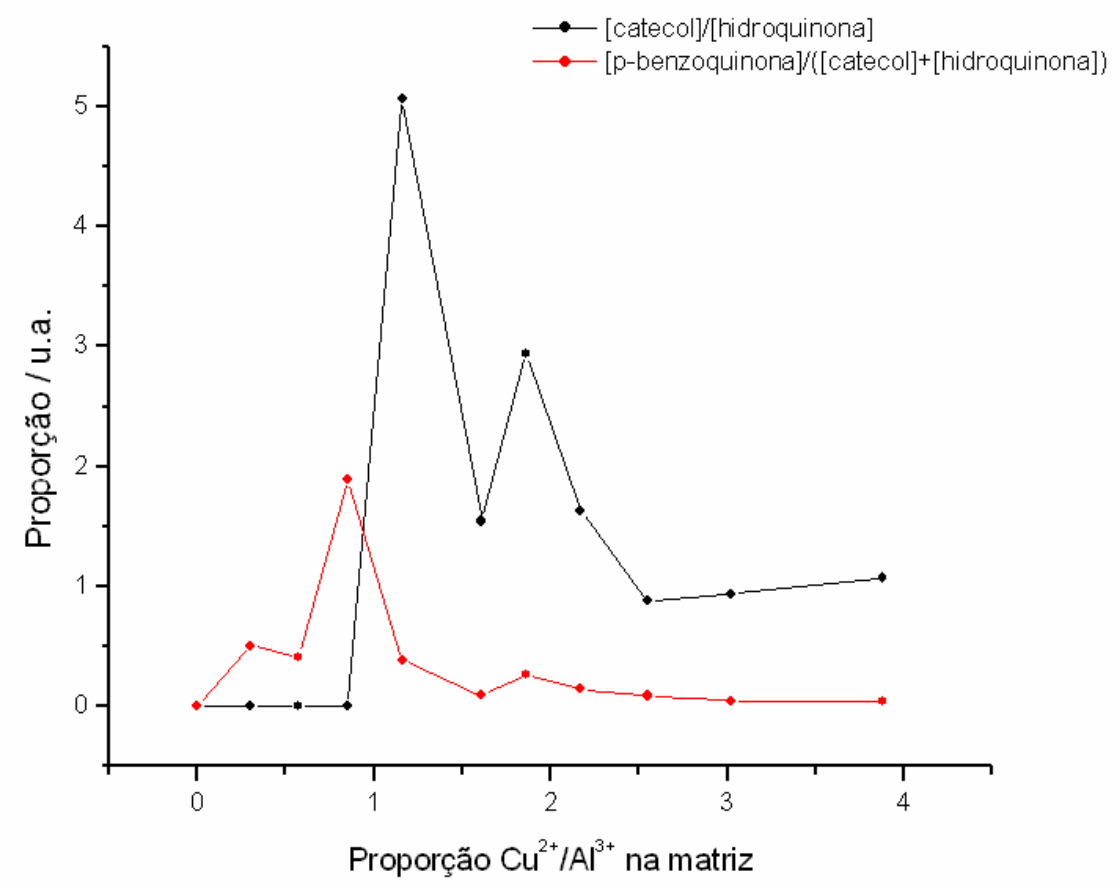

Figura 43 - Proporção dos produtos obtidos em solução na reação de hidroxilação de fenol em função da quantidade de íons $\mathrm{Cu}^{2+}$ no catalisador

De acordo com os resultados, os catalisadores sintetizados levam a uma posterior oxidação dos produtos de hidroxilação de fenol. Pode ser interessante o estudo desses catalisadores não para a produção de catecol e/ou hidroquinona, mas sim para processos de remediação ambiental de efluentes contaminados com fenol.

Atualmente, existem na literatura dois mecanismos propostos para a formação dos radicais hidroxil: através do par redox $\mathrm{Cu}^{2+} / \mathrm{Cu}^{+}$ou $\mathrm{Cu}^{2+} / \mathrm{Cu}^{3+}$. Porém com o estudo realizado nesta Dissertação é inviável fazer qualquer afirmação a favor de uma ou outra proposta.

Finalizando, o método de deconvolução de espectros eletrônicos mostrou-se eficiente para o acompanhamento das reações realizadas, 
confirmando dessa forma suas vantagens em relação aos métodos cromatográficos, particularmente considerando-se a cromatografia gasosa, uma vez que nesse caso suprime-se o aquecimento do analito, evitando-se assim posterior reação ou degradação dos compostos obtidos. É interessante ressaltar que o mesmo filtro utilizado para a filtração da mistura reacional é o comercializado para utilização em equipamentos de cromatografia. Logo, a detecção de partículas em suspensão indica não apenas que o filtro utilizado é inadequado para a filtração, mas também que utilizar equipamentos de cromatografia líquida ou gasosa nessas condições pode danificar a coluna utilizada. 


\section{Conclusões}

Apesar da baixa cristalinidade dos produtos com maior conteúdo de cobre(II), o método da co-precipitação em pH constante conforme a composição e com o envelhecimento feito à temperatura ambiente, mostrou-se eficiente para a obtenção de hidróxidos lamelares contendo grandes quantidades de $\mathrm{Cu}^{2+}$.

Aquecendo-se os materiais sintetizados em temperaturas entre 85 e $300^{\circ} \mathrm{C}$, observa-se a formação de fases nas quais os íons $\mathrm{CO}_{3}{ }^{2-}$ sofrem um abaixamento de simetria, de íon livre $D_{3 h}$ para $C_{2 v}$, característico de íon carbonato monodentado. Conforme se aumenta o conteúdo de íons $\mathrm{Cu}^{2+}$ na matriz, tal abaixamento de simetria necessita de menor temperatura para ocorrer, chegando a ser observado mesmo em temperatura ambiente, para as amostras com maior conteúdo de cobre(II). Tal fato explica a presença da banda $v_{1}$ do carbonato, inativa para o íon livre no infravermelho, em alguns dos espectros registrados. Ainda resta detectar a orientação desse íon carbonato, se este teria sofrido abaixamento de simetria devido à enxertia na lamela ou apenas devido a interações, provavelmente ligações de hidrogênio, com o meio.

$\mathrm{O}$ aquecimento, portanto pode gerar espécies nas quais o íon $\mathrm{CO}_{3}{ }^{2-}$ encontra-se interagindo de maneira mais intensa com a matriz, aumentando desta forma a sua estabilidade térmica, ou seja, dificultando a sua degradação em elevadas temperaturas. Talvez tal interação também esteja relacionada com a coloração diferente para amostras com baixa concentração de $\mathrm{Cu}^{2+}$. $\mathrm{A}$ não observação de tais espécies nos $\mathrm{DRX}$ se deve à baixa cristalinidade de tais fases em relação à das espécies detectadas. A presença de bandas 
atribuídas ao íon carbonato tanto nos espectros de espalhamento Raman quanto FTIR das amostras calcinadas, contribui para a sustentação da hipótese da existência de tais espécies. Porém, nada se pode afirmar acerca das amostras calcinadas a $900^{\circ} \mathrm{C}$ por $1 \mathrm{~h}$, mesmo algumas destas apresentando bandas atribuídas à presença de íons carbonato, uma vez que a medida não foi realizada com aquecimento in situ. Ao expor as amostras à atmosfera, existe a possibilidade do carbonato detectado em tais amostras ser resultante da interação entre espécies reativas da amostra (sítios básico $\mathrm{O}^{2-}$ ) e $\quad \mathrm{o} \quad \mathrm{CO}_{2}$ presente no ar, e não de íons $\mathrm{CO}_{3}{ }^{2-}$ remanescentes do material original.

O uso desses materiais em processos catalíticos de hidroxilação de fenóis utilizando peróxido de hidrogênio como agente oxidante apresentou boa atividade para as amostras contendo íons $\mathrm{Cu}^{2+}$. Como previamente esperado, a amostra HT não apresentou nenhuma atividade, uma vez que o mecanismo para gerar radicais hidroxila a partir do $\mathrm{H}_{2} \mathrm{O}_{2}$ depende da presença de um íon de metal de transição como o cobre(II).

Acerca da seletividade do catalisador, baseando-se nas grandes quantidades de p-benzoquinona formadas a partir da posterior oxidação da hidroquinona, pode-se afirmar que os catalisadores utilizados apresentaram baixa seletividade. Dessa forma, acredita-se que, para utilização desses materiais como catalisadores para a obtenção de catecol e/ou hidroquinona, maiores estudos devem ser realizados, envolvendo não apenas a composição do catalisador, mas também as condições reacionais. 


\section{Perspectivas Futuras}

Para a completa elucidação da estrutura do material sintetizado, principalmente da orientação e motivo do abaixamento de simetria dos íons carbonato, propõe-se a realização de estudos de ressonância magnética

nuclear de ${ }^{23} \mathrm{Al} \mathrm{e}{ }^{13} \mathrm{C}$ que podem ser viáveis, uma vez que a análise de EPR do material mostrou que os íons cobre(II) não apresentam comportamento paramagnético.

Com a finalidade de aprofundar o conhecimento do mecanismo da reação de hidroxilação do fenol usando peróxido de hidrogênio como agente oxidante e poder confirmar um dos mecanismos atualmente sugeridos, propõese efetuar medidas de EPR de alíquotas da reação, adicionadas de capturadores específicos de radicais e congeladas à temperatura de nitrogênio líquido. Acredita-se que a detecção de determinados radicais pode confirmar uma das hipóteses atualmente propostas.

Para melhor compreender as relações entre quantidade de íons cobre(II) na matriz, quantidade desse íon disponível no meio reacional, interferência da matriz e eficiência da reação, propõe-se a realização de testes catalíticos mantendo-se constante não mais a quantidade de íons $\mathrm{Cu}^{2+}$, mas sim a massa de matriz em função da quantidade de substrato.

Outro estudo que é conveniente ser realizado é a comparação da atividade catalítica entre a amostra original com a amostra calcinada em diferentes temperaturas, bem como a possibilidade de se estudar com maior detalhamento a eficiência do catalisador, estudando eventualmente o número de ciclos que este pode ser utilizado de maneira satisfatória e, eventualmente, 
estudar alguma maneira de "reciclar" o catalisador a fim de se verificar a viabilidade da aplicação do uso desse tipo de material em processos industriais.

Recomenda-se também um estudo cujo escopo seja não mais a obtenção de derivados hidroxilados de fenol, mas sim da total degradação desse e até mesmo de outros compostos fenólicos. Tais estudos teriam como objetivo aferir algo acerca da aplicabilidade dos HDLs contendo íons cobre(II) em processos de remediação ambiental, uma vez que as condições reacionais podem ser relativamente brandas e o agente oxidante utilizado, $\mathrm{H}_{2} \mathrm{O}_{2}$, possui a água como único produto de redução.

\section{Referências Bibliográficas}

[1] A. de Roy, C. Forano, K. El Malki e J.P. Besse, Anionic Clays: Trends in Pillaring Chemistry. In: Occelli, M.L. e Robson, H.E. (Eds.). "Expanded Clays and Other Microporous Solids", New York, Van Nostrand Reinhold, 1992, Vol. 2, Cap. 7, p.108-169.

[2] R. A. Schoonheydt, T. Pinnavaia, G. Lagaly e N Gangas, Pure Applied Chemistry, 71 (1999) 2367

[3] Y. Cudennec e A. Lecerf, C. R. Acad. Sci. Paris, Chimie / Chemistry, 4 (2001) 885-891

[4] F. Cavani, F. Trifirò e A. Vaccari, Catalysis Today, 11 (1991) 173-301

[5] W. T. Reichle, Solid State Ionics, 22 (1986)135

[6] F. Trifirò e A. Vaccari, Hydrotalcite-like Anionic Clays (Layered Double Hydroxides). In: Alberti, G. e Bein, T. (eds). "Solid State Supramolecular 
Chemistry: Two and Three-Dimensional Inorganic Networks". In: Atwood J. L. e Lehn, J-M (Eds). "Comprehensive Supramolecular Chemistry", New York, Pergamon, 1996, Vol. 7, Cap. 8, p.251-291.

[7] S. Miyata, Clays and Clay Minerals, 23 (1975) 369

[8] A. Schutz e P. Biloen, Journal of Solid State Chemistry, 68 (1987) 360-366

[9] O. Saber e H. Tagaya, Journal of Inclusion Phenomena and Macrocyclic Chemistry, 45 (2003) 109-116

[10] M. Intissar, J. C. Jumas, J. P. Besse e F. Leroux, Chemistry of Materials, 15 (2003) 4625-4632

[11] M. Intissar, S. Holler, F. Malherbe, J. P. Besse e F. Leroux, Journal of Physics and Chemistry of Solids, 65 (2004) 453-457

[12] I. Rousselot, C. Taviot-Guého, F. Leroux, P. Léone, P. Palvadeau e J. P. Besse, Journal of Solid State Chemistry, 167 (2002) 137-144

[13] U. Costantino, F. Marmottini, M. Nocchetti e R. Vivani, R., European Joural of Inorganic Chemistry, 10 (1998)1439

[14] M. Figlarz, Soft Chemistry: Thermodynamic and Structural Aspects. In: J. Rouxel, M. Tournoux e R. Brec (eds.). "Soft Chemistry Routes to New Materials - Chimie Douce". Materials Science Forum, vol. 152-153, p. 5567, Trans Tech Publications Ltda, 1994.

[15] A. Vaccari, Catalysis Today, 41 (1998) 53-71

[16] A. Vaccari, Applied Clay Science, 14 (1999) 161-198

[17] Y. Seida e Y. Nakano, Water Research, 36 (2002) 1306-1312 
[18] A. I. Khan, L. Lei, A. J. Norquist e D. O'Hare, Chemical Communications, (2001) 2342-2343

[19] M. Z. Hussein, Z. Zainal, A. H. Yahaya e D. W. V. Foo, Journal of Controlled Release, 82 (2002) 417-427

[20] http://www.bayerandina.com, consultado em 12/09/2005

[21] http://www.sud-chemie.com, consultado em 12/09/2005

[22] P.S. Braterman, Z. P. Xu e F. Yarberry, Layered Double Hydroxides (LDHs). In: S. M. Auerbach, K. A. Carrado e P. K. Dutta (eds). "Handbook of Layered Materials", New York, Marcle Dekker, Inc., Cap. 8, p.373-474, 2004.

[23] C. A. S. Barbosa, A. M. C. Ferreira, A. C. V. Coelho e V. R. L. Constantino, Journal of Inclusion Phenomena and Macrocyclic Chemistry, 42 (2002) 1523

[24] C. R. Gordijo, C. A. S. Barbosa, A. M. C. Ferreira, V. R. L. Constantino e D. O. Silva, Journal of Pharmaceutical Sciences, 94 (2005) 1135-1141

[25] D.S. Shriver e P. W. Atkins, Inorganic Chemistry, 3ª edição, University Press, Oxford, 1999.

[26]K. Shimizu, H. Maeshima, A. Satsuma e T. Hattori, Applied Catalysis B: Environmental, 18 (1998) 163

[27] P. W. Park e J. S. Ledford, Applied Catalysis B: Environmental, 15 (1998) 221.

[28] S. Velu, K. Suzuki, M. Okazaki, M. P. Kapoor, T. Osaki e F. Ohashi, Journal of Catalysis, 194 (2000) 373 
[29] I. Bertini, H. B. Gray, S. J. Lippard, J. S. Valentine, "Bioinorganic Chemistry", University Science Books, Sausalito, 1994.

[30] S. Velu, K. Suzuki e T. Osaki, Catalysis Letters, 62 (1999) 159-167

[31] R. P. Grosso Jr., S. L. Suib, R. S. Weber e P. F. Schubert, Chemistry of Materials, 4 (1992) 922-928

[32] E. M. Moujahid, F. Leroux, M. Dubois e J. P. Besse, C. R. Chimie, 6 (2003) 259-264

[33] A. M. Fogg, G. R. Williams, R. Chester e D. O'Hare, Journal of Materials Chemistry, 14 (2004) 2369-2371

[34] F. Li, L. Zhang, D. G. Evans e X. Duan, Colloids and Surfaces A, 244 (2004) 169-177

[35] J. Barrault, A. Derouault, G. Courtois, J. M. Maissant, J. C. Dupin, C. Guimon, H. Martinez e E. Dumitriu, Applied Catalysis A, 262 (2004) 43-51

[36] V. R. Choudhary, D. K. Dumbre, B. S. Uphade e V. S. Narkhede, Journal of Molecular Catalysis A, 215 (2004) 129-135

[37] A. Alejandre, F. Medina, X. Rodriguez, P. Salagre e J. E. Sueiras, Journal of Catalysis, 188 (1999) 311-324

[38] A. Alejandre, F. Medina, X. Rodriguez, P. Salagre, Y. Cesteros e J. E. Sueiras, Applied Catalysis B, 30 (2001) 195-207

[39] K. Bahranowski, R. Dula, M. Gasior, M. Labanowska, A. Michalik, L. A. Vartikian e E. M. Serwicka, Applied Clay Science, 18 (2001) 93-101

[40] L. Zhang, F. Li, D. G. Evans e X. Duan, Materials Chemistry and Physics, 87 (2004) 402-410 
[41] A. Dubey, V. Rives e S. Kannan, Journal of Molecular Catalysis A: Chemical, 181 (2002) 151-160

[42] V. Rives, A. Dubey e S. Kannan, Phys. Chem. Chem. Phys. 3 (2001) 48264836

[43] V. Rives e S. Kannan, J. Mater. Chem., 10 (2000) 489-495

[44] F. Leroux, E. M. Moujahid, H. Roussel, A. M. Flank, V. Briois e J. P. Besse, Clays Clay Miner., 50 (2002) 254.

[45] S. Kannan, T. Venkov, K. Hadjiivanov e H. Knözinger, Lagmuir 20 (2004) 730.

[46] S. Kannan, V. Rives e H. Knozinger, Journal of Solid State Chemistry 177 (2004) 319-331

[47] S. Kannan, A. Dubey e H. Knozinger, Journal of Catalysis, 231 (2005) 381392

[48] Z. Jiang, Z. Hao, J. Yu, H. Hou, C. Hu e J. Su, Catalysis Letters, 99 (2005) 3-4

[49] A. H. Iglesiasa, O. P. Ferreira, D. X. Gouveia, A. G. S. Filho, J. A.C. de Paivab, J. M. Filho, O. L. Alves, Journal of Solid State Chemistry, 178 (2005) 142-152

[50] G. Carja, R. Nakamura e H. Niiyama, Applied Catalysis A: General, 236 (2002) $91-102$

[51] K. Schulze, W. Makowski, R. Chyzy, R. Dziembaj e G. Geismar, Applied Clay Science, 18 (2001) 59-69

[52] Y. Cudennec e A. Lecerf, Solid State Sciences, 5 (2003) 1471-1474 
[53] Ullmann's Encyclopedia, "Industrial Organic Chemicals, Wiley-VCH, New York, vol. 5, p. 2941, 1999.

[54] Ullmann's Encyclopedia, "Industrial Organic Chemicals, Wiley-VCH, New York, vol. 6, p. 3758, 1999.

[55] R.A. Sheldon e R.S. Downing, Applied Catalysis A, 189 (1999) 163-183.

[56] A. L. Villa, C. A. Caro e C. M. de Correa, Journal of Molecular Catalysis A, 228 (2005) 233-240

[57] R. M. Liou, S. H. Chen, M. Y. Hung, H. Mu-Ya, L. Chin-Shan e J. Y. Lai, Chemosphere, 59 (2005) 117-125

[58] J. Wang, J. N. Park, H. C. Jeong, K. S. Choi, X. Y. Wei, S. I. Hong e C. W. Lee, Energy \& Fuels, 18 (2004) 470-476

[59] T. Atoguchi, T. Kanougi, T. Yamamoto e S. Yao, Journal of Molecular Catalysis A, 220 (2004) 183-187

[60] E. E. Kiss, M. M. Lazic e G. C. Boskovic, Reaction Kinetics and Catalysis Letters, 83 (2004) 221-227

[61] J. G. Mei, S. M. Yu e J. Chen, Catalysis Communications, 5 (2004) 437440

[62] J. H. Kim, Y. J. Do, J. H. Park, S. S. Park, S. S. Hong e G. D. Lee, Reaction Kinetics and Catalysis Letters, 83 (2004) 377-383

[63] C. H. Ling, A. R. Abdul e S. Bhatia, Chemosphere, 57 (2004) 547-554

[64] T. Atoguchi e T. Kanougi, Journal of Molecular Catalysis A, 222 (2004) 253-257 
[65] V. Parvulescu, C. Anastasescu e B. L. Su, Journal of Molecular Catalysis A, 211 (2004) 143-148

[66] F. Gao e R. Hua, Applied Catalysis A, 270 (2004) 223-226

[67] M. R. Maurya, H. Saklani, A. Kumar e S. Chand, Catalysis Letters, 93 (2004) 121-127

[68] J. L. Sotelo, G. Ovejero, F. Martinez, J. A. Melero e A. Milieni, Applied Catalysis B, 47 (2004) 281-294

[69] K. Zhu, C. Liu, X. Ye e Y. Wu, Applied Catalysis A: General, 168 (1998) 365-372

[70] S. Letaief, B. Casal, P. Aranda, M. A. Martín-Luengo e E. Ruiz-Hitzky, Applied Clay Science, 22 (2003) 263-277

[71] C. Chen, C. Xu, L. Feng, J. Suo e F. Quu, Chemistry Letters, 34 (2005) 206207

[72] N. Ma, Z. Ma, Y. Yue e Z. Gao, Journal of Molecular Catalysis A, 184 (2002) 361-370

[73] S. Miyata e A. Okada, Clays and Clay Minerals, 25 (1977) 14-18

[74] JCPDS\# 22-700

[75] JCPDS\# 5-0661

[76] B. Bovio e S. Locchi, J. Crystal. Spectr. Res., 12 (1982) 507

[77] Y. Cudennec e A. Lecerf, Solid State Sciences 5 (2003) 1471-1474

[78] S. Miyata, Clays and Clay Minerals, 4 (1983) 305-311

[79] I. Melián-Cabrera, M. L. Granados e J. L. G. Fierro, Phys. Chem. Chem. Phys., 4 (2002) 3122. 
[80] R. L. Frost e K. L. Erickson, Spectrochimica Acta Part A, 60 (2004) 30013005

[81] K. Nakamoto, Infrared and Raman Spectra of Inorganic and Coordination Compounds, 5ª edição, John Wiley \& Sons Inc., New York, 1997.

[82] W. Kagunya, R. Baddour-Hadjean, F. Kooli e W. Jones, Chemical Physics, 236 (1998) 225-234

[83] J. T. Kloprogge, L. Hickey e R. L. Frost, Journal of Raman Spectroscopy, 35 (2004) 967.

[84] E. V. Rybak-Akimova, A. Y. Nazarenko, L. Chen, P. W. Krieger, A. M. Herrera, V. V. Tarasov, P. D. Robinson, Inorganica Chimica Acta, 324 (2001) $1-15$

[85] A. F. Wells, Structural Inorganic Chemistry, 5a. ed., Oxford Clarendon: Oxford, 1987

[86] A. Wolberg e J. F. Roth, Journal of Catalysis, 15 (1969) 250.

[87] T. Yamamoto, T. Tanaka, S. Suzuki, R. Kuma, K. Teramura, Y. Kou, T. Funabiki e S. Yoshida, Topics in Catalysis, 18 (2002) Nos. 1-2

[88] JCPDF\#80-1917

[89] JCPDF\#99-0098

[90] JCPDF\#21-0540

[91] R. L. Frost, Z. Ding, J. T. Kloprogge, W. N. Martens, Termochimica Acta, 309 (2002) 133-144

[92] J. T. Kloprogge, Infrared and Raman Spectroscopy of Naturally Occurring Hydrotalcites and Their Synthetic Equivalents, em J. T. Kloprogge, The 
Application of Vibrational Specstrocopy to Clay Minerals and Layered Double Hydroxides, The Clay Minerals Society, Aurora, 2005, Volume 13

[93] S. Velu e C. S. Swamy, Journal of Materials Science Letters, 15 (1996) 1674-1677

[94] T. S. Starminova, I. Vergilov, G. Kirov e N. Petrova, Journal of Materials Science, 34 (1999) 4153-4161

[95] S. Kannan, V. Rives e H. Knözinger, Journal of Solid State Chemistry, 177 (2004) 319-331

[96] J. T. Kloprogge, L. Hickey e R. L. Frost, Applied Clay Science 18 (2001) $37-49$

[97] F. A. Cotton e G. Wilkinson, Advanced Inorganic Chemistry, 5a. ed., John Wiley e Sons, 1988, New York,

[98] G. D. Lei, B. J. Adelman, W. M. H. Sachtler, Applied Catalysis B:

Environmental, 5 (1995) 245-256

[99] K. C. Kurien e P. A. Robins, Physi. Org., (1970) 855-859

[100] A. I. Ononye, A. R. Mclntosh e J. R. Bolton, Journal of Physical Chemistry, 90 (1986) 6266-6270

[101] A. I. Ononye e J. R. Bolton, Journal of Physical Chemistry, 90 (1986) $6270-6274$

[102] O. Thomas e S. Gallot, Fresenius Journal of Analytical Chemistry, 338 (1990) 234-237

[103] O. Thomas, F. Theraulaz, C. Agnel e S. Suryand, Environmental Technology, 17 (1996) 251-261 


\section{Anexo A - Método para Deconvolução de Curvas}

A espectroscopia eletrônica está baseada na medida da transmitância ou absorbância de um determinado (ou um conjunto) de comprimento de onda. A capacidade de uma amostra de absorver uma determinada radiação eletromagnética é diretamente proporcional à sua concentração e ao caminho óptico percorrido pela radiação, conforme a Lei de Lambert-Beer para soluções de apenas uma espécie:

$$
A=\varepsilon \cdot b \cdot C
$$

onde $\mathrm{E}$ é a absortividade molar da espécie absorvente, $\mathrm{C}$ é a sua concentração e b é o comprimento do caminho óptico. No caso de soluções contendo duas ou mais substâncias, a lei de Lambert-Beer pode ser reescrita da seguinte forma:

$$
A=\Sigma \varepsilon_{n} \cdot C_{n} \cdot b
$$

A espectroscopia eletrônica é uma técnica de caracterização não invasiva, rápida e de custo extremamente baixo. Por não promover nenhuma mudança de estado físico na amostra a ser analisada nem, em alguns casos, diluições, esta é uma técnica branda e com erro experimental minimizado, que pode ser uma das técnicas possíveis para a quantificação dos produtos formados em reações de hidroxilação de fenol ${ }^{1}$.

Uma dificuldade na utilização da espectroscopia eletrônica neste caso é o fato dos principais produtos formados serem incolores, forçando que seja utilizada a região do ultravioleta. Nesta região, porém, as bandas de absorção dos compostos formados se sobrepõem, impossibilitando uma análise direta do

\footnotetext{
${ }^{1}$ B. Roig, C. Gonzalez, O. Thomas, Spectrochimica Acta Part A, (2002)
} 
espectro obtido. Para superar esta limitação é necessário fazer uso de técnicas matemáticas que se baseiam no princípio de absorção de Lambert-Beer para "separar" todas as bandas características de cada um dos componentes de uma mistura, num processo denominado deconvolução. Uma vez separadas as bandas, é possível então quantificar cada um dos componentes da mistura ${ }^{[2],[3]}$.

Existem diversos métodos capazes de solucionar este problema, porém o método aparentemente mais adequado é o método dos mínimos quadrados parciais, que basicamente consiste em selecionar alguns comprimentos de onda para transformar a lei de Lambert-Beer em um conjunto de $n$ equações com $n$ incógnitas.

Portanto, no desenvolvimento desse estudo, para a deconvolução das curvas obtidas através da espectroscopia eletrônica na região do ultravioleta foi utilizado o método dos mínimos quadrados ${ }^{[4], ~[5]}$. Este método resulta em equações com as quais é possível calcular a concentração de cada um dos $n$ componentes de uma mistura em $m$ comprimentos de onda. Através deste método é possível também quantificar, e até mesmo eliminar do espectro, ruídos causados por espécies interferentes, como partículas sólidas, por exemplo.

\footnotetext{
${ }^{2}$ V. Cerdà, J. M. Estela, R. Forteza, A. Cladera, E. Gómez e M. T. Oms, International Journal of Environmental Analytical Chemistry, 52 (1993) 159-178

${ }^{3}$ S. Gallot e O. Thomas, International Journal of Environmental Analytical Chemistry, 52 (1993) $149-158$

${ }^{4}$ H. A. Barnett e A. Bartoli, Analytical Chemistry, 32 (1960) 1153-1156

${ }^{5}$ A. Höskuldsson, Journal of Chemometrics, 2 (1988) 211-228
} 
Para a utilização deste método é necessário que se tenha em mãos cada uma das substâncias que compõe a mistura a ser analisada para que possam ser feitas as respectivas curvas de calibração. Uma vez determinadas as curvas de calibração para cada uma das espécies, pode-se então obter a absortividade molar $\varepsilon_{n}(\lambda)$ para cada comprimento de onda $\lambda$ e cada componente $n$.

Determinados os $\varepsilon_{n}(\lambda)$, pode-se então determinar os comprimentos de onda que serão utilizados para se efetuarem os cálculos. Diversas metodologias para a seleção destes já foram estudadas ${ }^{[6]}$, porém a selecionada no caso do presente estudo foi o método de Ranking, que consiste em eleger, para cada componente $n$ da mistura, o comprimento de onda com menor interferência e maior informação sobre este, seguindo a equação abaixo:

$$
r_{i}(\lambda)=\varepsilon_{i}(\lambda) /\left(\sum_{i=1}^{n} \varepsilon_{i}^{2}(\lambda)\right)^{1 / 2}
$$

onde o maior valor para $r_{i}(\lambda)$ representa o comprimento de onda $\lambda$ onde existe maior informação acerca do composto $i$. O gráfico gerado pelo método de ranking para os compostos estudados segue na Figura 44.

[6] I. Y. Bershtein, Fresenius Z Anal Chem, 332 (1988), 227-231 


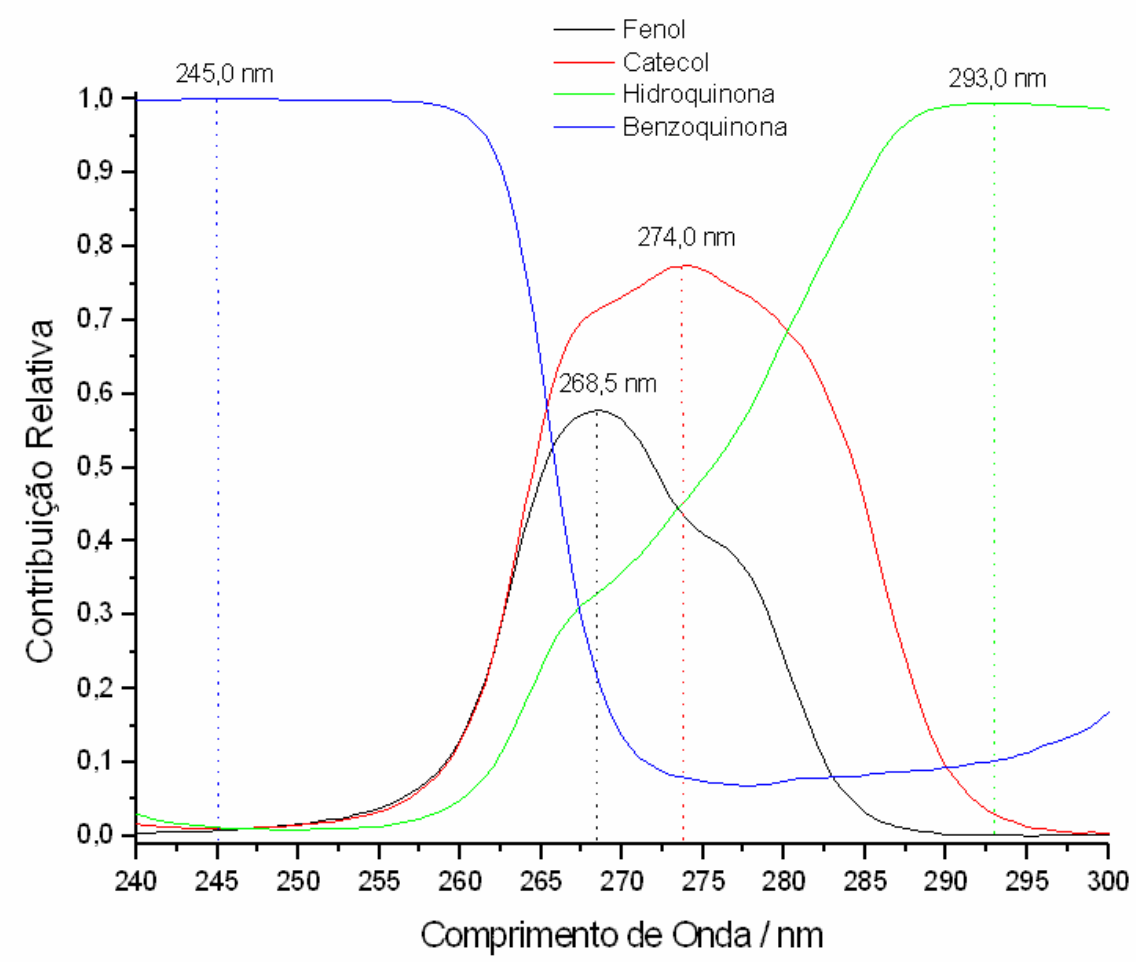

Figura 44 - Gráfico resultante do método de ranking

Uma vez selecionados os $m=n$ comprimentos de onda que serão utilizados, é possível então estabelecer o sistema de equações a partir do qual serão calculadas as concentrações:

$$
\begin{aligned}
& A(\lambda)=\sum_{i=1}^{n} C_{i} \cdot \varepsilon_{i}(\lambda) \Leftrightarrow \\
& \left(\begin{array}{llll}
\varepsilon_{1}\left(\lambda_{1}\right) & \varepsilon_{2}\left(\lambda_{1}\right) & \varepsilon_{3}\left(\lambda_{1}\right) & \varepsilon_{4}\left(\lambda_{1}\right) \\
\varepsilon_{1}\left(\lambda_{2}\right) & \varepsilon_{2}\left(\lambda_{2}\right) & \varepsilon_{3}\left(\lambda_{2}\right) & \varepsilon_{4}\left(\lambda_{2}\right) \\
\varepsilon_{1}\left(\lambda_{3}\right) & \varepsilon_{2}\left(\lambda_{3}\right) & \varepsilon_{3}\left(\lambda_{3}\right) & \varepsilon_{4}\left(\lambda_{3}\right) \\
\varepsilon_{1}\left(\lambda_{4}\right) & \varepsilon_{2}\left(\lambda_{4}\right) & \varepsilon_{3}\left(\lambda_{4}\right) & \varepsilon_{4}\left(\lambda_{4}\right)
\end{array}\right) \cdot\left(\begin{array}{l}
C_{1} \\
C_{2} \\
C_{3} \\
C_{4}
\end{array}\right)=\left(\begin{array}{l}
A\left(\lambda_{1}\right) \\
A\left(\lambda_{2}\right) \\
A\left(\lambda_{3}\right) \\
A\left(\lambda_{4}\right)
\end{array}\right)
\end{aligned}
$$

Uma vez calculadas as concentrações de cada um dos componentes, e possuindo um espectro de referência de cada um dos componentes, é possível calcular o espectro eletrônico para praticamente qualquer mistura feita a partir dos compostos considerados, sendo que o erro atribuído aos cálculos pode ser 
definido como o desvio padrão da diferença entre a curva obtida experimentalmente e a curva calculada.

No caso estudado, os componentes da mistura foram: fenol, catecol, hidroquinona e $p$-benzoquinona. Devido à grande diferença existente entre os valores máximos de absortividade molar destes compostos, para o cálculo foram utilizados espectros normalizados como referência, ou seja:

$$
A_{i}^{\prime}(\lambda)=\frac{A_{i}(\lambda)}{\varepsilon_{i} \cdot C^{\prime \prime}{ }_{i}} \therefore A_{i}^{\prime}(\lambda)=\frac{\varepsilon_{i}(\lambda)}{\varepsilon_{i}}
$$

Onde $C{ }^{\prime}{ }_{i}$ é a concentração da solução utilizada para a obtenção do espectro $A_{i}(\lambda)$ a ser normalizado e $\varepsilon_{i}$ é o valor máximo de $\varepsilon_{i}(\lambda)$. Desta maneira, o sistema a ser solucionado passa a ser:

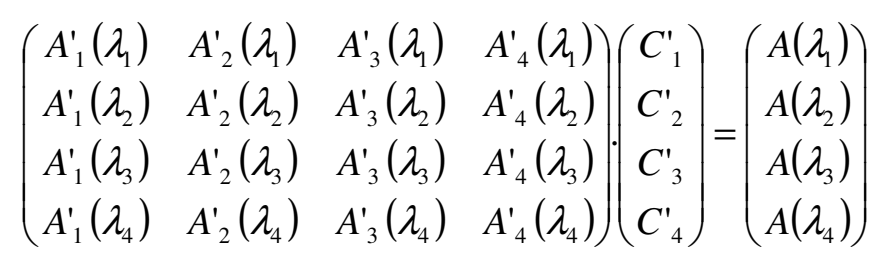

Onde $A_{i}^{\prime}(\lambda)$ é o valor da absorbância normalizada do composto $i$ no comprimento de onda $\lambda$ e $C^{\prime}{ }_{i}$ é a contribuição do espectro eletrônico normalizado de $i$ no espectro eletrônico obtido experimentalmente. Logo, a partir dos valores de $C^{\prime}{ }_{i}$ é possível calcular as concentrações reais de cada componente na mistura, uma vez que:

$$
C_{i}=C^{\prime}{ }_{i} \cdot \varepsilon_{i}
$$

Portanto, constantes utilizadas para a deconvolução dos espectros eletrônicos presentes neste estudo são as que se encontram listadas na Tabela 17 abaixo: 
Tabela 17 - Constantes $A_{i}^{\prime}(\lambda)$ e $\varepsilon_{l}$ utilizadas para cálculo de concentração

\begin{tabular}{ccccc}
\hline $\begin{array}{c}\text { Comprimento } \\
\text { de Onda }-\lambda\end{array}$ & Fenol & Catecol & Hidroquinona & Benzoquinona \\
\hline $245,0 \mathrm{~nm}$ & 0,103 & 0,083 & 0,079 & 0,992 \\
$268,5 \mathrm{~nm}$ & 0,955 & 0,758 & 0,292 & 0,024 \\
$274,0 \mathrm{~nm}$ & 0,848 & 0,978 & 0,489 & 0,012 \\
$293,0 \mathrm{~nm}$ & 0,004 & 0,031 & 0,936 & 0,013 \\
\hline$\varepsilon_{i}$ & 1395,8 & 2212,1 & 2572,9 & 21012,1 \\
\hline
\end{tabular}

Tomemos como exemplo uma mistura contendo a seguinte composição $6,5 \times 10^{-4} \mathrm{~mol} / \mathrm{L}$ de fenol, $4,0 \times 10^{-4} \mathrm{~mol} / \mathrm{L}$ de catecol, $9,5 \times 10^{-4} \mathrm{~mol} / \mathrm{L}$ de hidroquinona e $2,0 \times 10^{-4} \mathrm{~mol} / \mathrm{L}$ de benzoquinona. De acordo com o método acima descrito, temos que:
$C^{\prime}{ }_{1}=0,090$
$C_{2}^{\prime}=0,086$
$C_{3}^{\prime}=0,257$
$C^{\prime}{ }_{4}=0,422$

Logo o espectro eletrônico esperado para tal mistura seria o representado na Figura 45 abaixo, juntamente com o espectro obtido experimentalmente. 


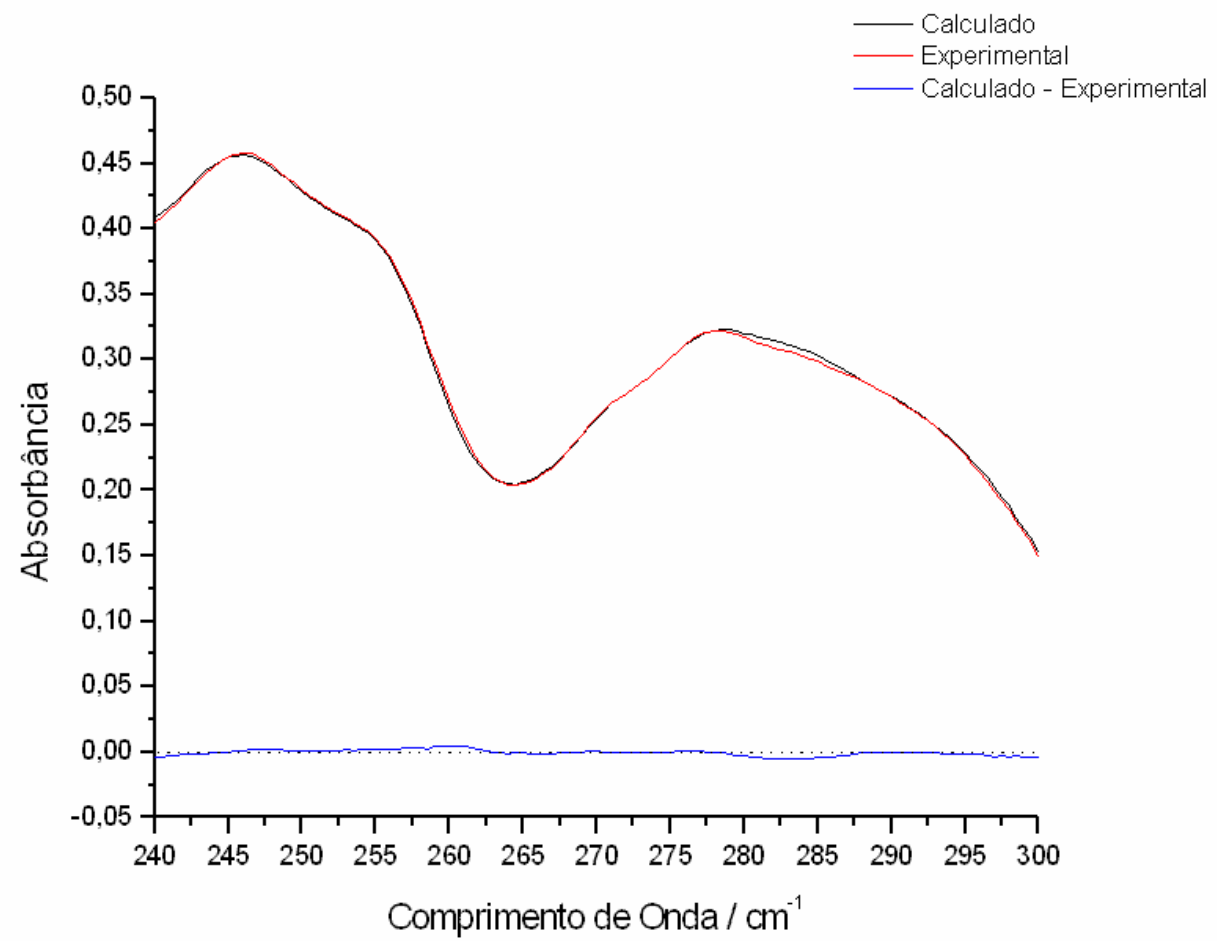

Figura 45 - Espectro eletrônico experimental e simulado para uma mistura conhecida Efetuando-se a deconvolução do espectro eletrônico obtido experimentalmente, obtêm-se as seguintes concentrações para cada um dos componentes da solução: $6,45.10^{-4} \mathrm{~mol} / \mathrm{L}$ de fenol, $3,89.10^{-4} \mathrm{~mol} / \mathrm{L}$ de catecol, $9,34 \cdot 10^{-4} \mathrm{~mol} / \mathrm{L}$ de hidroquinona e $2,01 \cdot 10^{-4} \mathrm{~mol} / \mathrm{L}$ de $p$-benzoquinona.

O resultado obtido tanto se calculando a provável curva do espectro eletrônico da mistura quanto a deconvolução das curvas apresentaram uma boa congruência com o obtido experimentalmente. 



\section{Anexo B - Espectros de Espalhamento Raman}

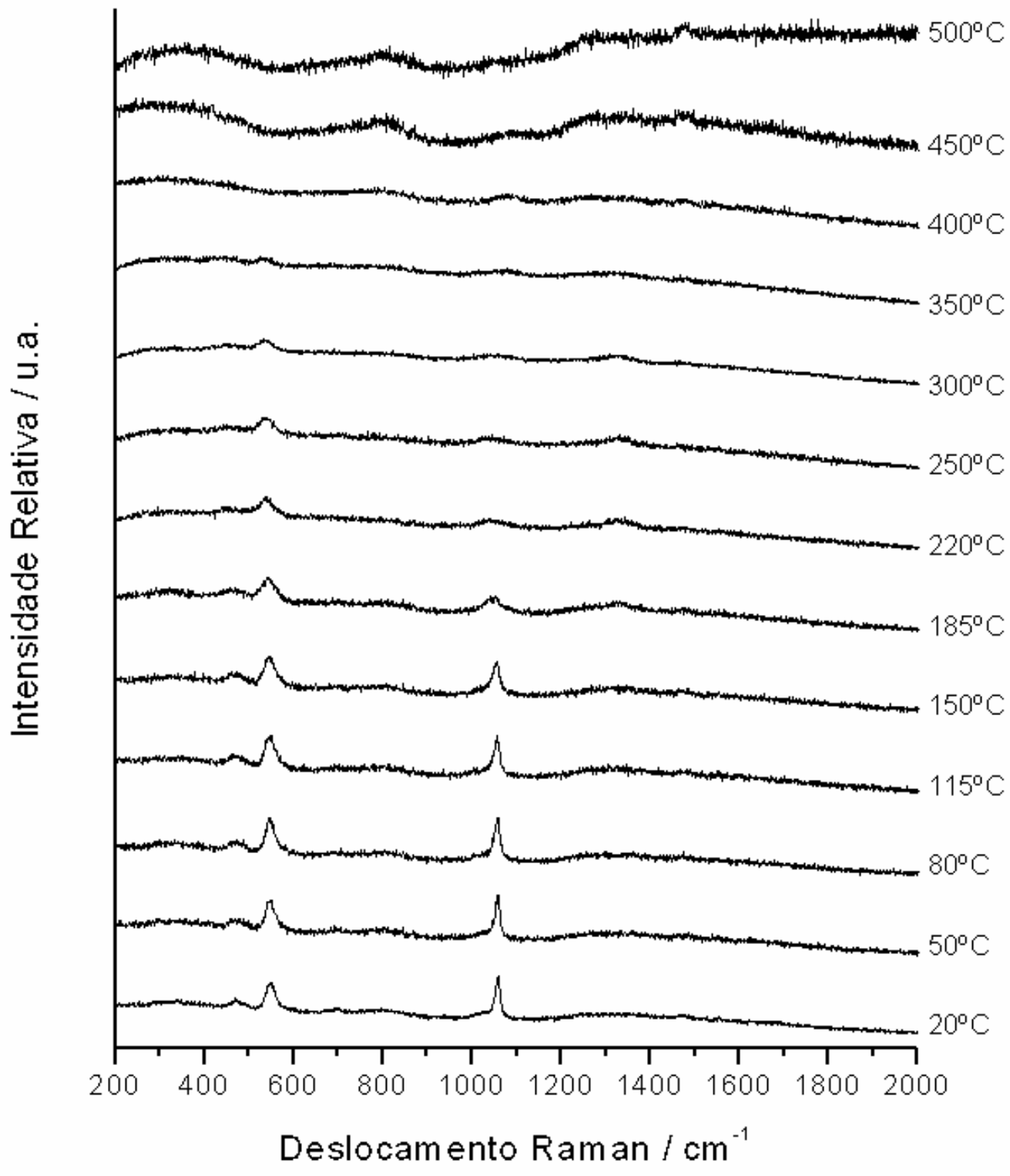

Figura 46 - Espectro de Espalhamento Raman da amostra HT calcinada em diferentes temperaturas 


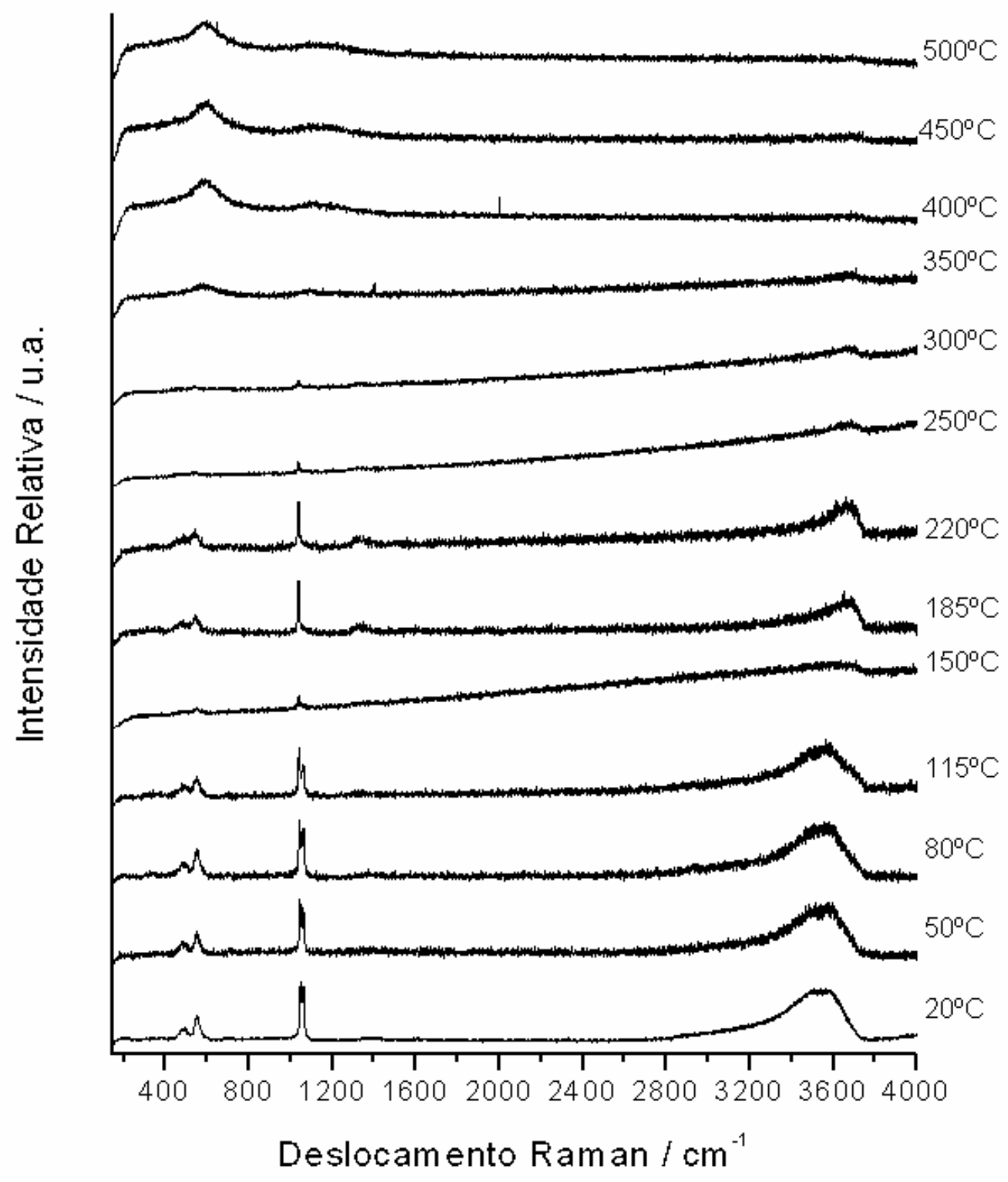

Figura 47 - Espectro de Espalhamento Raman da amostra HT-Cu0,3 calcinada em diferentes temperaturas 


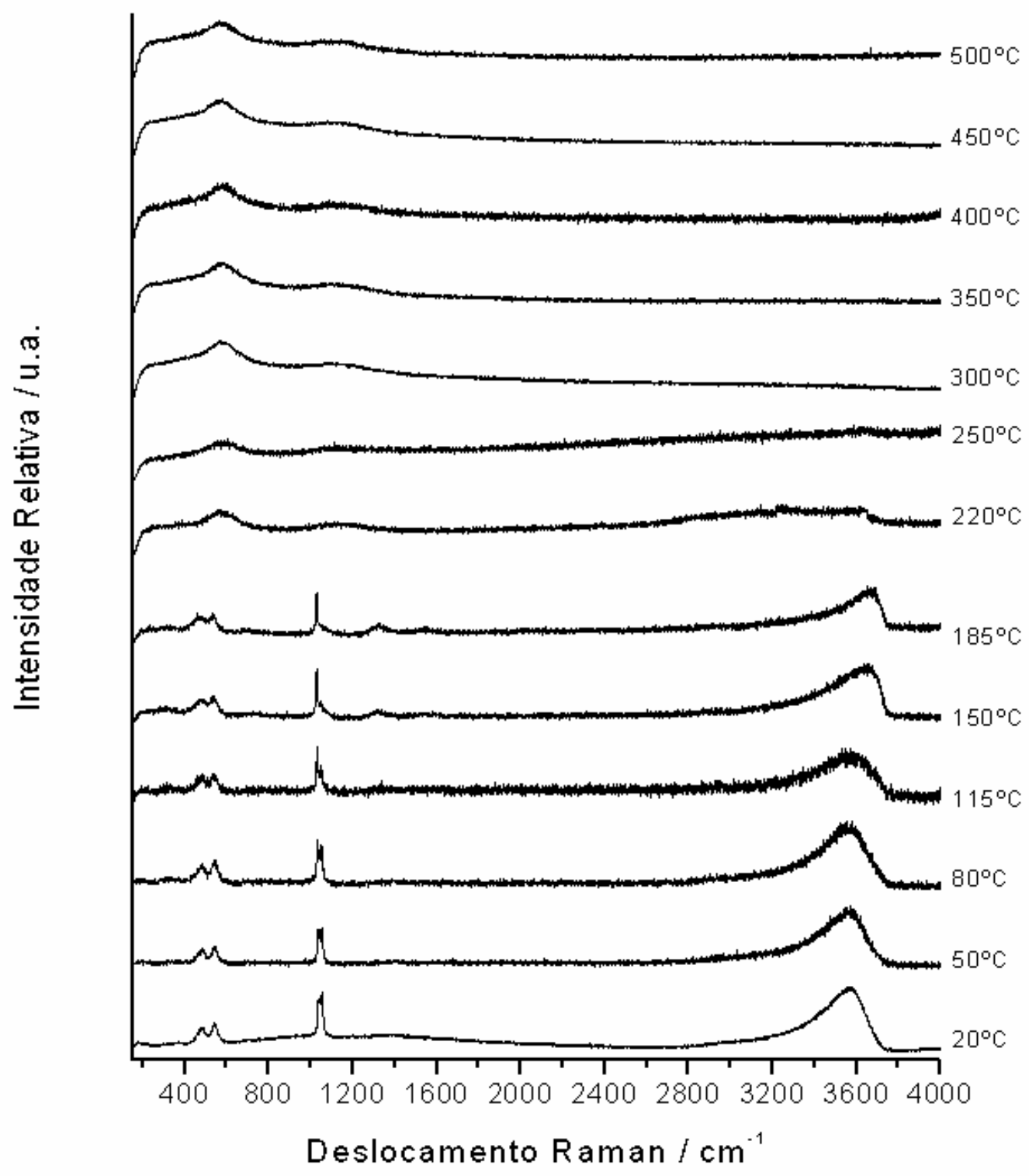

Figura 48 - Espectro de Espalhamento Raman da amostra HT-Cu0,6 calcinada em diferentes temperaturas 


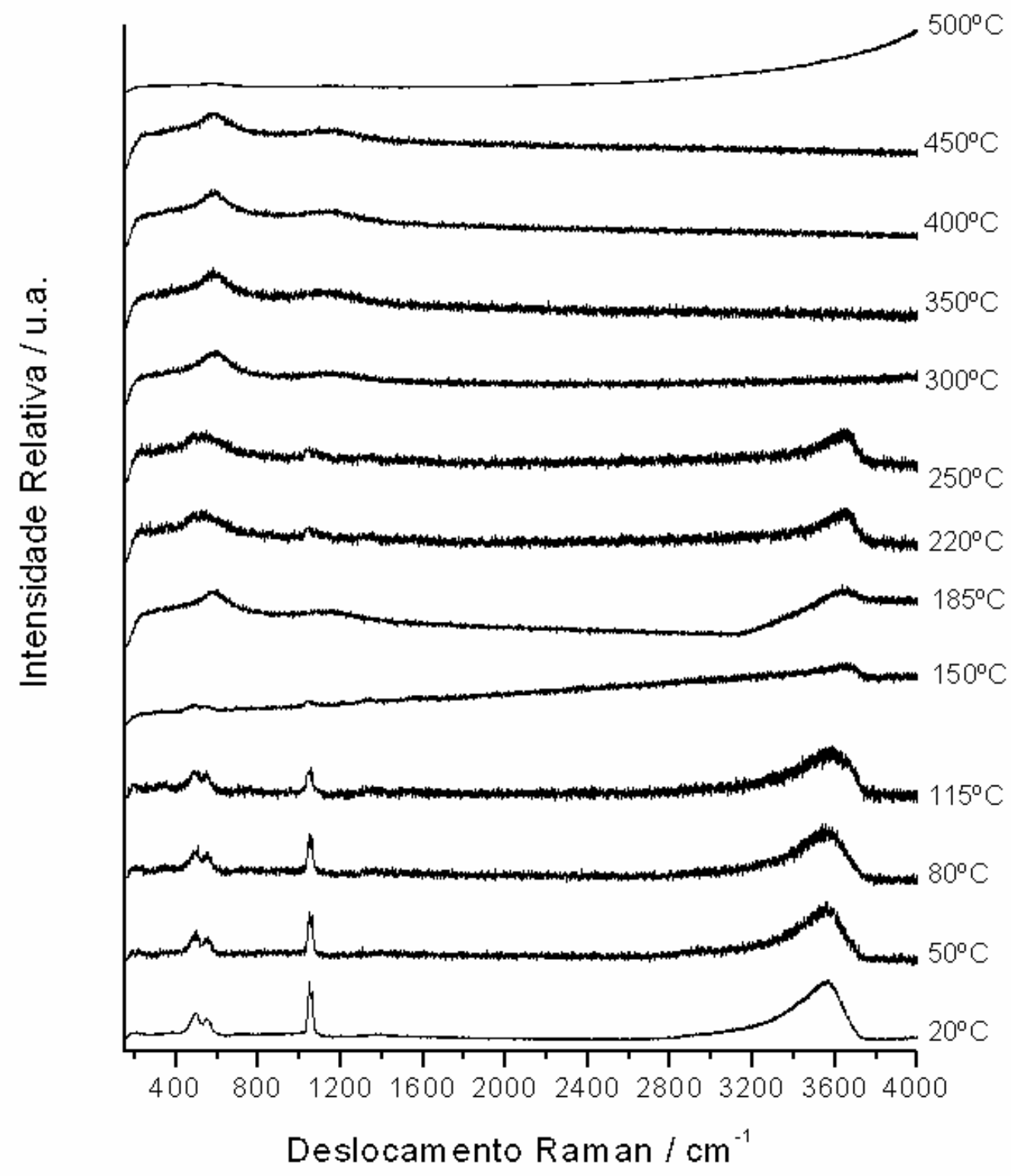

Figura 49 - Espectro de Espalhamento Raman da amostra HT-Cu0,9 calcinada em diferentes temperaturas 


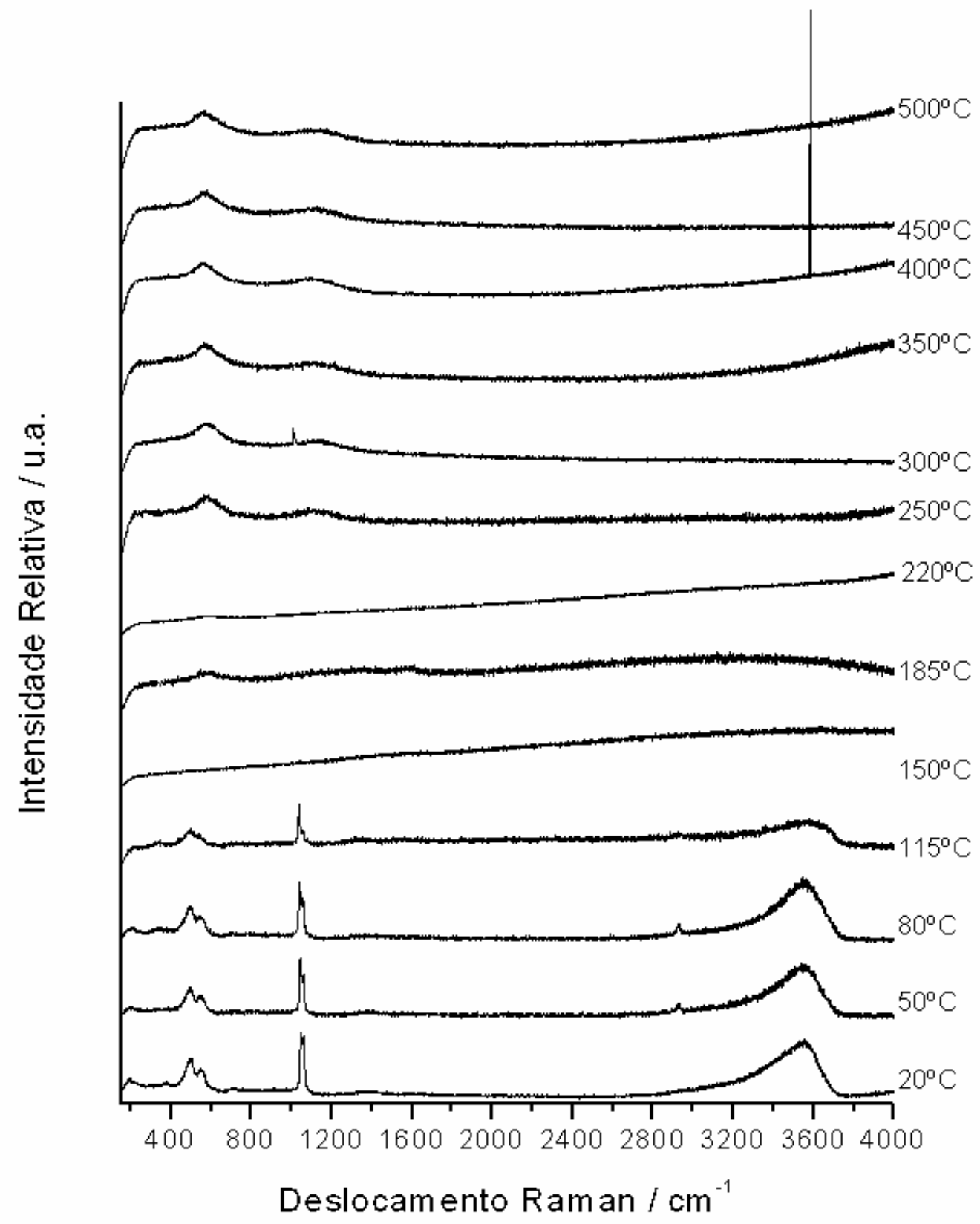

Figura 50 - Espectro de Espalhamento Raman da amostra HT-Cu1,2 calcinada em diferentes temperaturas 


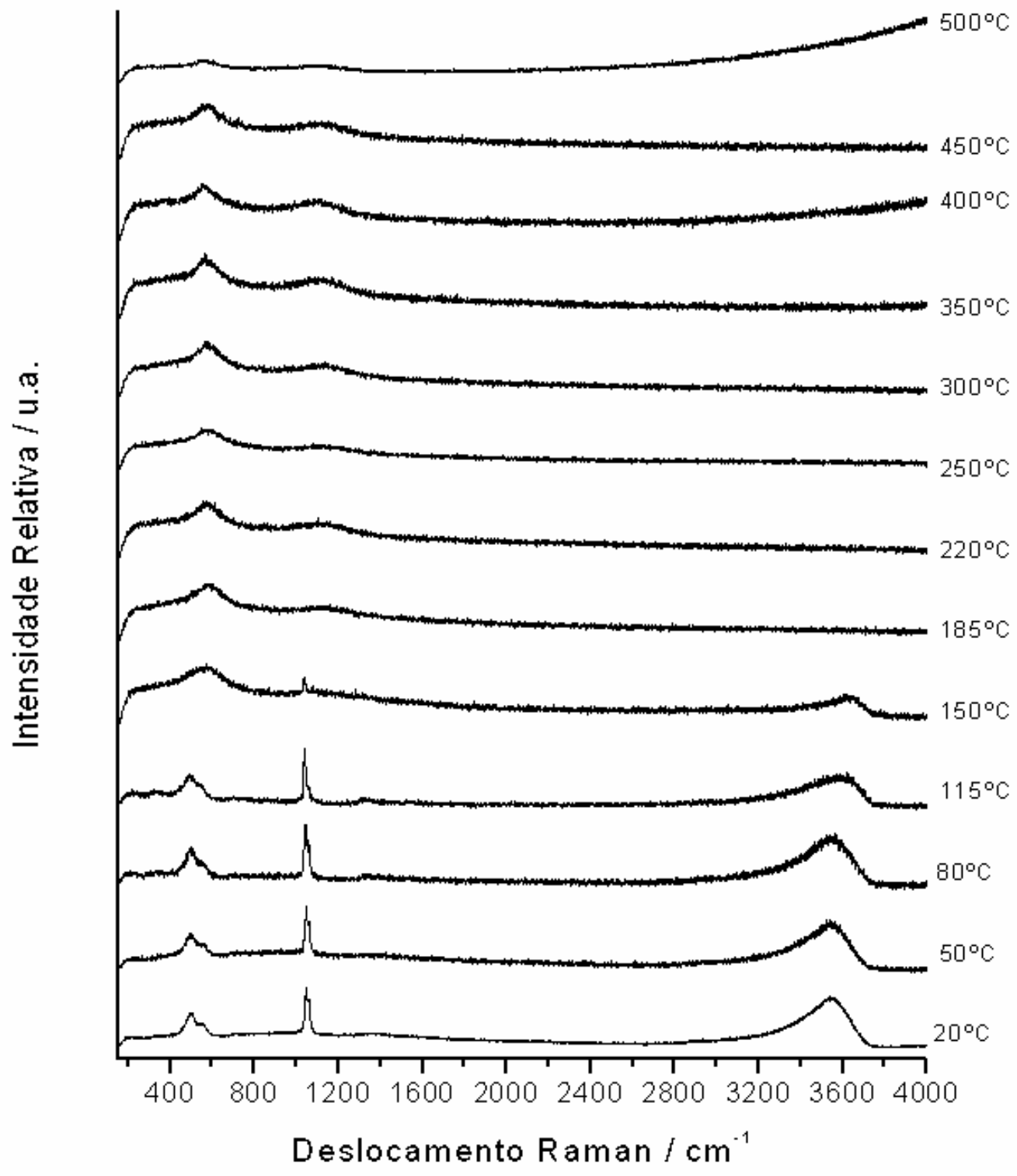

Figura 51 - Espectro de Espalhamento Raman da amostra HT-Cu1,5 calcinada em diferentes temperaturas 


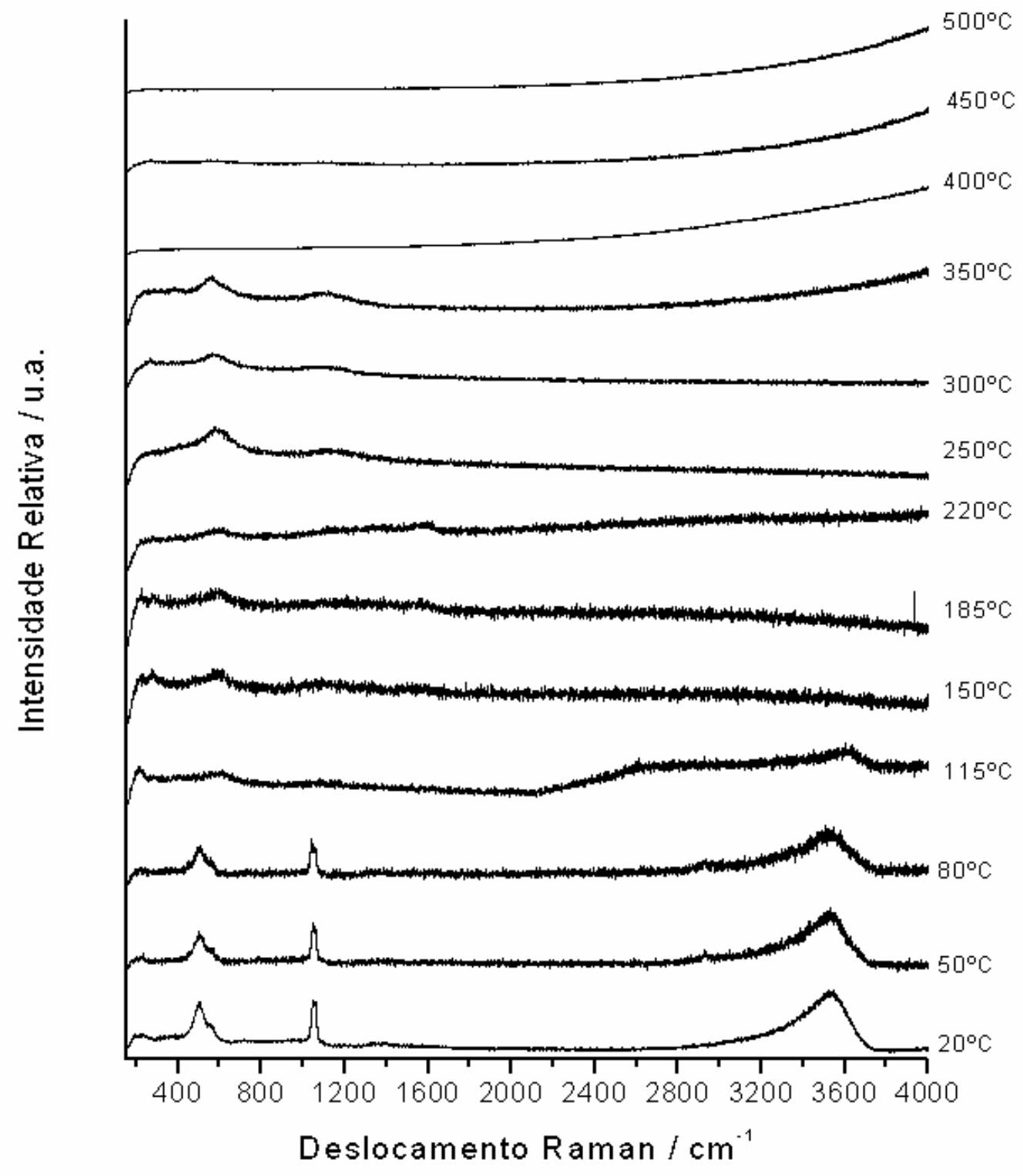

Figura 52 - Espectro de Espalhamento Raman da amostra HT-Cu1,8 calcinada em diferentes temperaturas 


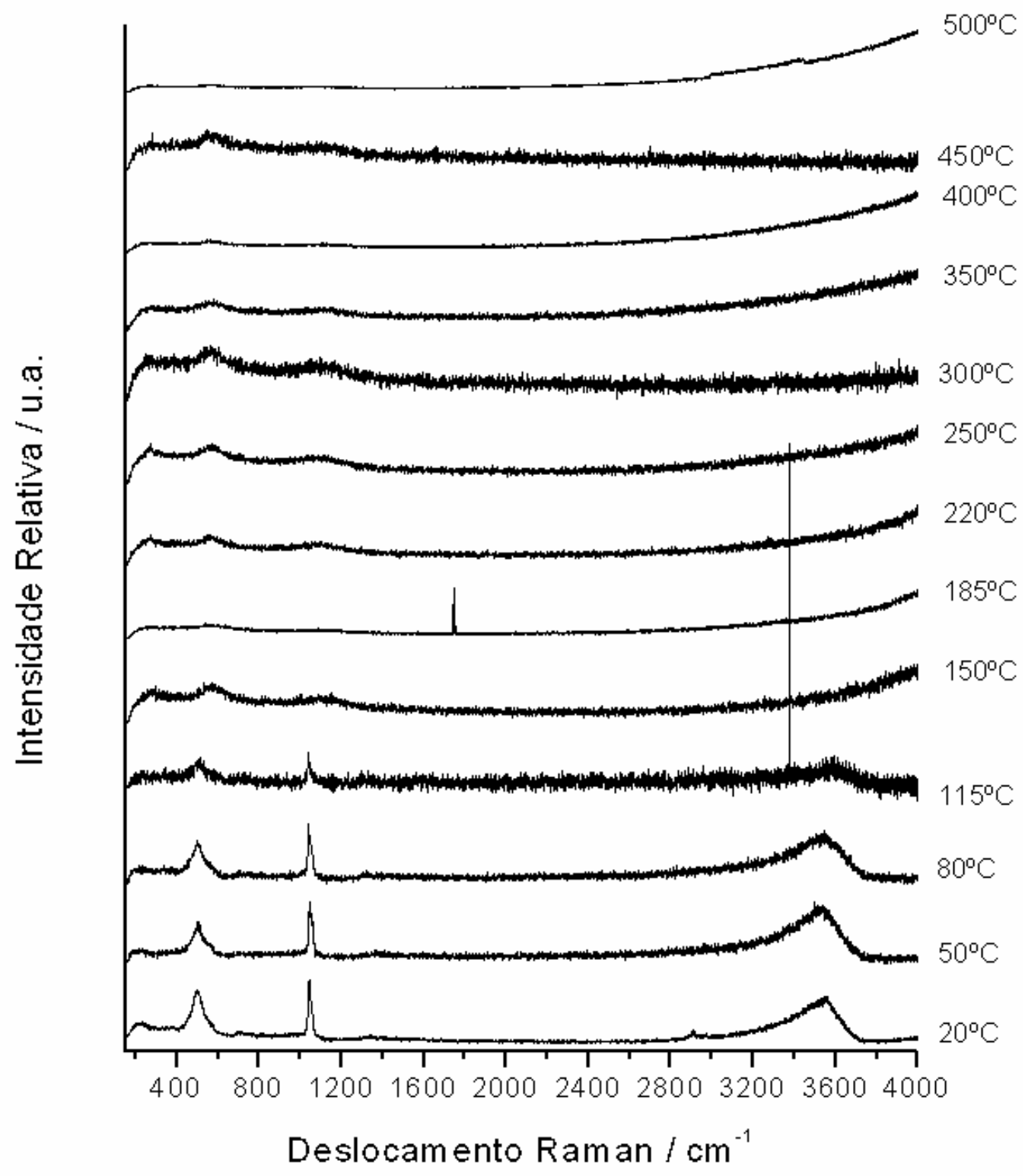

Figura 53 - Espectro de Espalhamento Raman da amostra HT-Cu2,1 calcinada em diferentes temperaturas 


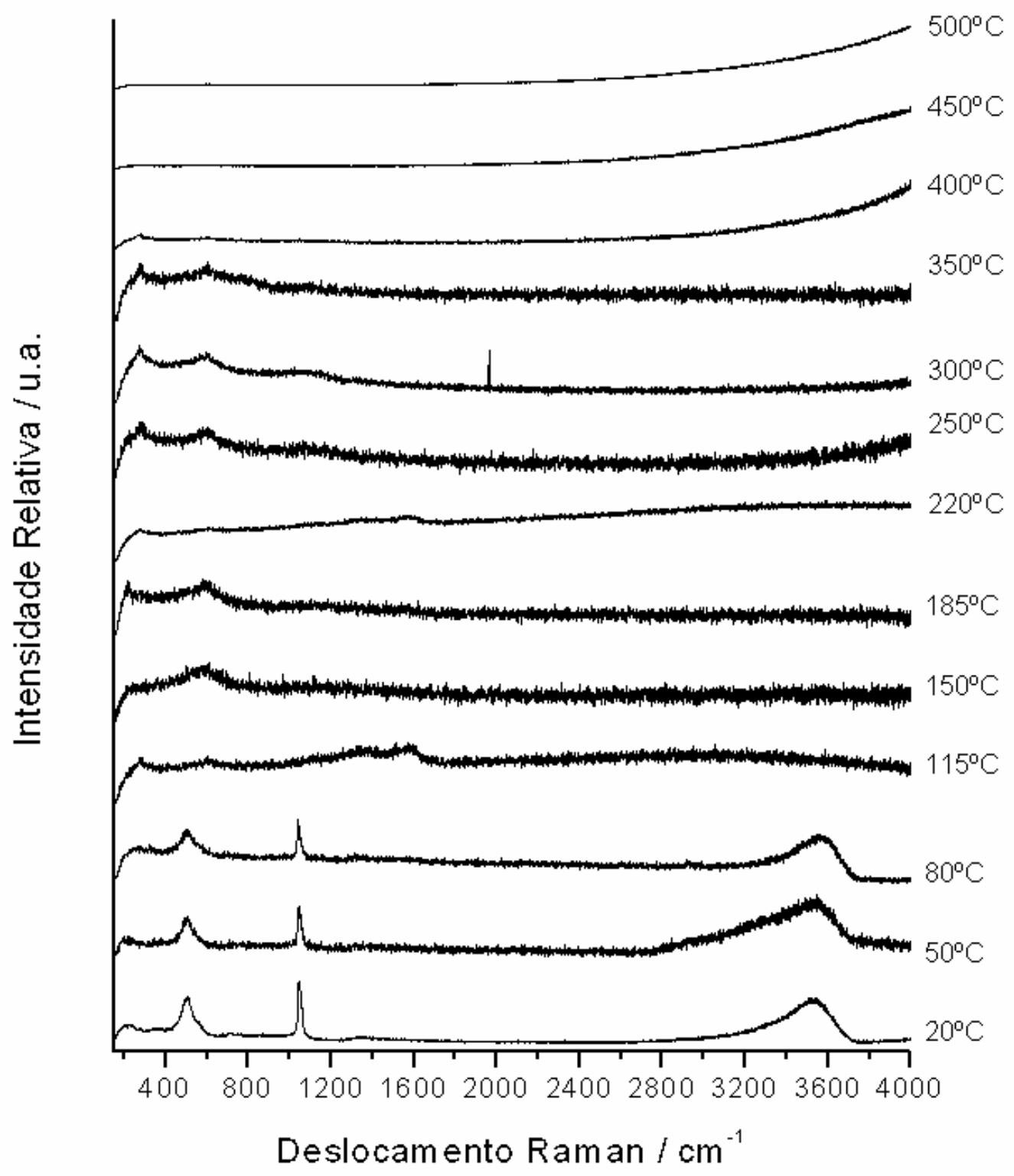

Figura 54 - Espectro de Espalhamento Raman da amostra HT-Cu2,4 calcinada em diferentes temperaturas 


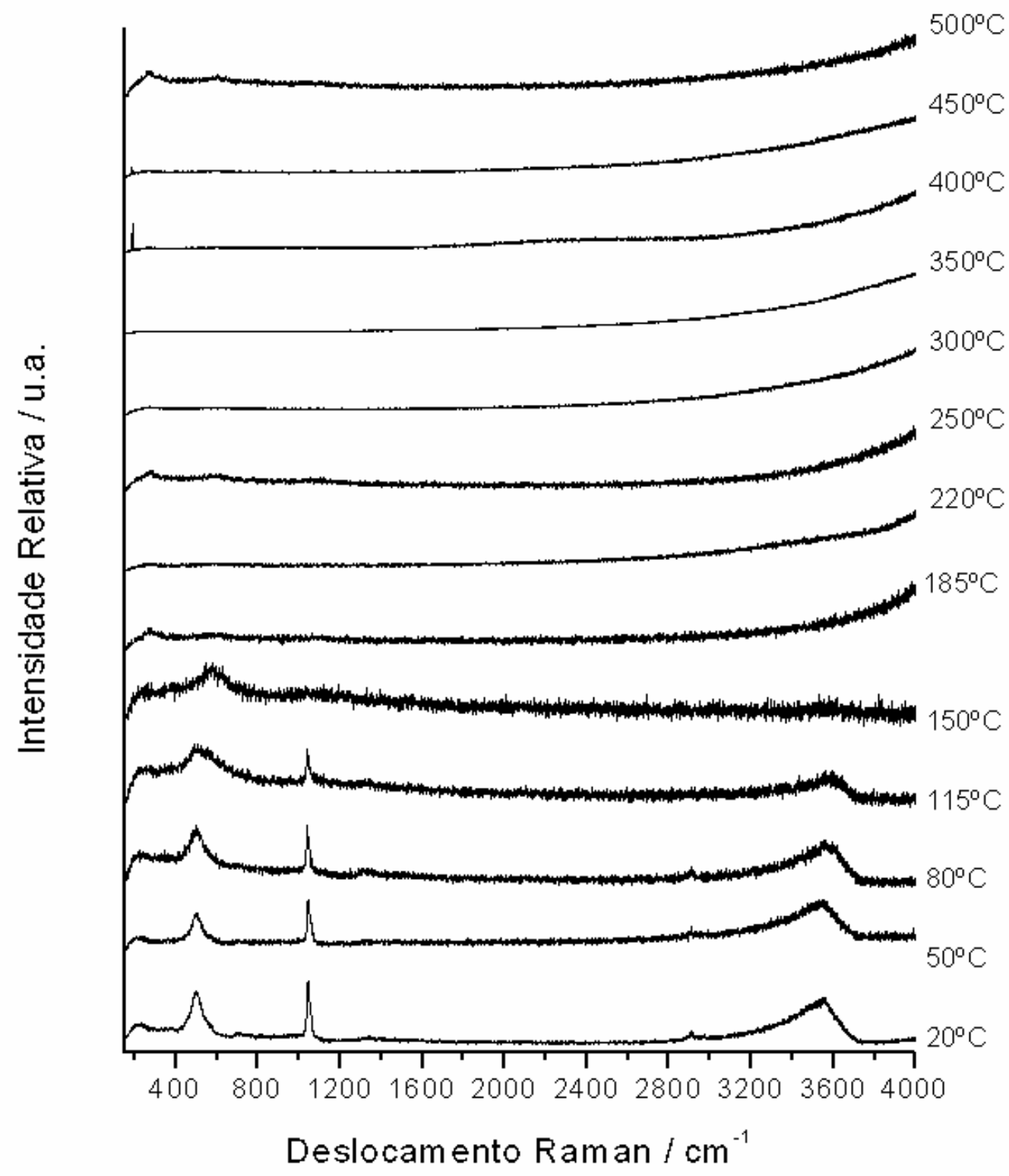

Figura 55 - Espectro de Espalhamento Raman da amostra HT-Cu2,7 calcinada em diferentes temperaturas 


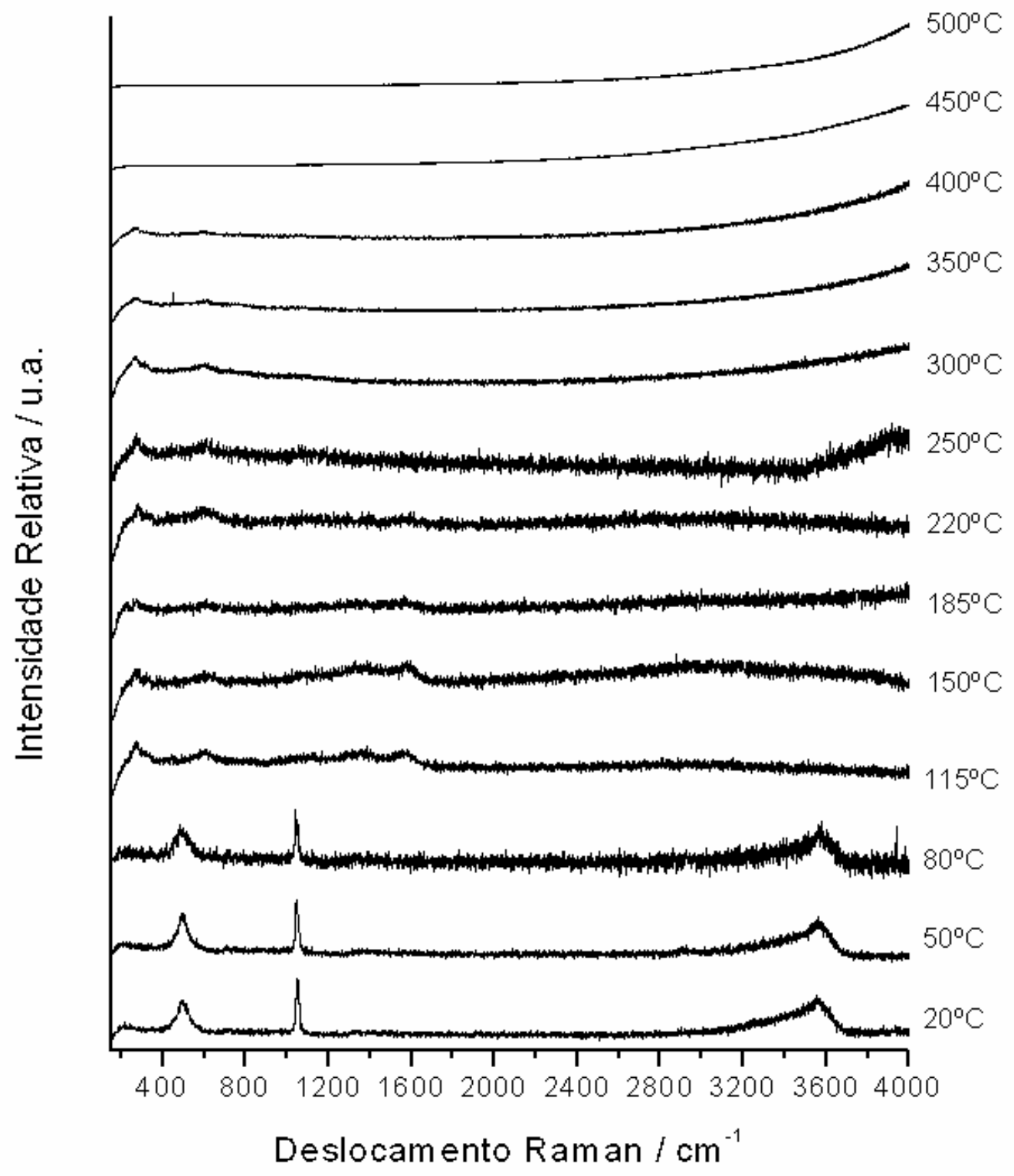

Figura 56 - Espectro de Espalhamento Raman da amostra HT-Cu3,0 calcinada em diferentes temperaturas 

Anexo C - Imagens das amostras HT-Cux sob aquecimento

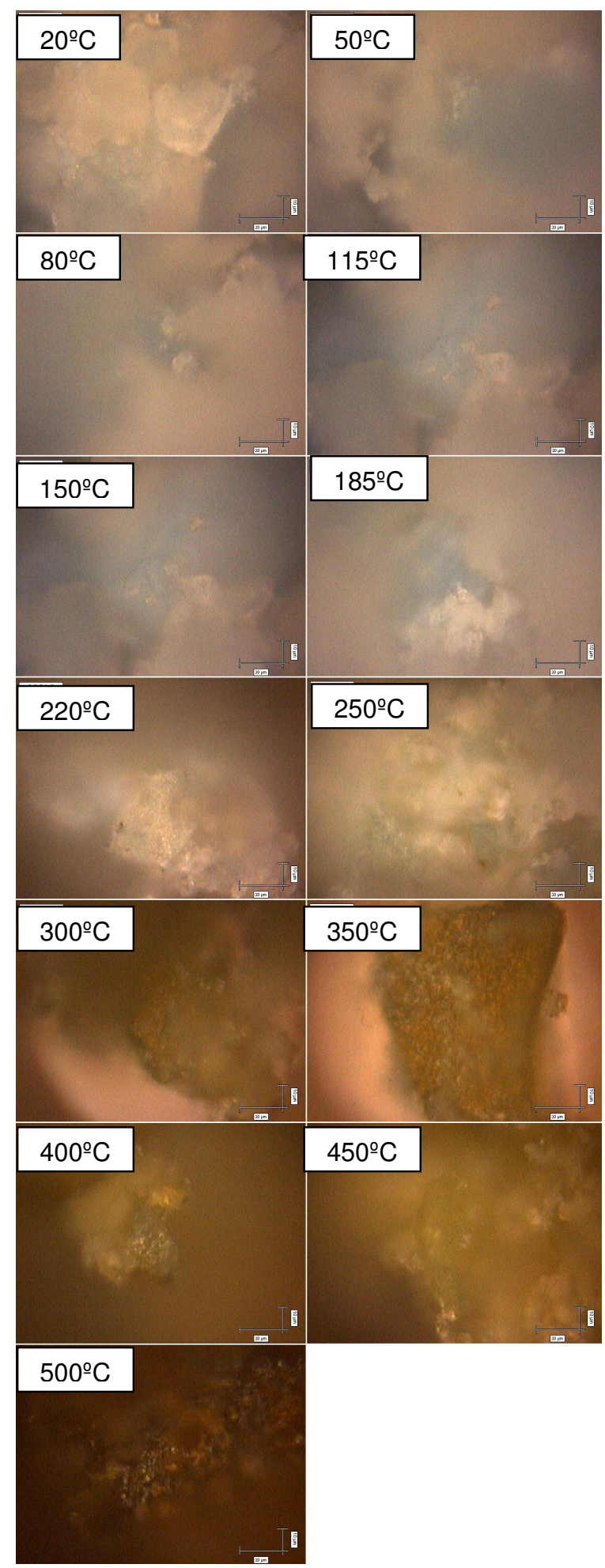

Figura 57 - Imagens em microscópio óptico, com lente de 50x, da amostra HT-Cu0,3 em diferentes temperaturas 


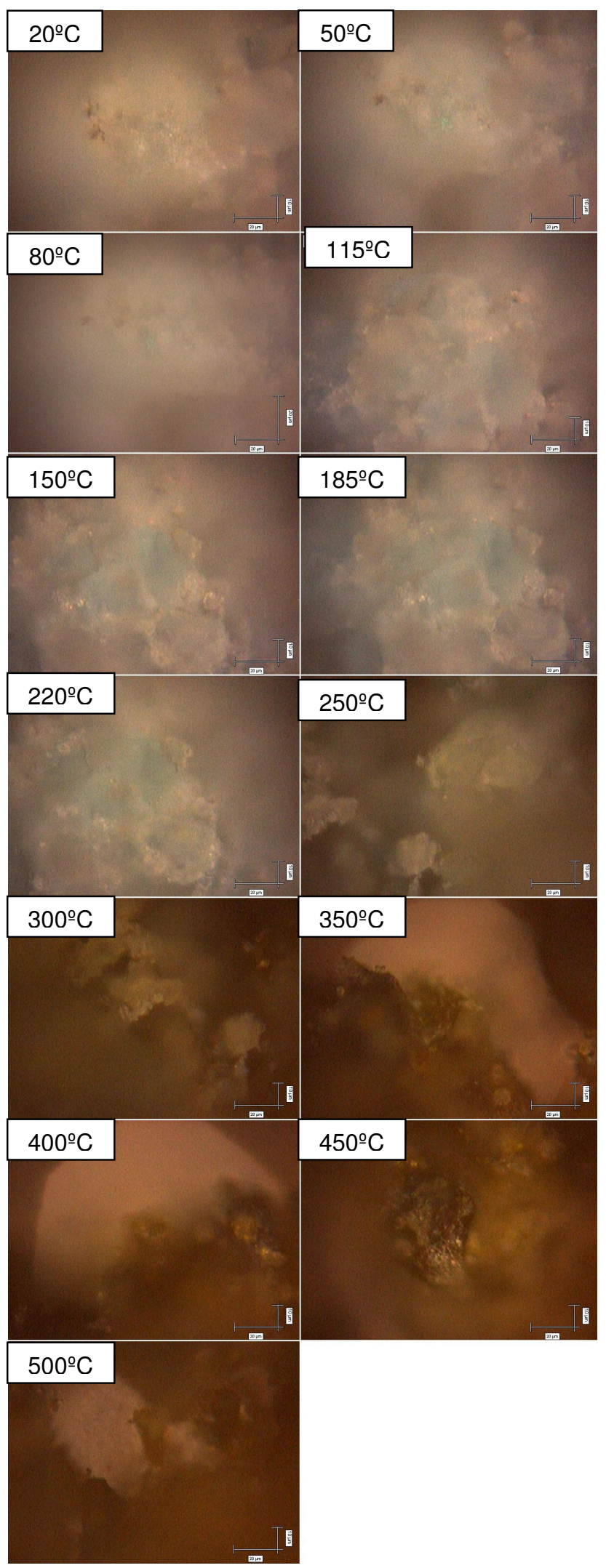

Figura 58 - Imagens em microscópio óptico, com lente de 50x, da amostra HT-Cu0,6 em diferentes temperaturas 


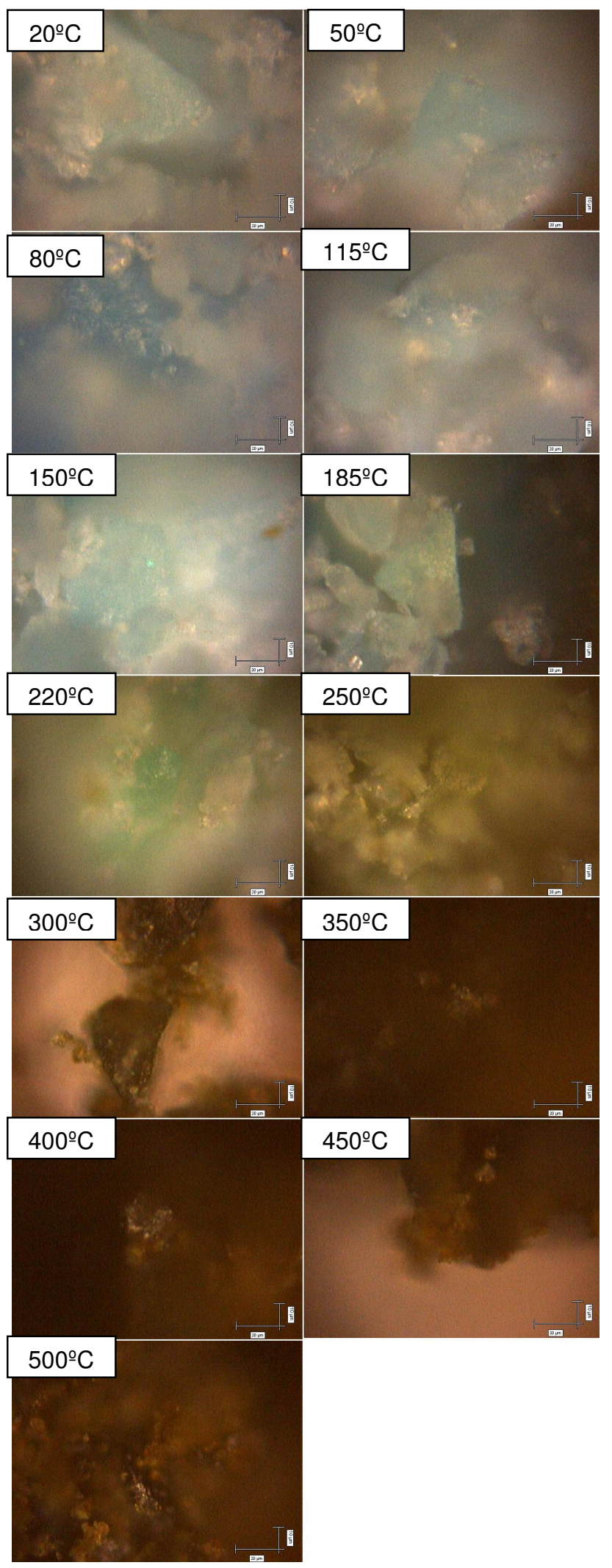

Figura 59 - Imagens em microscópio óptico, com lente de 50x, da amostra HT-Cu0,9 em diferentes temperaturas 


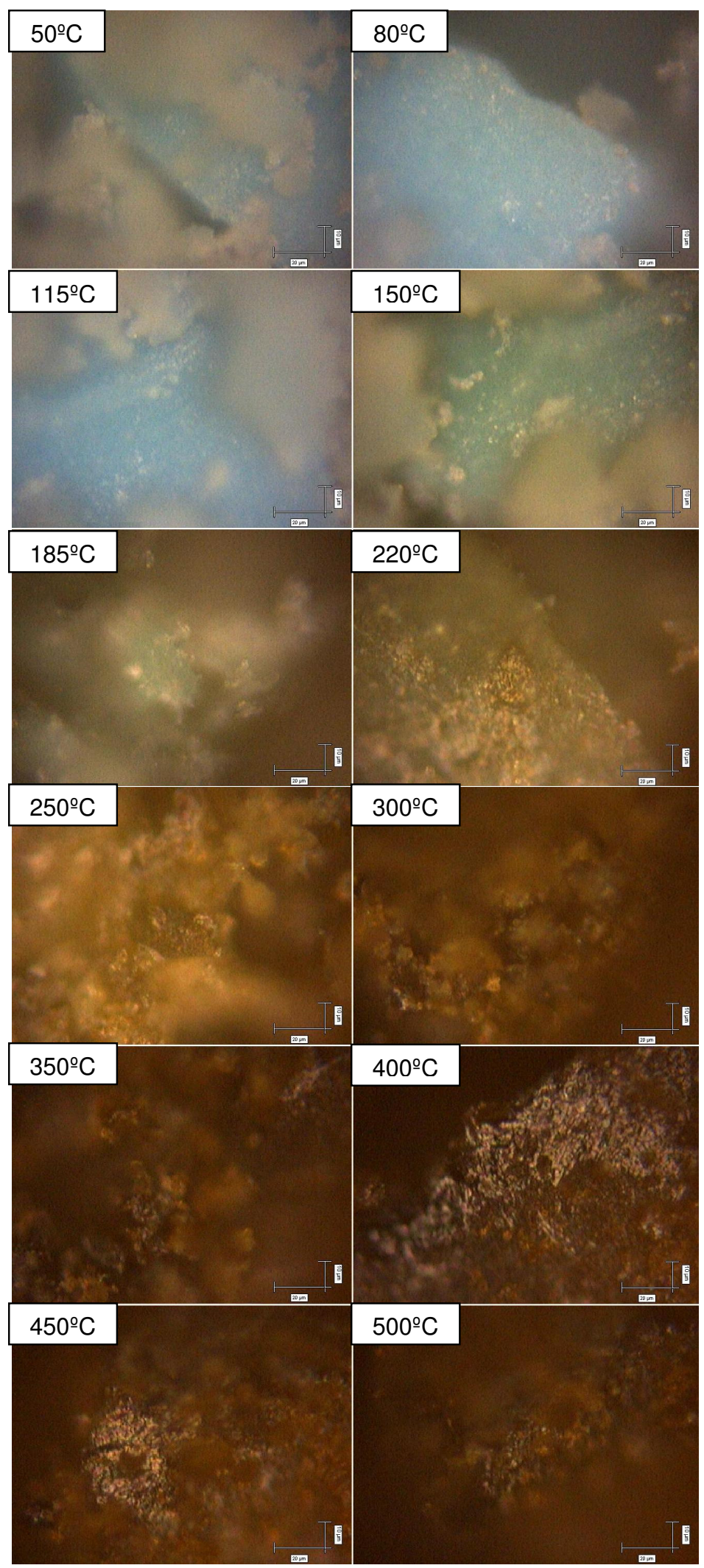

Figura 60 - Imagens em microscópio óptico, com lente de 50x, da amostra HT-Cu1,2 em diferentes temperaturas 


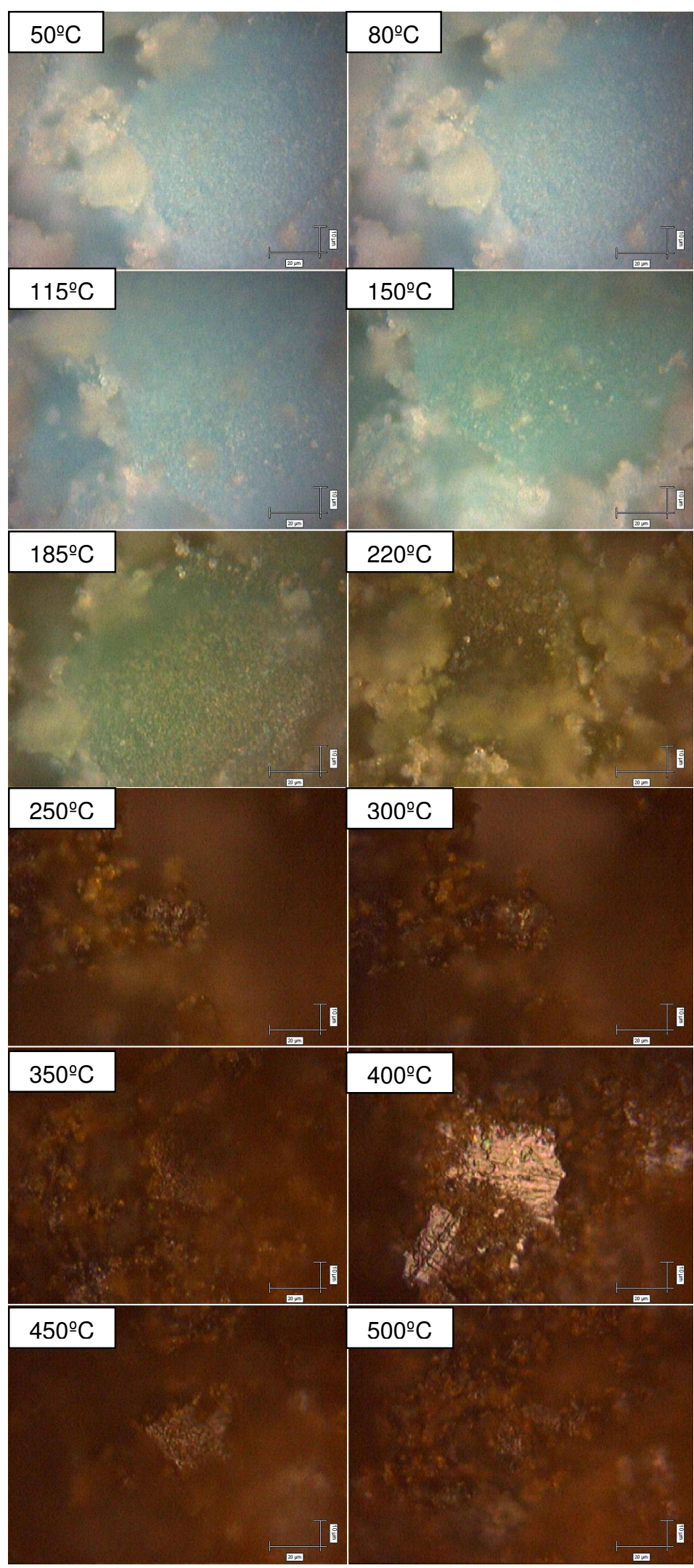

Figura 61 - Imagens em microscópio óptico, com lente de 50x, da amostra HT-Cu1,5 em diferentes temperaturas 


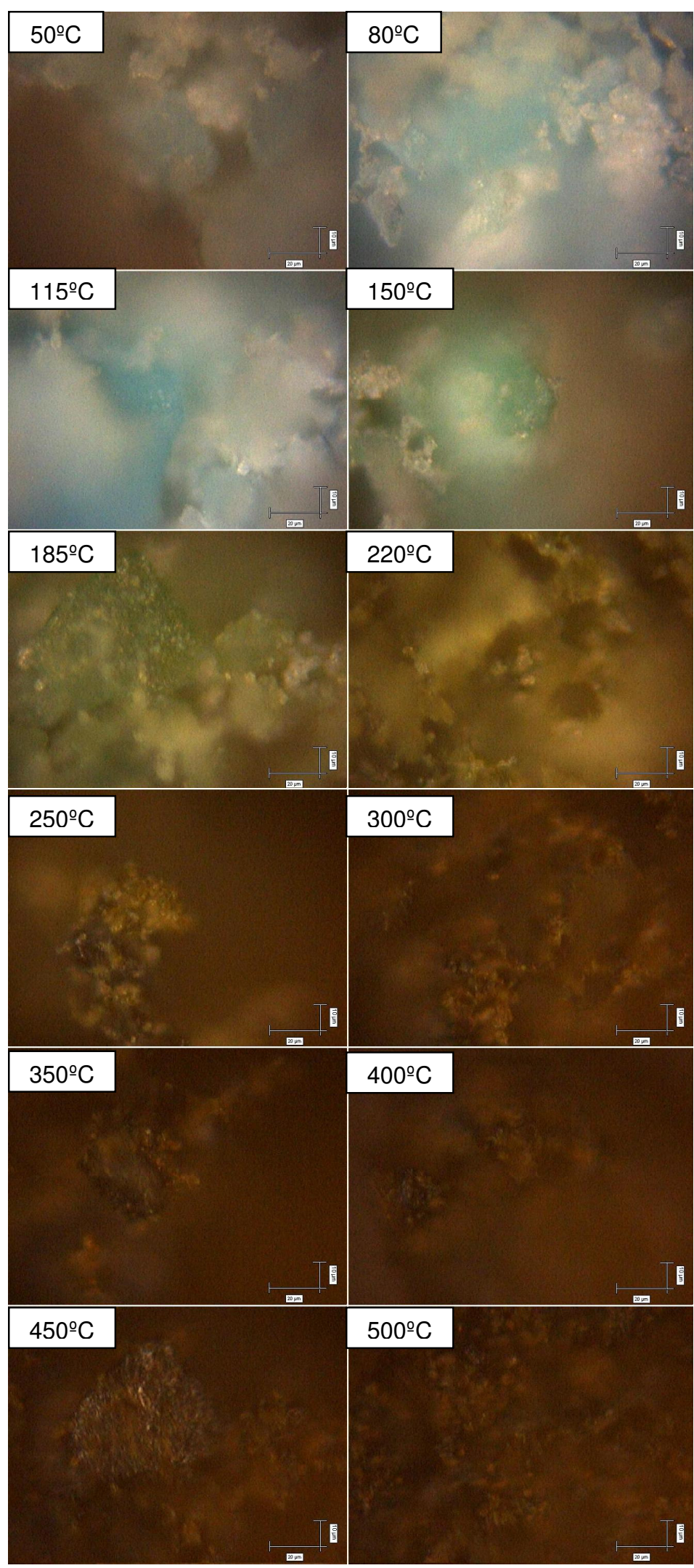

Figura 62 - Imagens em microscópio óptico, com lente de 50x, da amostra HT-Cu1,8 em diferentes temperaturas 


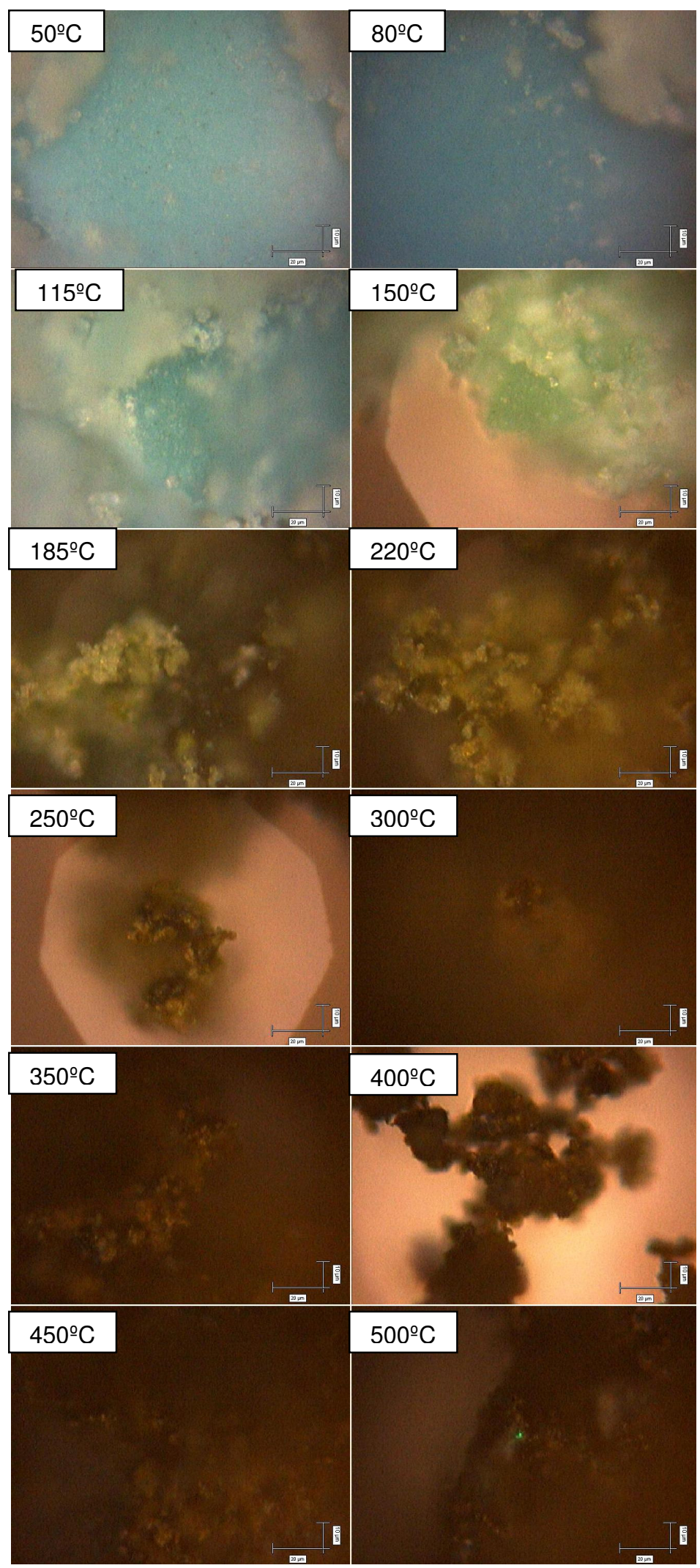

Figura 63 - Imagens em microscópio óptico, com lente de 50x, da amostra HT-Cu2,1 em diferentes temperaturas 


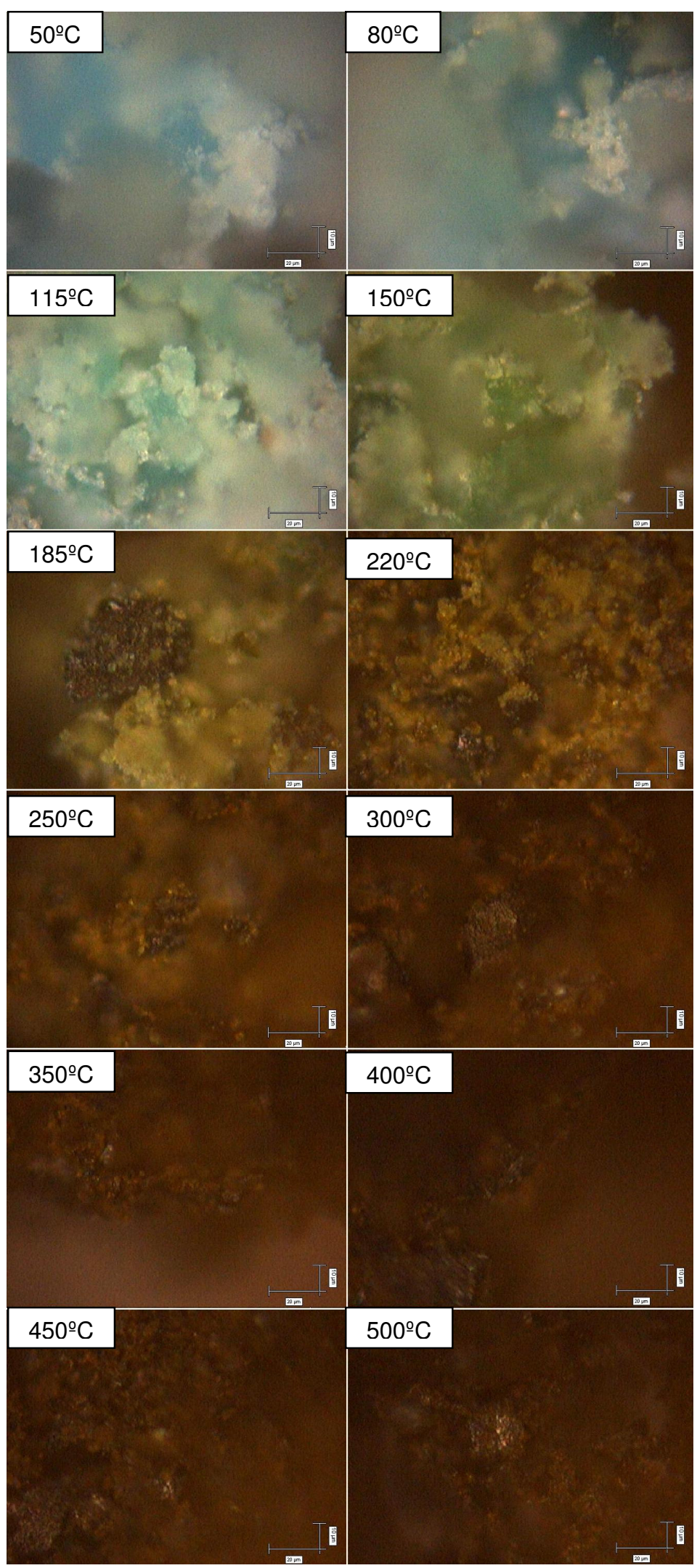

Figura 64 - Imagens em microscópio óptico, com lente de 50x, da amostra HT-Cu2,4 em diferentes temperaturas 


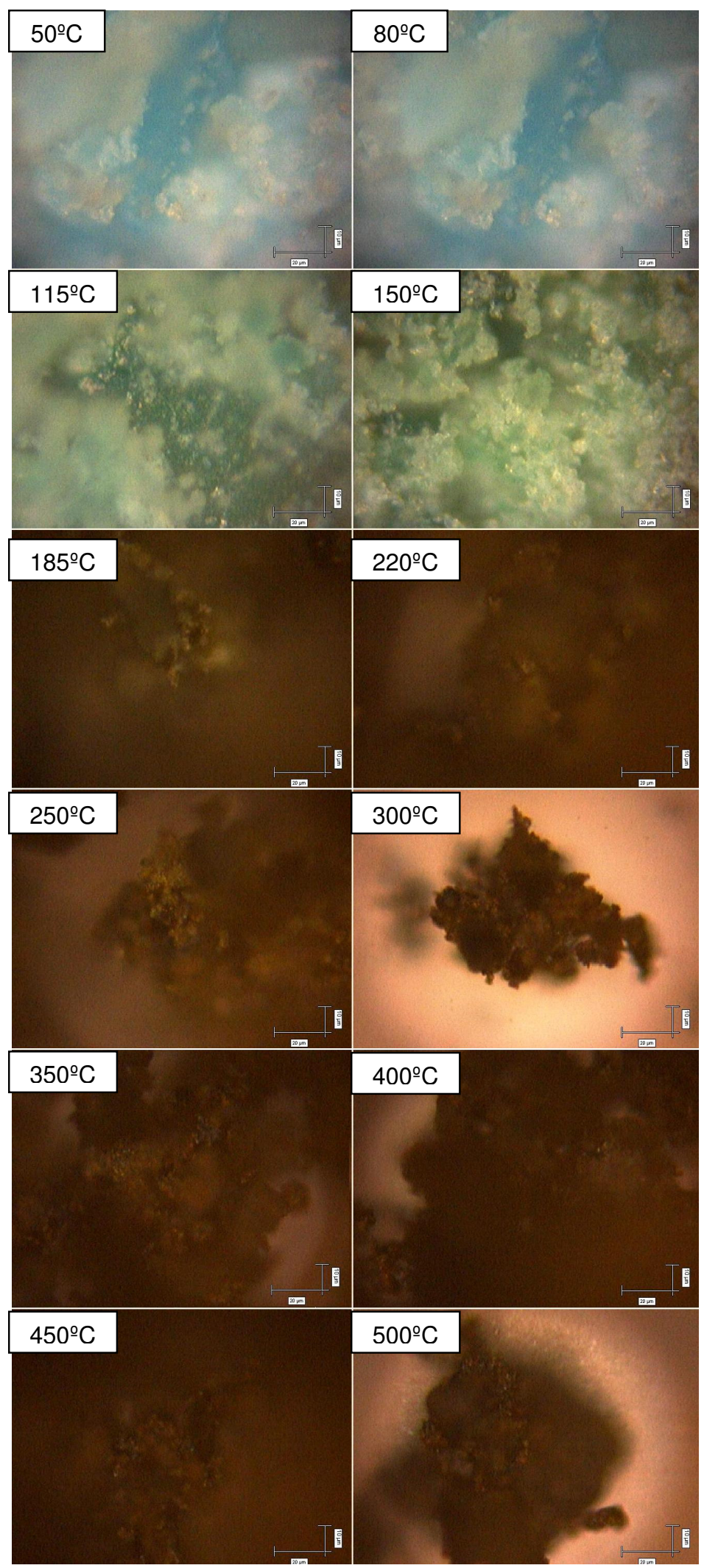

Figura 65 - Imagens em microscópio óptico, com lente de 50x, da amostra HT-Cu2,7 em diferentes temperaturas 


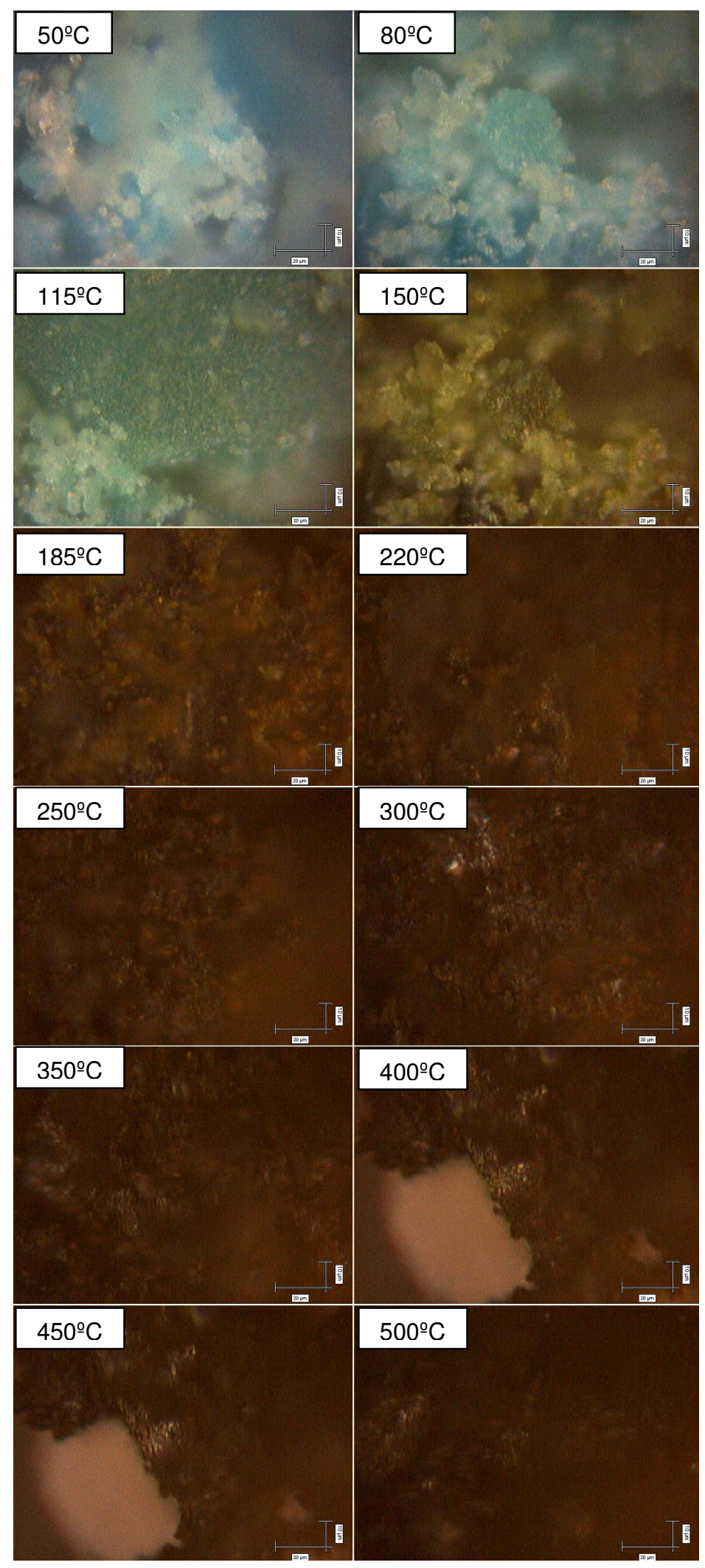

Figura 66 - Imagens em microscópio óptico, com lente de 50x, da amostra HT-Cu3,0 em diferentes temperaturas 



\section{Curriculum Vitae}

\section{Formação Acadêmica}

Mestrado em Química Inorgânica

Universidade de São Paulo - Campus de São Paulo

Título do Projeto: Síntese e Caracterização de Hidróxidos Lamelares

Orientadora: Prof. ${ }^{\text {a }}$ Dr. ${ }^{\text {a }}$ Vera Regina Leopoldo Constantino

Início em julho de 2003

Graduação em Bacharelado em Química

Universidade Federal de São Carlos

Início em março de 1999

Concluído em julho de 2003

\section{Formação Complementar}

Mini-Curso "Catálise aplicada a Processos Industriais"

Carga Horária: 20 horas

Escola de Verão em Química - 2003 - UFSCar

Mini-Curso "Introdução à Química Combinatória"

Carga Horária: 20 horas

Escola de Verão em Química - 2003 - UFSCar

Mini-Curso "Tópicos em Química Medicinal”

Carga Horária: 20 horas

Escola de Verão em Química - 2003 - UFSCar

Mini-Curso "Implementação da Gestão da Qualidade Ambiental”

Carga Horária: 20 horas

Escola de Inverno em Físico-Química e Química Analítica- 2001 - UFSCar

Mini-Curso "Introdução à Química Forense"

Carga Horária: 20 horas

Escola de Inverno em Físico-Química e Química Analítica- 2001 - UFSCar

Mini-Curso "Métodos Quimiométricos de Otimização"

Carga Horária: 20 horas

Escola de Inverno em Físico-Química e Química Analítica- 2000 - UFSCar

Mini-Curso "Segurança em Laboratório e Tratamento de Resíduos"

Carga Horária: 20 horas

Escola de Inverno em Físico-Química e Química Analítica- 2001 - UFSCar 


\section{Bolsas recebidas}

$\mathrm{CNPq}$ - Mestrado

Projeto: Síntese e Caracterização de Materiais Lamelares

Início em: agosto de 2003

Duração: 24 meses

Orientadora: Prof. $\stackrel{\text { a }}{\text { Dr. }}{ }^{\text {a }}$ Vera R. L. Constantino

Monitoria - Graduação

Disciplina: Química Inorgânica Experimental

Início em: agosto de 2002

Duração: 6 meses

Docente Responsável: Prof. Dr. Mitsukimi Tsunoda

Monitoria - Graduação

Disciplina: Química de Coordenação Experimental

Início em: janeiro de 2002

Duração: 6 meses

Docente Responsável: Prof. Dr. Mitsukimi Tsunoda

CNPq - Iniciação Científica

Projeto: Desenvolvimento de Software para Potenciostato Solartron modelo 1286

Início em: julho de 2000

Duração: 12 meses

Orientador: Prof. Dr. Ernesto C. Pereira

\section{Projetos de Iniciação Científica Desenvolvidos}

"Síntese e Caracterização de Alumino-Fosfatos Lamelares"

Período: julho de 2002 até julho de 2003

Orientador: Prof. Dr. Mitsukimi Tsunoda

"Síntese de complexos de vanadilo"

Período: julho de 2001 até dezembro de 2001

Orientador: Prof. Dr. Alzir A. Batista

"Desenvolvimento de Software para Potenciostato SI-1286"

Período: julho de 2000 até julho de 2001

Orientador: Prof. Dr. Ernesto C. Pereira

"Desenvolvimento de Sistema para Teste de Estabilidade de Eletrodos"

Período: março de 1999 até julho de 2000

Orientador: Prof. Dr. Ernesto C. Pereira 


\section{Trabalhos em Eventos}

SOlYMOSSY, V., CONSTANTINO, V. R. L., BARBOSA, C. A. S. e FERREIRA, A. M. C.. "Synthesis and Characterization of Copper Hydrotalcite-like Materials"

XIII International Symposium on Intercalation Compounds

Clermont-Ferrand, França, 2005

SOLYMOSSY, V., CONSTANTINO, V. R. L. e BRITO, H. F.. "Synthesis and Characterization of Hydrocalumite-Like Compounds"

XII Brazilian Meeting on Inorganic Chemistry

São Carlos, Brasil, 2004

SOLYMOSSY, V., TEREZO, A. J. e PEREIRA, E. C.. "Montagem de Sistema para Testes de Estabilidade de Eletrodos em mais de uma Célula"

IX Congresso de Iniciação Científica da UFSCar

São Carlos, Brasil, 2001

SOlYMOSSY, V., TEREZO, A. J. e PEREIRA, E. C.. "Montagem de Sistema para Testes de Estabilidade de Eletrodos em mais de uma Célula"

XII Simpósio Brasileiro de Eletroquímica e Eletroanalítica Gramado, Brasil, 2001

SOLYMOSSY, V., TEREZO, A. J. e PEREIRA, E. C.. "Montagem de Sistema para Testes de Estabilidade de Eletrodos em mais de uma Célula Simultaneamente"

XXIII Reunião Anual da Sociedade Brasileira de Química

Poços de Caldas, Brasil, 2000

\section{Softwares sem registro de patentes}

SOLYMOSSY, V. e CONSTANTINO, V. R. L.. "Deconv"

Descrição: Programa para deconvolução de espectros eletrônicos de misturas com 4 componentes em solução e interferente em suspensão

Versão Beta, 2004

SOLYMOSSY, V. e NEVES, E. F. A.. "Condutometria"

Descrição: Programa para tratamento de dados de titulação condutométrica

Versão Beta, 2003

SOLYMOSSY, V., TEREZO, A. J. e PEREIRA, E. C.. "AST"

Descrição: Programa para gerenciamento e aquisição de dados de sistema para teste de estabilidade de eletrodos em 3 células simultaneamente

Versão Beta, 2000

SOLYMOSSY, V., FARIAS, R. C. e BULHOES, L. O. S.. "Voltametria Cíclica"

Descrição: Programa para cálculo de carga em dados de voltametria cíclica, utilizando a fórmula de integração de Simpson

Versão 1,0, 1999 